\title{
Ecological impact and spread of an invasive paper wasp in New Zealand (Hymenoptera: Vespidae)
}

\author{
By
}

Matthew Howse

A thesis submitted to Victoria University of Wellington in partial fulfilment of the requirements for a degree of Master of Science in Ecology and Biodiversity

Victoria University of Wellington

Te Herenga Waka 
This thesis was conducted under the supervision of:

\author{
Prof. Philip J. Lester \\ Victoria University of Wellington, \\ Wellington, New Zealand
}




\section{General Abstract:}

Social wasps are considered among the most successful and impactful invasive species in the world. One species, Polistes dominula has spread from its native Mediterranean range to every continent except Antarctica. This wasp reached New Zealand in the last decade where it has established in the north of the South Island, however, reports of its presence are increasing throughout the country. Due to its recent arrival in New Zealand, little is known about where this species is likely to establish or what impacts it may have on local insect communities. In this thesis, I conducted two studies to investigate these questions, providing valuable information that may inform future management of this invasive species.

In chapter 2, I used two bioclimatic modelling methods to predict areas of suitable habitat across four regions in the southern hemisphere. These models were informed by global temperature and precipitation data as well as global distribution occurrence data of $P$. dominula. These data were used to estimate conditions most highly correlated with the presence of this wasp. The models identified large areas across the target regions that were climatically suitable for the establishment of $P$. dominula. Many of these areas are not known to currently contain populations of this species, representing habitat potentially vulnerable to further invasion by P. dominula. Areas across South America, South Africa and Australia were predicted to be climatically suitable. In New Zealand, much of the North Island and eastern parts of the South Island were predicted to be suitable habitat for this wasp. These results suggest that $P$. dominula could potentially establish across more of the country and expand its invaded range. Information provided by these models may guide conservation and biosecurity management by highlighting key areas where prevention and mitigation should be prioritized.

In chapter 3, I used molecular diet analysis to investigate the range of prey being utilised by $P$. dominula in New Zealand. Using DNA barcoding, larval gut contents of $P$. dominula and another closely related species, Polistes chinensis, were analysed to identify what species were present in the diet of both wasps. Butterflies and moths (Lepidoptera) were found to be the most highly represented order in both species' diets. True bugs (Hemiptera) and flies (Diptera) were also abundant. Both wasps were shown to consume a range of native and introduced species including a number of agricultural pests. $P$. dominula was found to utilise a wider range of prey than $P$. chinensis. This more diverse prey range, combined with known 
differences in nesting behaviour, suggest that $P$. dominula may represent a more significant threat to invertebrate diversity than the already well-established $P$. chinensis. These results may inform conservation and biosecurity managers on which species are most at risk where this new invasive wasp becomes established.

This thesis provides insights into the potential impacts of a new invasive species to New Zealand. Both chapters represent the first time that these methods have been used to study P. dominula. This work highlights the need for continued monitoring of wasp populations throughout New Zealand, especially in regions highlighted as vulnerable to $P$. dominula establishment. We also suggest the need to prioritise the conservation of 'at-risk' species in coastal and human-altered habitats. Increased public engagement through the citizen-science initiatives should be encouraged while more research into management and control methods is recommended. 


\section{Acknowledgements}

Thank you to Phil Lester for his support and guidance throughout the past two years.

Thank you to Rose McGruddy for her collaboration and assistance during data collection and writing of this thesis.

Thank you to the Lester Lab group: John Haywood, Jana Dobelmann, Mariana Bulgarella, Antoine Felden, Zoe Smeele and James Baty, who have all contributed useful and constructive feedback and advice throughout the writing of this thesis. A special thanks to John Haywood for the hours of statistical assistance that you provided.

Thank you to Richard Toft for his support during fieldwork and data collection over two summers.

I would like to thank Victoria University of Wellington for their financial support.

Finally, I would like to thank my friends and family for their ongoing support. 


\section{Table of Contents}

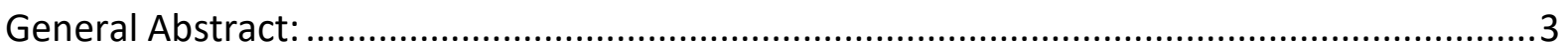

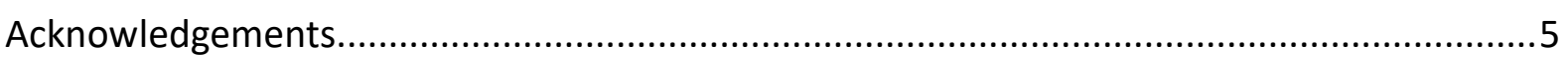

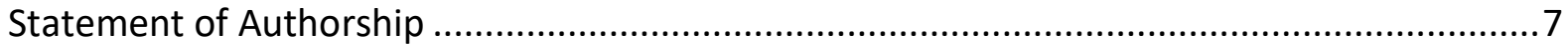

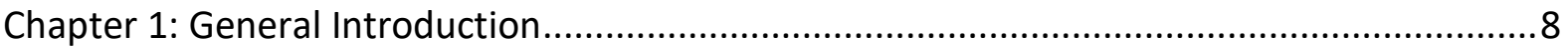

Chapter 2: Bioclimatic Modelling Identifies Suitable Habitat for the Establishment of the Invasive European Paper Wasp (Hymenoptera: Vespidae) across the Southern Hemisphere

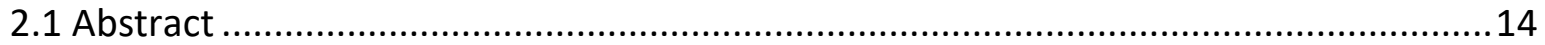

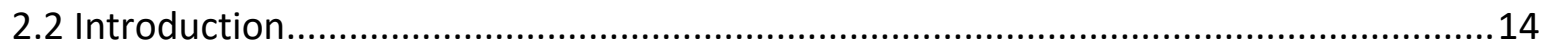

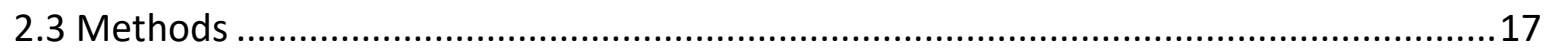

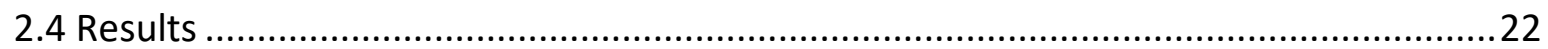

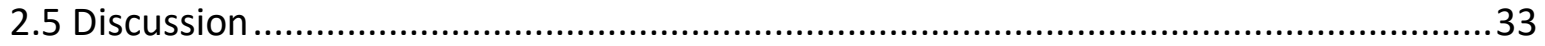

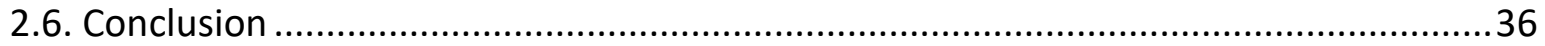

Chapter 3: DNA Barcoding Reveals the Diverse Prey Community of Two Invasive Paper

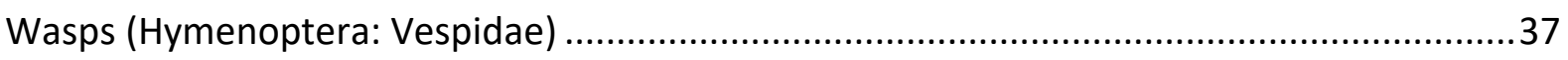

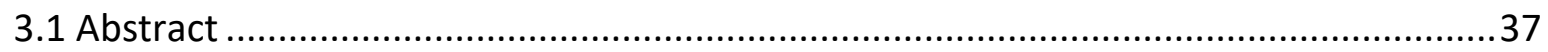

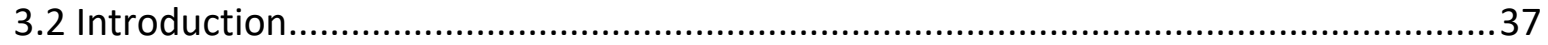

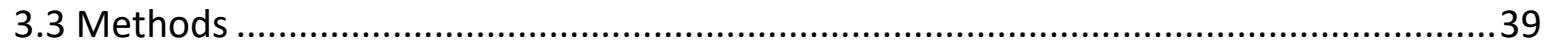

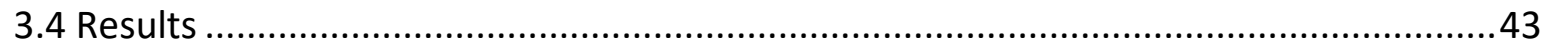

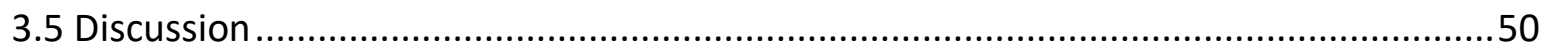

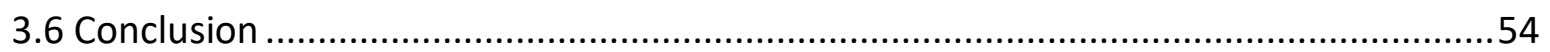

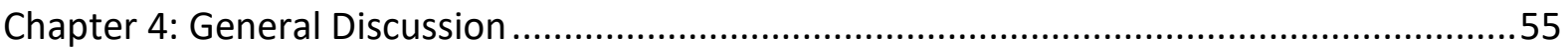

4.1 Polistes dominula spread and their impact on local species ......................................55

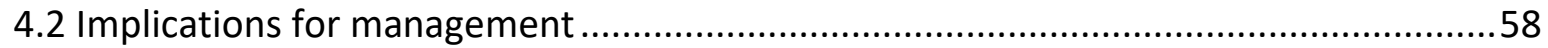

4.3 Limitations and suggestions for future study ..........................................................60

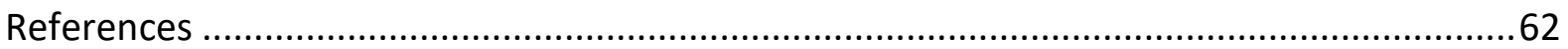

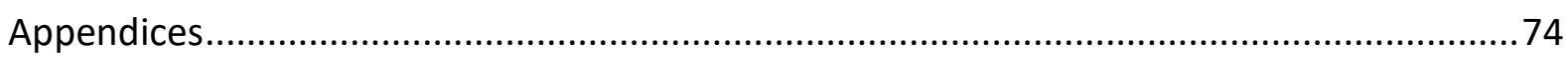

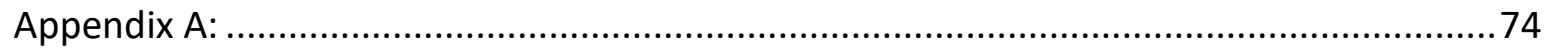




\section{Statement of Authorship}

I hereby declare that this thesis is my own work and that all sources paraphrased or referred to have been properly acknowledged in the references.

Chapter 2 was published in Insects in November 2020. Author contributions: M.W.F.H. and P.J.L. developed research aims and questions. M.W.F.H wrote the draft manuscript.

M.W.F.H. and J.H. conducted data analysis. P.J.L. and J.H. assisted with review and editing of the manuscript.

Chapter 3 author contributions: M.W.F.H. and P.J.L developed research aims and questions M.W.F.H. wrote the draft manuscript. M.W.F.H and R.A.M. conducted sampling in the field and sample preparation. J.B. conducted laboratory work. A.F. and J.H. assisted with data analysis. P.J.L., J.H., A.F. and J.B. assisted with review and editing of the manuscript.

Author initials and names: M.W.F.H. Matthew Howse, P.J.L. Philip Lester, J.H. John Haywood, R.A.M. Rose McGruddy, A.F. Antoine Felden, J.B. James Baty. 


\section{Chapter 1: General Introduction}

The definition of a biological invasion has been debated heavily since the idea's inception. One definition aims to summarise the phenomenon as "a species acquiring a competitive advantage following the disappearance of natural obstacles to its proliferation, which allows it to spread rapidly and to conquer novel areas within recipient ecosystems in which it becomes a dominant population" (Valéry et al. 2008). Often it is implied that this disappearance of obstacles is as a result of human mediation differentiating it from natural dispersion and colonisation (Wilson et al. 2016). The impacts of such invasions are often the decline or extinction of resident species of the ecosystem receiving the invading species (Bellard et al. 2016b, Pyšek et al. 2017, Romanuk et al. 2017). Biological invasions are occurring at a rate not seen before (Ricciardi 2007). Increasing globalisation through migration and trade has led to a reshuffling of the world's flora and fauna (Lockwood et al. 2005, Seebens et al. 2017, Bertelsmeier 2021). This reshuffling has led biological invasions to be ranked among the leading causes of global biodiversity decline (Bellard et al. 2016a, Doherty et al. 2016).

Of all the invasive species, social wasps are perhaps some of the most important globally. The common wasp (Vespula vulgaris) was ranked within the top 100 invasive alien species (Lowe et al. 2000). It and others in the family Vespidae have widespread invasive ranges and often become dominating forces in the recipient environment (Beggs et al. 2008, Lester and Beggs 2019). While not only impacting native flora and fauna, invasive wasps pose risks to human health where aggressive behaviour and high population densities lead to stings to people, which have been known to be deadly (Maclntyre and Hellstrom 2015).

Wasps' seasonal life cycle makes the species effective invaders. New queens emerge from the nest at the end of the season to be fertilised before entering a diapause over the cooler winter months (Beggs et al. 2011). During this period queens hide away in holes and crevices for several months. In human-altered environments these queens have been known to hide away in objects such as pots and furniture that are then shipped overseas (Villemant et al. 2011). The ability of these queens to conceal themselves in such small spaces makes them difficult to locate in quarantine efforts by biosecurity officials. Once these fertile queens emerge in the spring, they begin building nests and reproducing, potentially establishing in a new range. 
The phenological plasticity exhibited by many species of wasps has also been shown to aid their establishment (Lester and Beggs 2019). At lower latitudes, where temperatures are warmer and more consistent, many species of wasps have been shown to stay active yearround. These perennial nests continue to forage and reproduce throughout the year (Plunkett et al. 1989, Leathwick and Godfrey 1996, Wilson et al. 2009), dramatically increasing their abundance. The sociality of wasps also appears to increase their colonisation ability through mechanisms such as increased foraging that enhances reproductive success (Moller 1996, Beggs et al. 2011).

The predatory nature of invasive wasps and their ability to reach very high population densities allows them to exert a great predation pressure within ecosystems (Beggs et al. 2011). For example, the high abundances reached by invasive Vespula vulgaris in New Zealand Beech forests, and the resulting predation, has been shown to significantly reduce populations of native invertebrates (Toft and Rees 1998, Beggs and Rees 1999). Another invasive wasp is Polistes versicolor, which was shown to harvest up to $154 \mathrm{~g}$ of insects per hectare, per day in its invaded range in the Galapagos Archipelago (Parent et al. 2020). The same study suggested that the biomass consumed by $P$. versicolor was larger than that of the native finches, suggesting that these wasps are major competitors in the insectivore community. Invasive wasps have been shown to outcompete native species, leading to declines in native populations and even competitive exclusion. For example, Vespula pennsylvanica has been shown to both directly and indirectly exclude native hymenopterans from foraging sites in Hawai'i (Wilson and Holway 2010). Invasive Vespula spp. were shown to reduce the availability of honey dew in New Zealand beech forests by up to $90 \%$ (Beggs 2001). This major carbohydrate resource is used by many species within this ecosystem and such heavy exploitation of the resource by wasps leads to a decline in both vertebrate and invertebrate species (Beggs and Wilson 1991, Moller et al. 1991).

New Zealand has a diverse native invertebrate fauna that is itself, critically understudied (Lester et al. 2014). Predation by invasive species has led to the decline and even extinction of New Zealand's native terrestrial invertebrates (Gibbs 2009). Among these predators, invasive social wasps have been identified as a threat to New Zealand's invertebrate diversity (Beggs and Rees 1999, Lester et al. 2014). New Zealand has evolved with no native social wasps (Lester et al. 2013), so native flora and fauna have not evolved to deal with the predation and competition pressures these wasps exert. There are also few predators that 
exist in New Zealand that have evolved to feed on social wasps. To date, there have been three parasitoid wasps (Sphecophaga spp.) introduced as potential biocontrol for Vespulid wasps in New Zealand (Lester and Beggs 2019). These have largely been unsuccessful due to lack of establishment or low rates of wasp nest parasitism (Beggs et al. 2002, Beggs et al. 2008). Currently the most effective control method for social wasps in New Zealand is the use of pesticide baits (Lester and Beggs 2019). Toxic baits developed to reduce social wasp populations have been shown to reduce wasp abundance by over 90\% (Hanna et al. 2012, Rust et al. 2017) but there are limitations to such an approach. Excessive use of pesticides can lead to the build-up of resistance in the target species (Troczka et al. 2012, Abbas et al. 2016) and there can be negative effects on non-target species (Harris and Rees 2000, Pisa et al. 2015).

Currently there are five species of invasive social wasps established in New Zealand. Two species from the genus Vespula, the German wasp ( $V$. germanica) and the common wasp ( $V$. vulgaris) becoming common in New Zealand by the 1950s and 1980s, respectively (Donovan 1984). Both species can reach very high population densities, especially in honeydew-beech forests (Sandlant and Moller 1989, Barlow et al. 2002a). The three other introduced social wasp species are paper wasps belonging to the genus Polistes. The Australian paper wasp (Polistes humilis) established in New Zealand in the late $19^{\text {th }}$ century where they are confined to the northern North Island (Thomson 1922, Clapperton et al. 1996). The Asian paper wasp (Polistes chinensis) was discovered in the 1970s and has since spread throughout the North Island and northern parts of the South Island of New Zealand (Clapperton et al. 1989, Clapperton et al. 1996). The most recent species to establish in New Zealand is the European paper wasp (Polistes dominula). Polistes dominula was discovered for the first time in New Zealand in the Nelson and Marlborough regions in 2016 (Ministry for Primary Industries 2016). At this time, however, it was noted that the species was already widespread and well established, with the Ministry suggesting the species has been in the country since at least 2011. This species superficially resembles the more widespread and previously established $P$. chinensis, which could be why it was not identified for several years after its arrival. 


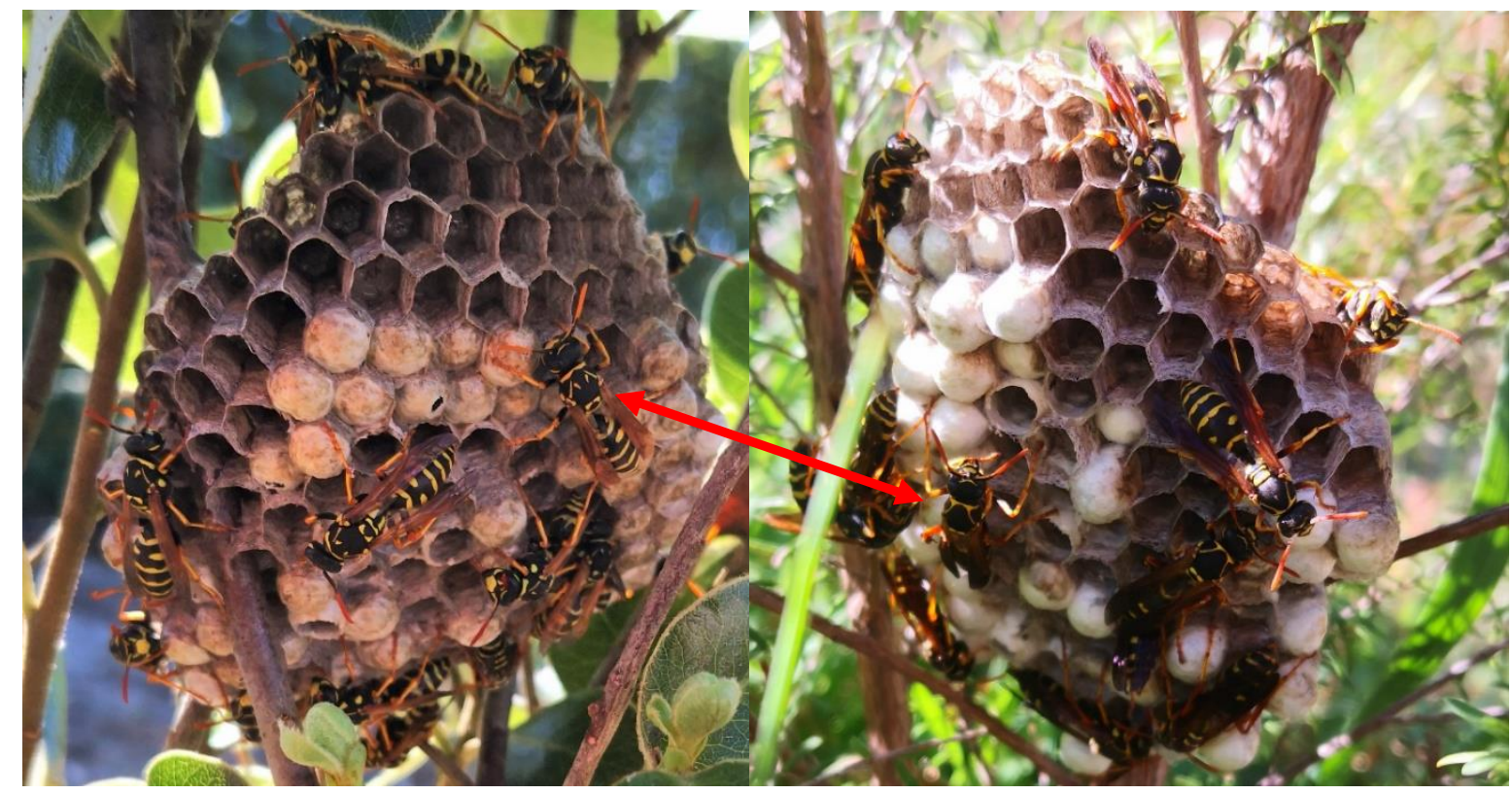

Figure 1.1: Left: Polistes dominula nest on a shrub in Nelson, New Zealand. Right: Polistes chinensis nest on a shrub in Nelson, New Zealand. Note the difference in markings on the thorax with $P$. dominula possessing characteristic "tick marks" that are lacking on $P$. chinensis. The two species' similar appearance led to $P$. dominula not being discovered in the country until 2016 . It has been speculated that the wasp had arrived at some point before 2011. Photos by Matthew Howse (2020).

Polistes dominula has been a particularly successful invader globally. Found naturally throughout Europe, North Africa and into parts of Asia, it has been introduced to North America, South America, Australia, South Africa (Carpenter 1996, Buck et al. 2008), and most recently New Zealand (Ministry for Primary Industries 2016). Like other species of Polistes, they are predatory in nature, feeding on other invertebrates, especially Lepidopterans (Kasper et al. 2004, Cranshaw et al. 2011, Ward and Ramón-Laca 2013, Jeon et al. 2019, Baker and Potter 2020). Polistes dominula has been shown to exhibit more generalist feeding behaviours (Schenk and Bacher 2002), a factor that may add to this species' invasion success (Cervo et al. 2000). This predatory behaviour combined with the ability to reach high population densities earlier in the season makes this wasp species a potential issue in invaded ranges. Invasive $P$. dominula were shown to be more productive than three other Polistes species in their respective native ranges (Pickett and Wenzel 2000, Pilowsky and Starks 2018, Roets et al. 2019). Nests of the invasive $P$. dominula were typically larger and produced more workers than the nests of two North American species Polistes metricus and $P$. fuscatus (Pickett and Wenzel 2000, Pilowsky and Starks 2018). Polistes dominula has been shown to reach greater abundances than that of the native Polistes marginalis in South Africa, despite only being discovered in the country in 2008 (Roets et al. 2019). These observations of $P$. 
dominula rising to high population densities in the presence of sympatric Polistes species has led to suggestions of the competitive exclusion or displacement of native paper wasps (Gamboa et al. 2002, Gamboa et al. 2004, Pilowsky and Starks 2018).

Due to the recent arrival of $P$. dominula to New Zealand, it is not yet fully known how far the species has spread or how it is impacting the ecosystems it has invaded. Polistes dominula is found in temperate climates all over the world, often in close proximity to human habitation (Cervo et al. 2000, Benadé et al. 2014, Höcherl and Tautz 2015). This species spread has been well documented across Europe and North America, however, less is known about its invaded ranges in the southern hemisphere. Species distribution models are one method that scientists may use to investigate the spread of invasive species such as $P$. dominula. These models use data of known occurrences of a species, as well as local environmental or climatic data to identify conditions most favourable for the establishment of a chosen species. This information can then be used to predict the areas of potentially suitable habitat around the globe, informing conservation and biosecurity management (Srivastava et al. 2019). Before this study, no such models had been used to study $P$. dominula. New Zealand is a country with a mild, temperate climate, so it is probable that this species will continue to spread across more of the country.

It is not yet known how the establishment of $P$. dominula will impact New Zealand's existing invertebrate fauna. The advent of methods such as DNA barcoding in diet analysis allows for a deeper insight into what prey are consumed by a species (Valentini et al. 2009). Historical diet analysis relied on visual inspection of crop or gut contents, which can be inaccurate due to processes such as mastication and digestion. Molecular techniques such as DNA barcoding can provide a more accurate representation of a species' diet and have been successfully implemented in the study of invasive wasps (Kasper et al. 2004, Ward and Ramón-Laca 2013, Jeon et al. 2019, Lefort et al. 2020). To date, no diet analysis has yet been conducted on $P$. dominula. Work on related species that have also been introduced to New Zealand such as $P$. chinensis, showed both native and introduced species of Lepidoptera made up the majority of their diet (Ward and Ramón-Laca 2013, Lefort et al. 2020). It is likely that $P$. dominula will prey on a similar assemblage of species, adding to the predation pressure on New Zealand native invertebrates. Polistes spp. have been shown to prey on agricultural pest species (Oliveira et al. 2017, Southon et al. 2019), suggesting that $P$. dominula could potentially act as a form of biocontrol against other pests. 
In chapter 2, my objective was to investigate the potential for range expansion by the newly invasive $P$. dominula in New Zealand and across three additional regions in the Southern Hemisphere. To achieve this goal, I constructed two predictive models using global occurrence data of $P$. dominula and global climate data. These models highlighted regions that were most climatically suitable for this species' establishment. I then discuss how climatic conditions impacted an area's suitability for $P$. dominula, as well as potential consequences of this species spread in these areas.

In chapter 3, I aimed to analyse the diet of $P$. dominula in New Zealand for the first time. To do this, DNA barcoding was used to identify the range of prey in the gut of $P$. dominula and $P$. chinensis larvae. I was then able to provide insight into what species $P$. dominula is feeding on in its newly invaded range and compare their diet to that of another invasive paper wasp in New Zealand. From this analysis, the potential impact of $P$. dominula on New Zealand's invertebrate fauna was discussed. This represents the first time that molecular analysis of the diet of P. dominula has been carried out in New Zealand, and to our knowledge, the world.

In chapter 4, I discuss the implications of my research and how they may impact the management of $P$. dominula. This thesis suggests that $P$. dominula is likely to continue to increase its range, not only in New Zealand but in other invaded regions around the world. The implications of this spread are discussed with attention to what are most threatened by this wasps' spread. Important directions of future study are also identified. 


\section{Chapter 2: Bioclimatic Modelling Identifies Suitable Habitat for the Establishment of the Invasive European Paper Wasp (Hymenoptera: Vespidae) across the Southern Hemisphere}

\subsection{Abstract}

Species distribution models (SDMs) are tools used by ecologists to help predict the spread of invasive species. Information provided by these models can help direct conservation and biosecurity efforts by highlighting areas likely to contain species of interest. In this study, two models were created to investigate the potential range expansion of Polistes dominula Christ (Hymenoptera: Vespidae) in the southern hemisphere. This palearctic species has spread to invade North and South America, South Africa, Australia, and more recently New Zealand. Using the BIOCLIM and MAXENT modelling methods, regions that were suitable for $P$. dominula were identified based on climate data across four regions in the southern hemisphere. In South America areas of central Chile, eastern Argentina, parts of Uruguay, and southern Brazil were identified as climatically suitable for the establishment of $P$. dominula. Similarly, southern parts of South Africa and Australia were identified by the model to be suitable as well as much of the North Island and east of the South Island of New Zealand. Based on outputs from both models, significant range expansion by $P$. dominula is possible across its more southern invaded ranges.

\subsection{Introduction}

Species distribution models (SDMs) are becoming increasingly important in ecology, due to their ability to help predict the potential distributions of invasive organisms. These models bring together known species occurrence records and environmental data to provide users with an estimation of the conditions a species requires to survive. This information can be used to identify locations that could support populations of a particular species (Pearson 2007). Species distribution models have been used to guide the creation of more effective reserves (Leathwick et al. 2005), to project impacts of climate change (Moor et al. 2015), and to predict the spread of invasive species (Curry et al. 2020).

Polistes dominula Christ (Hymenoptera: Vespidae) is a well-known and wide-ranging invasive social wasp species (Buck et al. 2008). A palearctic species native to Europe, North Africa, and parts of Central Asia, P. dominula has spread to both North and South America, 
South Africa, Australia, and more recently, New Zealand (Figure 2.1) (Carpenter 1996, Buck et al. 2008, Ministry for Primary Industries 2016). This species is largely predatory by nature (Brown et al. 2012). Similar to its Vespid relatives, $P$. dominula is a frequent predator of Lepidoptera larvae (Kasper et al. 2004, Ward and Ramón-Laca 2013, Jeon et al. 2019, Baker and Potter 2020) though it is thought that this predatory wasp has a more generalist diet than that of other related species (Cervo et al. 2000, Schenk and Bacher 2002). Polistes dominula has also been shown to have several competitive advantages over closely related species. Studies in North America and South Africa have shown that $P$. dominula nests are more productive than other Polistes species, able to produce more offspring over a longer active season (Pickett and Wenzel 2000, Gamboa et al. 2002, Roets et al. 2019). This high nest productivity has led $P$. dominula to reach large population densities in their invaded areas.

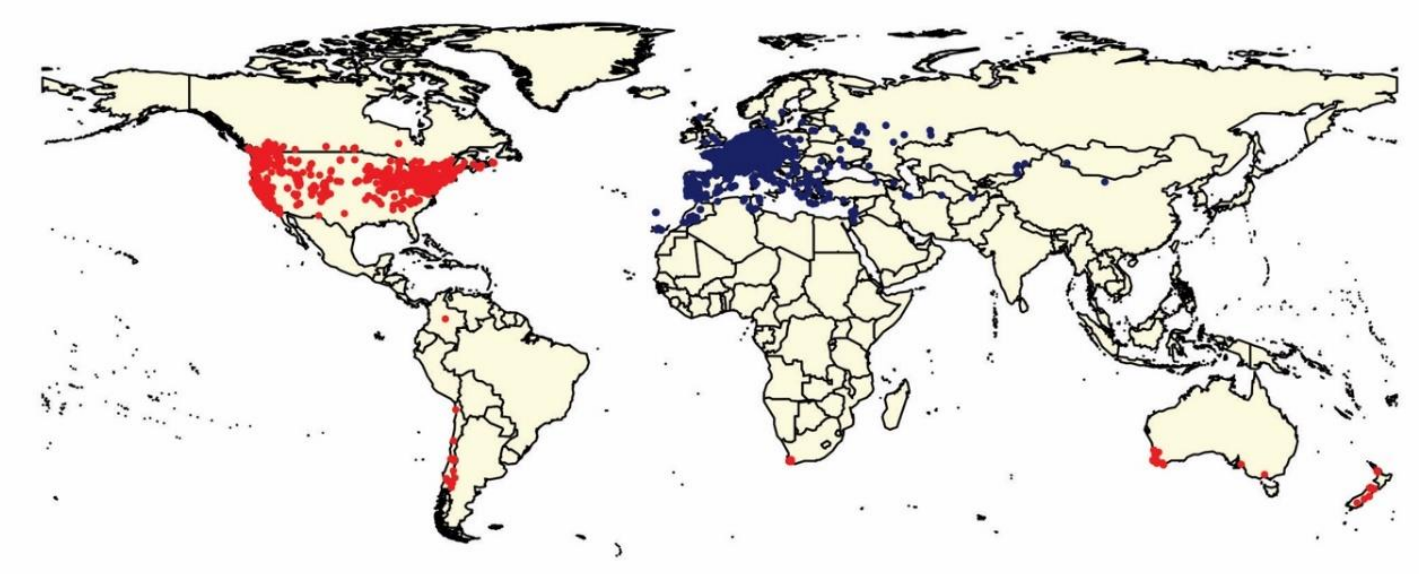

Figure 2.1: Global distribution of $P$. dominula constructed from data retrieved from Global Biodiversity Information Facility database (GBIF) (GBIF.org 2020). Red points indicate occurrences in an invaded range. Blue points indicate occurrences in the assumed native range (Carpenter 1996, Buck et al. 2008). In total 9246 occurrences were used in this study. Of the total, 3028 occurrences were from invaded ranges and 6218 were from the assumed native range.

The invasion of $P$. dominula across the globe has been fairly well studied but not equally across affected regions. In the northern hemisphere $P$. dominula has famously invaded from the east to west coasts of the United States over the last 50 years (Liebert et al. 2006). Polistes dominula is known to have become established throughout the southern hemisphere but its spread in these regions has been critically understudied. This invasive species appears to have established in the southern hemisphere by the 1980s in Australia (Taylor et al. 1985) and Chile (Elgueta 1989, González 1989). It was found to have established in Argentina by 2003 
(Sackmann et al. 2003), South Africa by 2008 (Eardley et al. 2009), and in New Zealand by 2016 (Ministry for Primary Industries 2016). Except in South Africa, little research has been conducted on the status of these invasive populations and how they have affected local ecosystems. Many of these invaded areas contain native invertebrate communities that already face threats from other invasive species, habitat alteration, and climate change (Stringer and Hitchmough 2012, Lester et al. 2014, Sands 2018). The establishment of $P$. dominula throughout more of these regions may add to these threats. Thus, predicting and preparing for future invasions or range expansions may help mitigate this effect.

Since their inception, there have been many changes and improvements to how SDMs are formed. One of the earliest and most widely used methods is BIOCLIM (Nix 1986, Booth et al. 2014). BIOCLIM is a profile method of species distribution modelling, whereby the algorithm determines the environmental similarity between a target species' current range and other locations, using a percentile distribution of values (Hijmans and Elith 2017). The model will designate a location more suitable if the environmental values are closer to the median values of known occurrence sites. BIOCLIM is a presence-only method and so does not require known absence data. Another modelling method, known as MAXENT, can also be used with presence-only data, but there are some key differences from BIOCLIM. MAXENT is a machine learning method. The aim of MAXENT is to minimize the relative entropy between the probability density estimated from the occurrence data and the probability density estimated from the rest of the landscape (Elith et al. 2011). The MAXENT method was developed more recently than the BIOCLIM approach, is also widely used, and is thought to be one of the better performing modelling methods (Elith et al. 2006, Phillips et al. 2006, Duan et al. 2014).

A species distribution model would identify regions that are conducive to supporting populations of $P$. dominula and provide an insight into where these wasps are likely to spread. In this study two prediction models were produced, respectively using the BIOCLIM and MAXENT methods. Using global occurrence and climate data, these models were used to predict the bioclimatic suitability of four regions across the southern hemisphere for the establishment of $P$. dominula. These findings can inform future biosecurity and control plans for regions anticipated to be impacted by this invasive wasp. 


\subsection{Methods}

Polistes dominula occurrence data was downloaded from Global Biodiversity Information Facility database (GBIF) (GBIF.org 2020) using the "gbif" function in the package dismo (Hijmans et al. 2017) in R version 4.0.2 (R Core Team 2020). A total of 20,616 records from 125 published datasets were downloaded. As GBIF data was pooled from a range of sources, from peer reviewed studies to citizen reports, data quality could vary. It has been shown, however, that a combination of data from citizen science and long term expert surveying can still produce robust distribution models (Sumner et al. 2019).

A number of data-cleaning procedures were carried out to ensure the best quality data were used in creating the models. Following the procedures outlined by Hijmans and Elith (2017), data were prepared by first removing data points with missing latitude or longitude values. Data were then assessed for the presence of duplicate coordinates which were removed to prevent pseudo replication. This assessment was accomplished using "duplicated", a base function in R (R Core Team 2020) that identifies records with identical coordinates to others, which were removed. Remaining data points were then cross checked against a simple world map to identify any coordinates that were located on water. These values were likely to be occurrences recorded with low resolution coordinates and had to be excluded.

A set of climate variables containing temperature and precipitation was used for modelling the distribution of $P$. dominula. Climate data were obtained in the form of 19 environmental layers, each representing a global bioclimatic variable at 2.5 -min $\left(5 \mathrm{~km}^{2}\right)$ resolution (available from: https://worldclim.org/data/worldclim21.html). The WorldClim database is based on global weather station data from 1970 to 2000 and provides high resolution, global layers of monthly climate data (Fick and Hijmans 2017). These monthly data were used to create the 19 annual bioclimatic variable layers used in this study (Table 2.1) and in a variety of other distribution models (Ward 2007, Rodder et al. 2009, Beckham and Atkinson 2017, Dudaniec et al. 2018, Raghavan et al. 2019).

Pseudoabsence points were created by selecting 10,000 random points from around the globe. This number was chosen to provide an appropriate ratio of presence to pseudoabsence points and maximize model reliability (Barbet-Massin et al. 2012a). Climate data was applied to these pseudoabsence points as well as the cleaned occurrence data using the "extract" 
function in the raster package (Hijmans 2020). Presence data were randomly partitioned into test and training data using the "kfold" function, as recommended by (Hijmans and Elith 2017) and used by (Phillips et al. 2006). Model predictions were made using the training data, which contained 7397 of the 9246 occurrence points. The predictions were then tested against the remaining 1849 occurrence points as well as 10,000 random pseudoabsence points.

Table 2.1: List of bioclimatic variables used in this study. These variables, created by Fick and Hijmans (2017), were downloaded as $2.5 \mathrm{~min}\left(5 \mathrm{~km}^{2}\right)$ resolution environmental layers from worldclim.org. Variables used monthly climate data collected over 30 years between 1970 and 2000. A subset of bioclimatic variables, identified by tick marks, was produced by stepwise regression analysis to be used in the BIOCLIM and MAXENT modelling approaches.

\begin{tabular}{|c|c|c|c|}
\hline $\begin{array}{l}\text { Variable } \\
\text { Code }\end{array}$ & Variable Title & Unit & $\begin{array}{c}\text { Inclusion in Final } \\
\text { Model }\end{array}$ \\
\hline Bio1 & Annual Mean Temperature & ${ }^{\circ} \mathrm{C}$ & $\checkmark$ \\
\hline Bio2 & $\begin{array}{l}\text { Mean Diurnal Range (mean of monthly (max temp- } \\
\text { min temp)) }\end{array}$ & ${ }^{\circ} \mathrm{C}$ & $\checkmark$ \\
\hline Bio3 & Isothermality ((Bio2/Bio7) × 100) & $\%$ & $\checkmark$ \\
\hline Bio4 & Temperature Seasonality (standard deviation $\times 100$ ) & ${ }^{\circ} \mathrm{C}$ & $\checkmark$ \\
\hline Bio5 & Max Temperature of Warmest Month & ${ }^{\circ} \mathrm{C}$ & $\checkmark$ \\
\hline Bio6 & Min Temperature of Coldest Month & ${ }^{\circ} \mathrm{C}$ & \\
\hline Bio7 & Temperature Annual Range (Bio5-Bio6) & ${ }^{\circ} \mathrm{C}$ & $\checkmark$ \\
\hline Bio8 & Mean Temperature of Wettest Quarter & ${ }^{\circ} \mathrm{C}$ & $\checkmark$ \\
\hline Bio9 & Mean Temperature of Driest Quarter & ${ }^{\circ} \mathrm{C}$ & $\checkmark$ \\
\hline Bio10 & Mean Temperature of Warmest Quarter & ${ }^{\circ} \mathrm{C}$ & $\checkmark$ \\
\hline Bio11 & Mean Temperature of Coldest Quarter & ${ }^{\circ} \mathrm{C}$ & $\checkmark$ \\
\hline Bio12 & Annual Precipitation & $\mathrm{mm}$ & \\
\hline Bio13 & Precipitation of Wettest Month & $\mathrm{mm}$ & $\checkmark$ \\
\hline Bio14 & Precipitation of Driest Month & $\mathrm{mm}$ & $\checkmark$ \\
\hline Bio15 & Precipitation Seasonality (coefficient of variation) & $\%$ & \\
\hline Bio16 & Precipitation of Wettest Quarter & $\mathrm{mm}$ & $\checkmark$ \\
\hline Bio17 & Precipitation of Driest Quarter & $\mathrm{mm}$ & \\
\hline Bio18 & Precipitation of Warmest Quarter & $\mathrm{mm}$ & $\checkmark$ \\
\hline Bio19 & Precipitation of Coldest Quarter & $\mathrm{mm}$ & $\checkmark$ \\
\hline
\end{tabular}


Variable selection was performed using stepwise logistic regression to produce a subset of variables that would be used in the models (Table 2.1). The use of an automatic selection method was chosen to remove bias from the selection process. The procedure adds or removes variables from generalized linear models, one by one, checking the significance of all variables in the model each time. If a variable in the new model is deemed nonsignificant it is removed. Variable importance was measured by the Akaike Information Criterion (AIC). Important variables are added to the model while less relevant variables are removed. Using this analysis, the subset of variables that produced the model with the lowest AIC was chosen to perform the subsequent predictions. This process removed unnecessary variables from the model and reduced multicollinearity. The generalized linear model used all presence and background data with associated climatic variables and assumed a binomial distribution for the occurrence of $P$. dominula at each global location.

Two prediction models describing the global distribution of $P$. dominula were made using the worldwide occurrence of $P$. dominula and their associated climatic variables. One model was built using the BIOCLIM modelling method while the other used the MAXENT approach with the default settings (Hijmans and Elith 2017). With these models, suitable climatic conditions were predicted and identified across four regions of the southern hemisphere. All these regions have been previously invaded by $P$. dominula and include southern South America, South Africa, Australia, and New Zealand. The models' raw predictive outputs produced maps at $5 \mathrm{~km}^{2}$ resolution with each cell containing values of habitat suitability. For both models, this predictive value was a number between zero and one. Following the BIOCLIM method, a cell would have a value of one if the environmental variables were equal to the median value for the occurrence data (Hijmans and Elith 2017). A zero value is conversely applied to any cell that possesses climatic values lower than the 10th and higher than the 90th percentile values in the occurrence data. Raw output values produced by the MAXENT modelling method are an approximate probability that the species will be present, given the local environmental conditions, otherwise known as the relative occurrence rate (ROR) (Elith et al. 2011, Merow et al. 2013). Using the "var.importance" function from the package ENMeval (Muscarella et al. 2014), values of variable permutation importance to the model produced by MAXENT were identified. Variable permutation importance is a percentage value showing how heavily the model depends on a specific variable. Values of 
each variable in training, testing and background data are permuted and the resulting model is evaluated. The degree to which the permuted data weakens the MAXENT produced model's performance is normalised to a percentage for each variable and presented as variable permutation importance (Table 2.2) (Phillips et al. 2006).

Presence/absence predictions show cells that contain predicted values of climate similarity above a determined threshold specific to each model. This threshold was determined as the maximum of the sum of the sensitivity (true positive rate) and specificity (true negative rate), also known as the maxSSS method (Liu et al. 2016). Any cell with a value of climatic similarity over the threshold was predicted as a presence point, while any cell under this would be considered an absence (Hijmans and Elith 2017). This method of threshold selection has been recommended as appropriate when working with presence-only data (Liu et al. 2013, Liu et al. 2016).

The models were evaluated looking at the area under the receiver operating characteristic curve (AUROC, abbreviated to AUC) value. Test data with known presence or pseudoabsence status were entered into the models. The degree to which the model could correctly assign these data points to presence or pseudoabsence classes was used to calculate the AUC. This value is a number between zero and one and represents how accurately a model predicts presence/absence. A model with an AUC value of 1 predicts presence/absence with $100 \%$ accuracy while a model with an AUC score of 0.5 is one that predicts a presence or absence correctly 50\% of the time (Hosmer et al. 2013, Hijmans and Elith 2017).

To investigate patterns presented in the final models, histograms of the known occurrence climatic values were plotted with the "hist" function (R Core Team 2020) and visually compared with the corresponding bioclimatic layer for each of the focus regions. This was conducted for the two bioclimatic variables with the highest permutation importance. 
Table 2.2: The 15 variables used in the MAXENT method, listed in order of permutation importance. Variable permutation importance is a value showing how heavily the final model depends on a certain variable. Values of each variable in training, testing and background data are randomized and the resulting model is evaluated. The degree to which the randomly permuted data weakens the model's performance, as originally selected by MAXENT, is normalised to a percentage for each variable and presented as permutation importance (Phillips et al. 2006). A variable with a high permutation importance is therefore important to the model, since if its values were randomized, the power of the model would decrease significantly.

\begin{tabular}{lll}
$\begin{array}{c}\text { Variable } \\
\text { Code }\end{array}$ & \multicolumn{1}{c}{ Variable Title } & Permutation \\
\hline Bio1 & Annual Mean Temperature & $37.9 \%$ \\
\hline Bio19 & Precipitation of Coldest Quarter & $15.9 \%$ \\
\hline Bio4 & Temperature Seasonality (standard deviation $\times 100)$ & $11.4 \%$ \\
\hline Bio10 & Mean Temperature of Warmest Quarter & $9.0 \%$ \\
\hline Bio16 & Precipitation of Wettest Quarter & $4.7 \%$ \\
\hline Bio18 & Precipitation of Warmest Quarter & $4.2 \%$ \\
\hline Bio11 & Mean Temperature of Coldest Quarter & $3.8 \%$ \\
\hline Bio3 & Isothermality ((Bio2/Bio7) $\times 100)$ & $2.8 \%$ \\
\hline Bio9 & Mean Temperature of Driest Quarter & $2.7 \%$ \\
\hline Bio14 & Precipitation of Driest Month & $2.3 \%$ \\
\hline Bio2 & Mean Diurnal Range (mean of monthly (max temp-min & $1.8 \%$ \\
\hline Bio5 & temp)) & $1.4 \%$ \\
\hline Bio13 & Pax Temperature of Warmest Month & $1.1 \%$ \\
\hline Bio7 & Temperature Annual Range (Bio5-Bio6) & $0.5 \%$ \\
\hline Bio8 & Mean Temperature of Wettest Quarter & $0.4 \%$ \\
\hline
\end{tabular}




\subsection{Results}

After the data cleaning procedure, a total of 9246 occurrence points of $P$. dominula remained for use in the model. Of these points, 3028 occurred in an invaded range while the other 6218 points originate in assumed native range (Figure 2.1).

Stepwise logistic regression analysis using the 19 bioclimatic explanatory variables identified a subset of variables that produced the best model, as indicated by the lowest AIC value (Table 2.1). The analysis used generalized linear models predicting presence or absence of $P$. dominula, with variables added or removed based on changes in the resulting AIC values. The final model contained 15 of the 19 WorldClim variables with the analysis removing Minimum Temperature of the Coldest Month (Bio6), Annual Precipitation (Bio12), Precipitation Seasonality (Bio15) and Precipitation of Driest Quarter (Bio17) (Table 2.1).

Modelling produced by the BIOCLIM method showed a number of regions in southern South America to have a climate conducive to the establishment of $P$. dominula (Figure 2.2). Once the threshold was applied, the model identified areas of central Chile, central and eastern Argentina as well as parts of Uruguay and southern Brazil as climatically suitable (Figure 2.3). Records of $P$. dominula are currently restricted to Chile and western Argentina, indicating the potential for a range expansion eastward. The raw output of the model produced by MAXENT highlighted a wider area of potentially suitable habitat than that of BIOCLIM (Figure 2.2); however, once the threshold was applied a more conservative potential range was predicted (Figure 2.3). Though not as expansive as the range predicted by BIOCLIM, it follows a similar pattern. Two main clusters of suitable habitats were identified by the MAXENT method with one spreading throughout central Chile and another in eastern Argentina and southern Uruguay (Figure 2.3).

In southern Africa, the BIOCLIM method identified an extensive range of climatically suitable habitat. The raw output of the BIOCLIM method highlighted areas of South Africa from the southwest of the country, eastward into the interior, encompassing much of Lesotho and into parts of Eswatini (Figure 2.2). With the threshold applied, much of this described area was predicted to be suitable for $P$. dominula (Figure 2.3). The raw output of the MAXENT method highlighted a wider area of the region but followed a pattern much the same as that of the BIOCLIM prediction (Figure 2.2). With the threshold applied, however, the MAXENT model identified a much smaller potential range than that of BIOCLIM. Only areas in the 
southwest of South Africa were predicted to be climatically suitable for the establishment of P. dominula (Figure 2.3). These areas fell within the South Cape province, which contains all known P. dominula occurrences within the southern Africa region.

Both prediction models identified much of the southern portion of Australia as climatically suitable for the establishment of $P$. dominula. The raw output of the BIOCLIM method highlighted most of the country south of approximately -30 degrees latitude (Figure 2.2). Once the threshold was applied the model identified most of this area as climatically suitable, with most of southwest and southeast of the country denoted a potential present value (Figure 2.3). The raw output of the MAXENT method again highlighted a larger area of Australia than the BIOCLIM method, focused around the south and east of the country (Figure 2.2). When the threshold was applied the model identified two main clusters of suitable habitat in the south of Australia. One cluster was predicted around the southern parts of the state of Western Australia expanding eastward from where $P$. dominula is currently known to occur. The other cluster is focused around the south-east of the country in a pattern similar to, but more conservative than that of the BIOCLIM method (Figure 2.3).

In New Zealand, the raw output produced by the BIOCLIM method indicated suitable climatic conditions throughout the upper and lower parts of the North Island, with central and western areas deemed less suitable. Much of the eastern side of the South Island was highlighted by the prediction model as climatically suitable, while the west coast was not (Figure 2.2). Once the threshold was applied, much of the country highlighted in the raw output was predicted as climatically suitable for $P$. dominula (Figure 2.3). Similarly, the raw output produced by the MAXENT method highlighted an extensive area across New Zealand with much of the North Island and east of the South Island receiving the highest values of suitability (Figure 2.2). With the threshold applied, the MAXENT method predicted that much of the North Island and the east of the South Island is climatically suitable for $P$. dominula (Figure 2.3). The potential invadable range identified by both the BIOCLIM and MAXENT methods indicate that known populations of $P$. dominula in New Zealand are likely to expand their range. 
South America

BIOCLIM raw output

MAXENT raw output
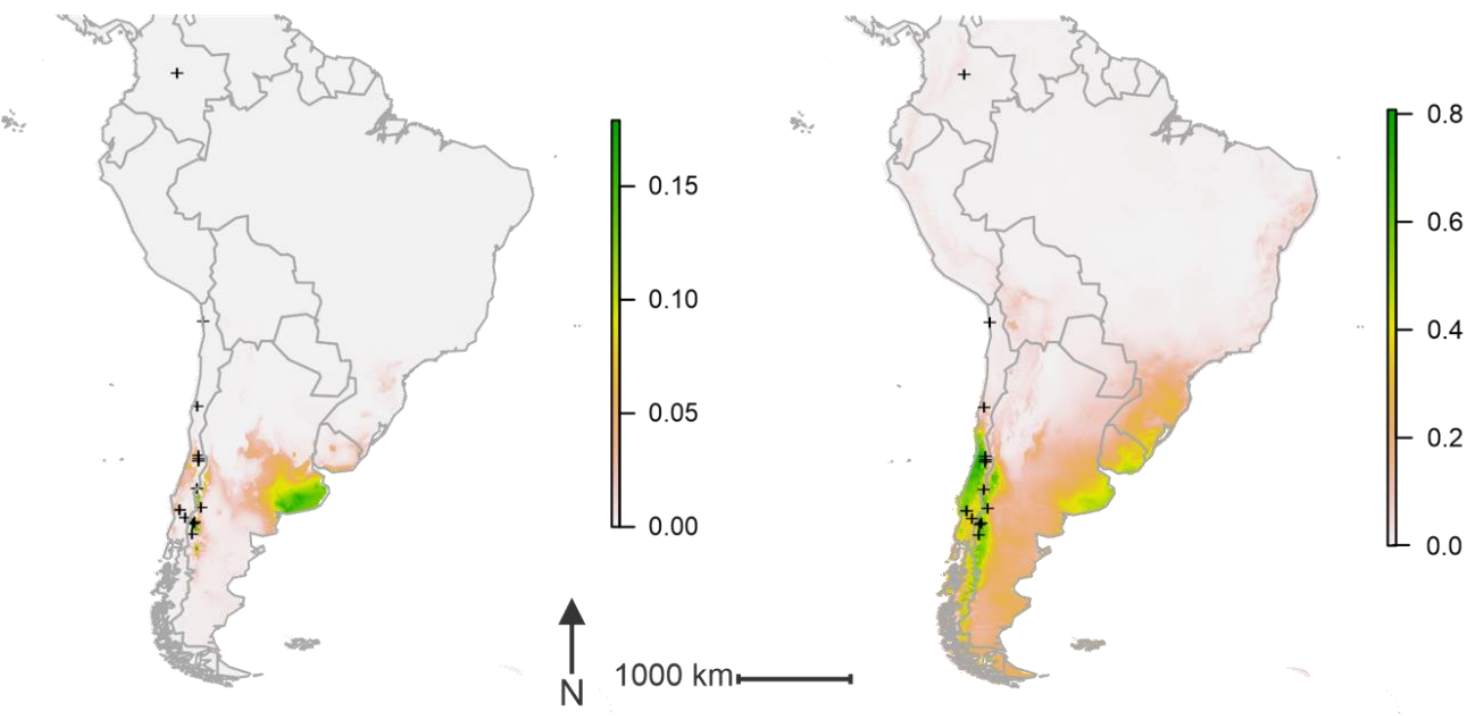

\section{Southern Africa}

BIOCLIM raw output

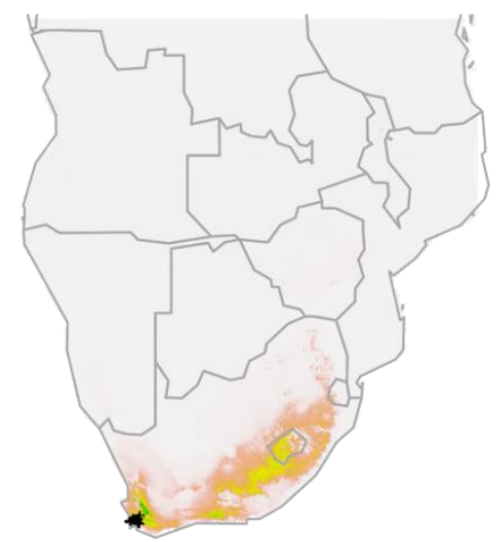

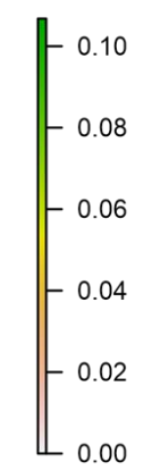

$\overbrace{\mathrm{N}} 1000 \mathrm{~km}$
MAXENT raw output

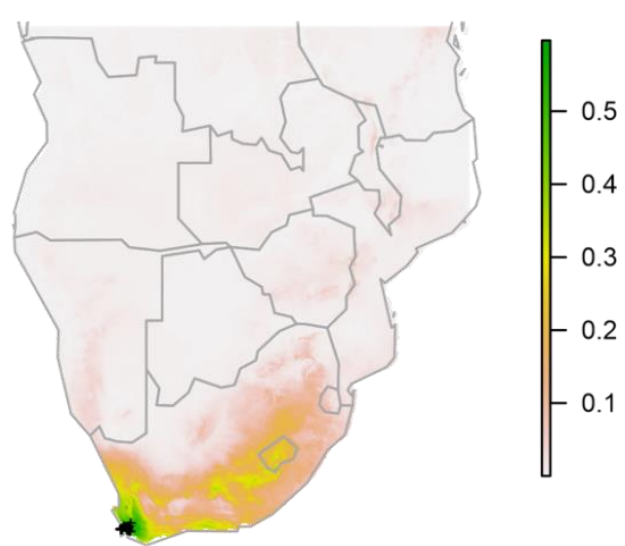




\section{Australia}

BIOCLIM raw output

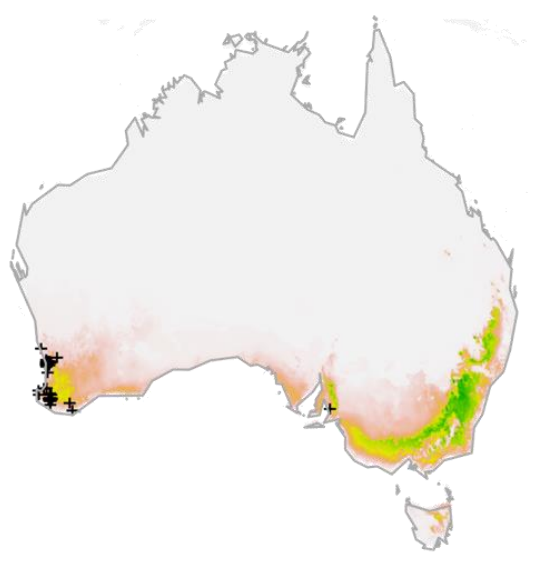

\section{MAXENT raw output}

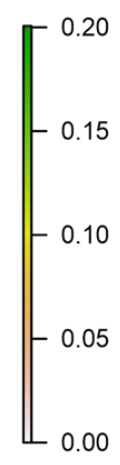

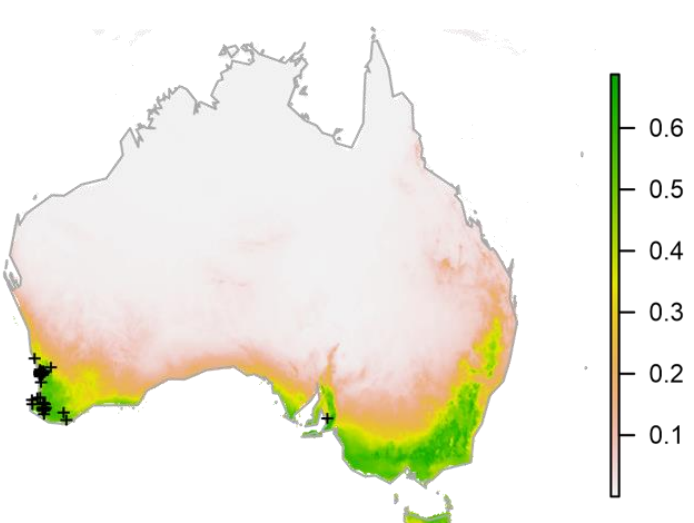

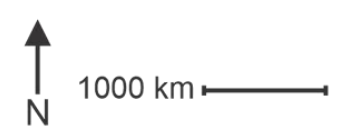

\section{New Zealand}

\section{BIOCLIM raw output}

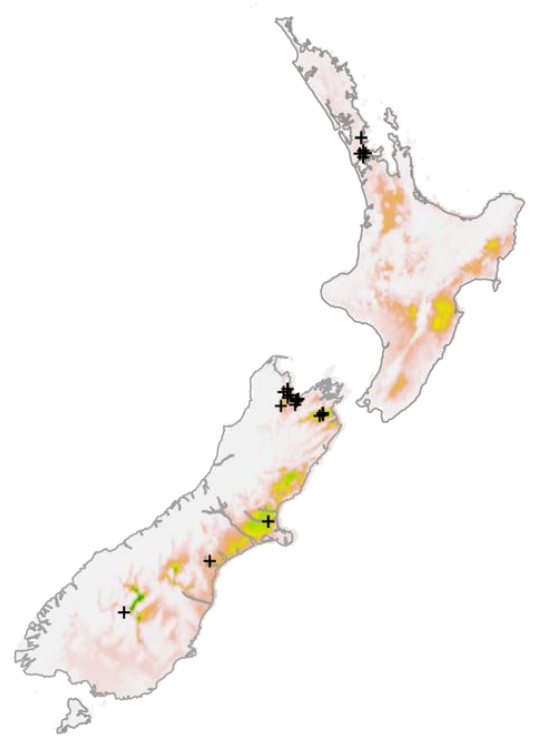

MAXENT raw output

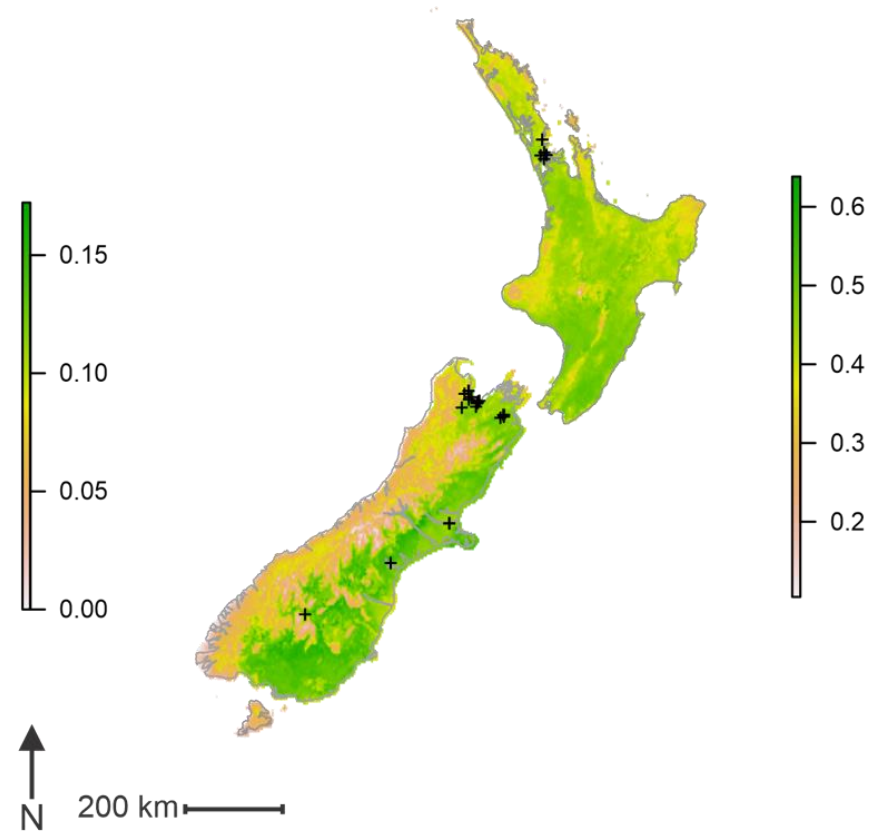

Figure 2.2: Raw outputs of both prediction models. The left images show the raw output given by BIOCLIM. The raw output of the BIOCLIM prediction is a value between 0 and 1 where the higher the number the more suitable the environment is. The BIOCLIM algorithm compares the environmental values of a cell to the median values of the environmental values of cells containing known occurrences of the target species. Percentile scores closest to 0.5 are most suitable so values over this are subtracted from 1 . The resulting score is multiplied by 2 to get a final value between 0 and 1 (Hijmans and Elith 2017). The right images show the raw output given by MAXENT where the value is an approximate probability that the species will be present given the local environmental conditions (Elith et al. 2011, Merow et al. 2013). The black crosses indicate known occurrences of $P$. dominula. 


\section{South America}

BIOCLIM with threshold applied

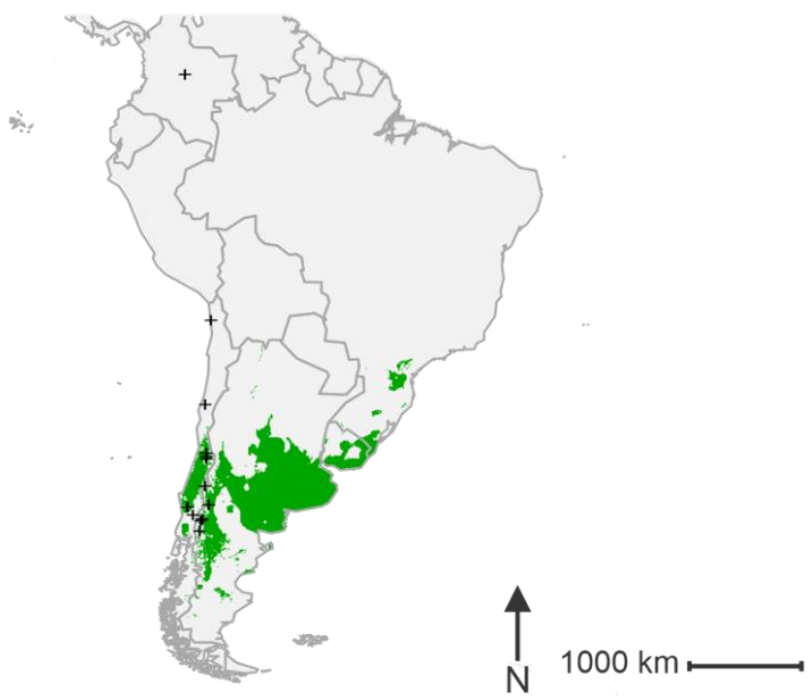

MAXENT with threshold applied

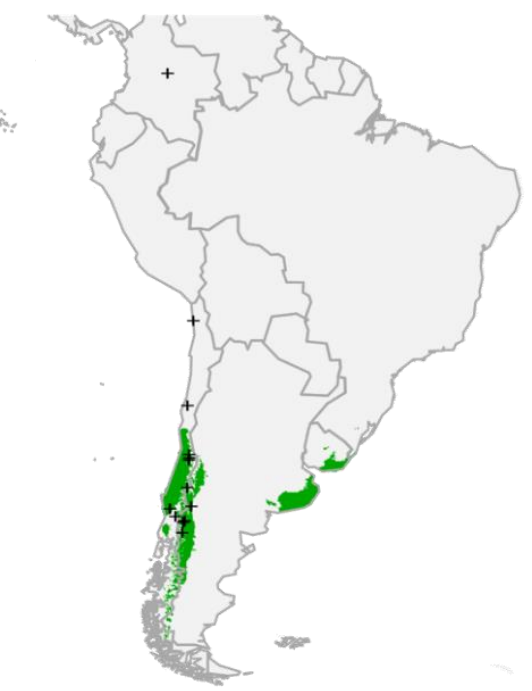

\section{Southern Africa}

BIOCLIM with threshold applied

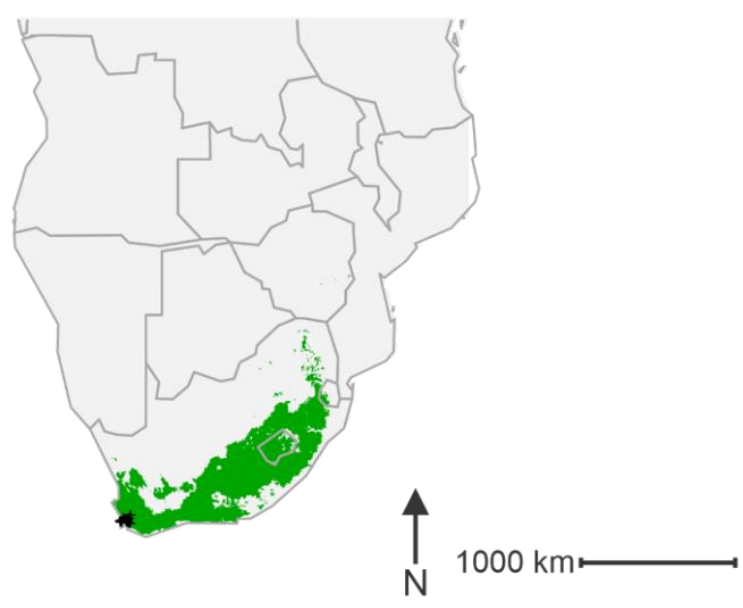

MAXENT with threshold applied

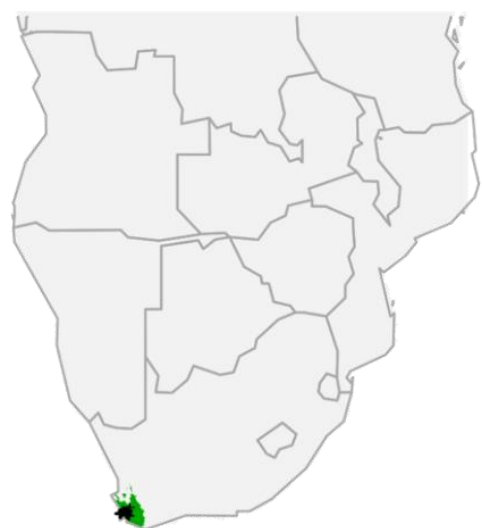




\section{Australia}

BIOCLIM with threshold applied

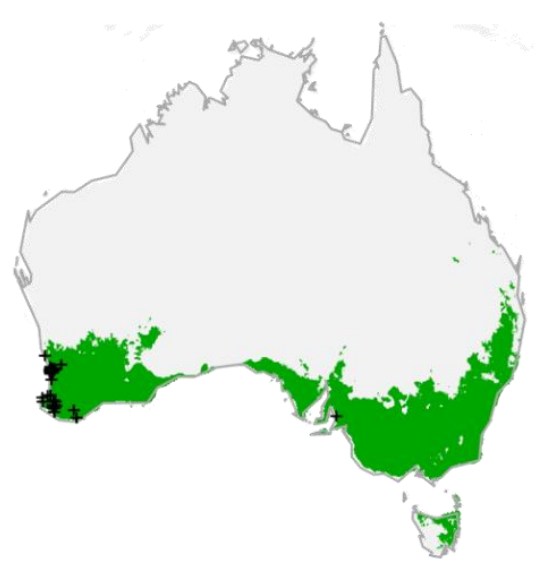

MAXENT with threshold applied

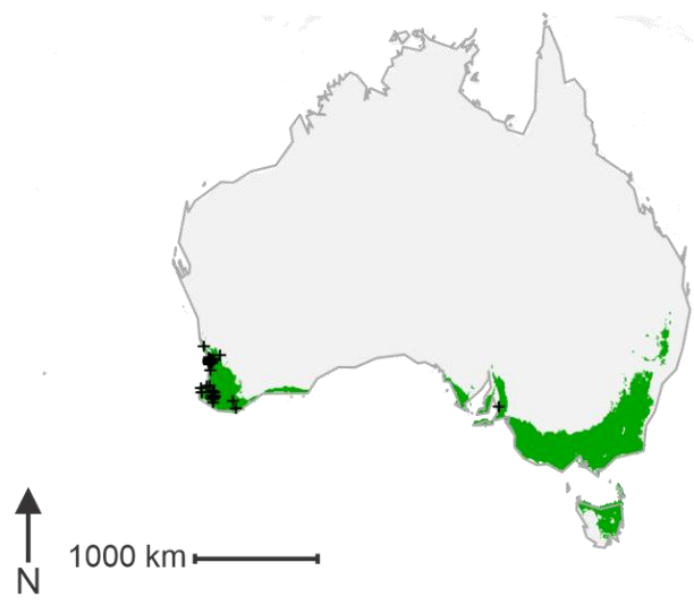

New Zealand

BIOCLIM with threshold applied

MAXENT with threshold applied
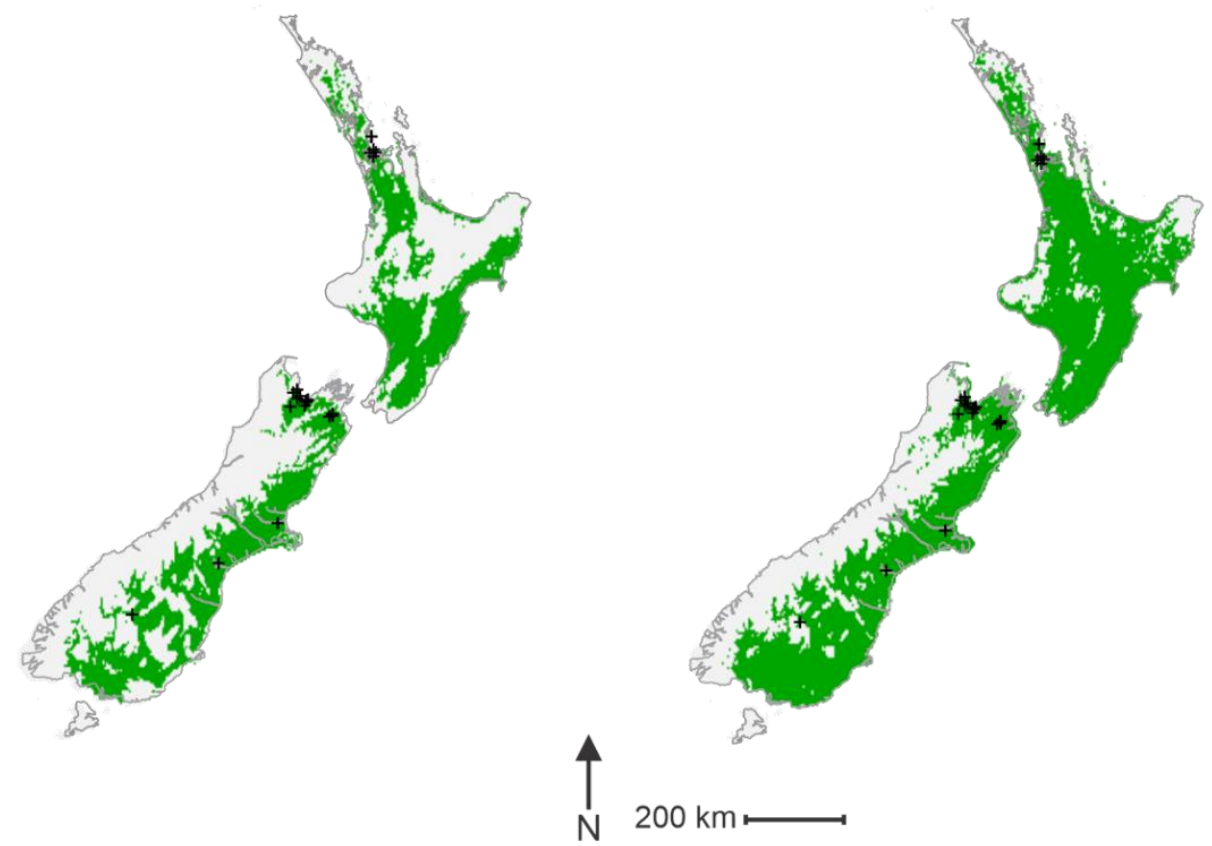

Figure 2.3. Predicted presence/absence plots for each region based on the two model outputs. For both models, thresholds ( 0.005 and 0.38 , respectively) are calculated as the raw output value at which the sum of the true positive and true negative rates is maximized. Locations where the raw output values are over these thresholds are denoted a present status (1) and highlighted in green. Locations where raw output values are lower than the threshold are denoted an absent status (0) and remain grey. Black crosses indicate known occurrences of $P$. dominula. 
The BIOCLIM method's performance as evaluated by AUC was 0.970 while the MAXENT method's performance was slightly higher with a value of 0.982 (Figure 2.4). These can be considered high AUC values as both values are close to 1, indicating the BIOCLIM and MAXENT methods were able to discriminate between the test-presence and background points $97 \%$ and $98.2 \%$ of the time respectively (Hosmer et al. 2013). For the MAXENT method, variable permutation importance showed that annual mean temperature (Bio1) was the most important variable with a value of $37.9 \%$, followed by precipitation of the coldest quarter (Bio19) at 15.9\%, temperature seasonality (Bio4) at $11.4 \%$, and mean temperature of the warmest quarter (Bio10) at 9.0\% (Table 2.2).

Histograms were produced (Figure 2.5) for the highest-ranking climatic variables, as measured by permutation importance (Table 2.2). Known occurrences of $P$. dominula were found to experience average annual temperatures (Bio1) between $-1{ }^{\circ} \mathrm{C}$ and $26.6{ }^{\circ} \mathrm{C}$, with a sharp peak between $8{ }^{\circ} \mathrm{C}$ and $10^{\circ} \mathrm{C}$ (Figures 2.5 and 2.6). Known occurrences of $P$. dominula were found to experience values of precipitation during the coldest quarter (Bio19) of 0-1057 $\mathrm{mm}$, with most falling between $100 \mathrm{~mm}$ and $300 \mathrm{~mm}$ (Figures 2.5 and 2.7). 

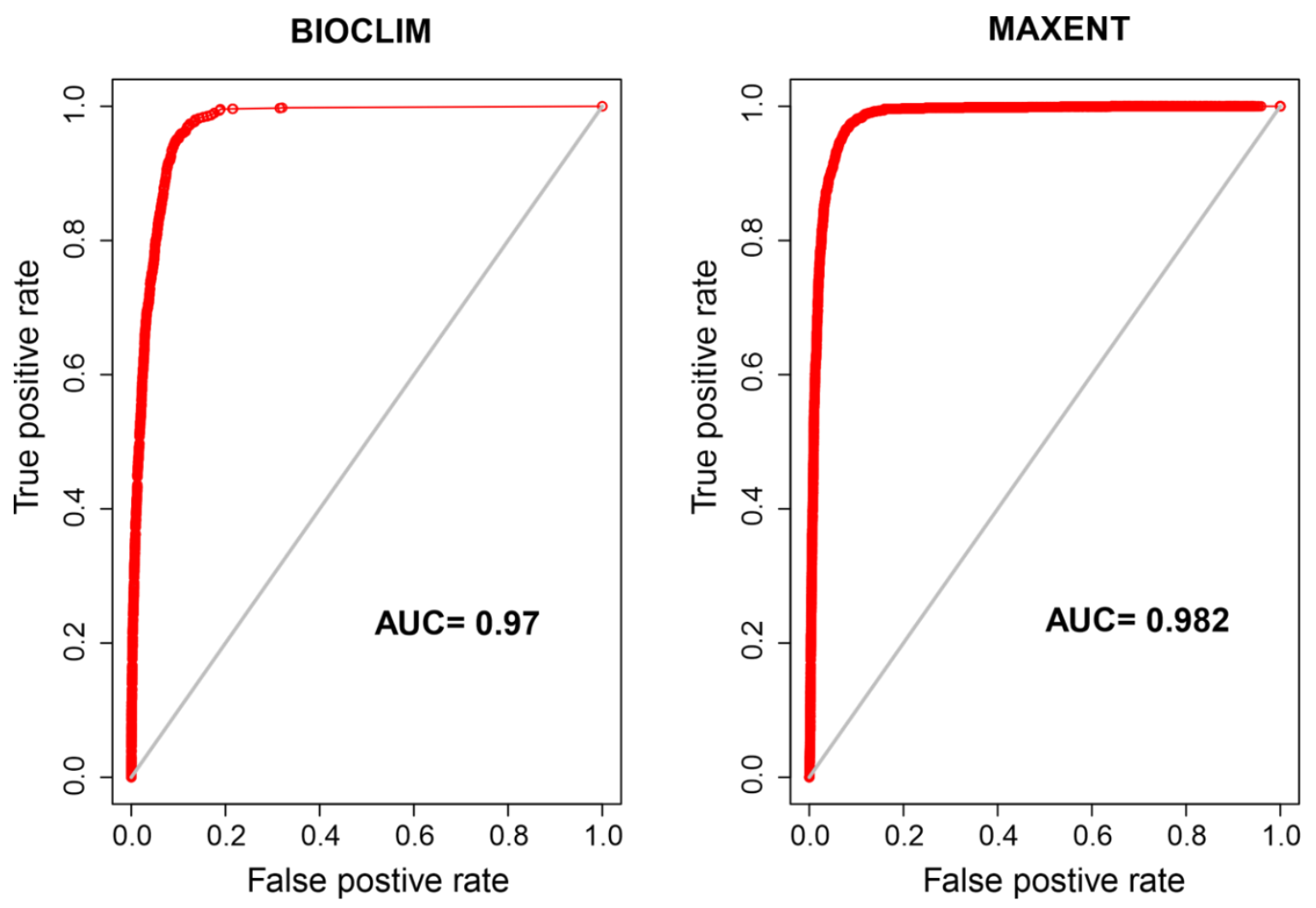

Figure 2.4: Area under the receiver operating characteristic curve (AUC) plots for BIOCLIM prediction and MAXENT prediction. This value is a number between zero and one and represents how accurately a model predicts presence/absence. A model with an AUC value of 1 predicts presence/absence with 100\% accuracy while a model with an AUC score of 0.5 is one that predicts presence or absence correctly $50 \%$ of the time (Hijmans and Elith 2017). 

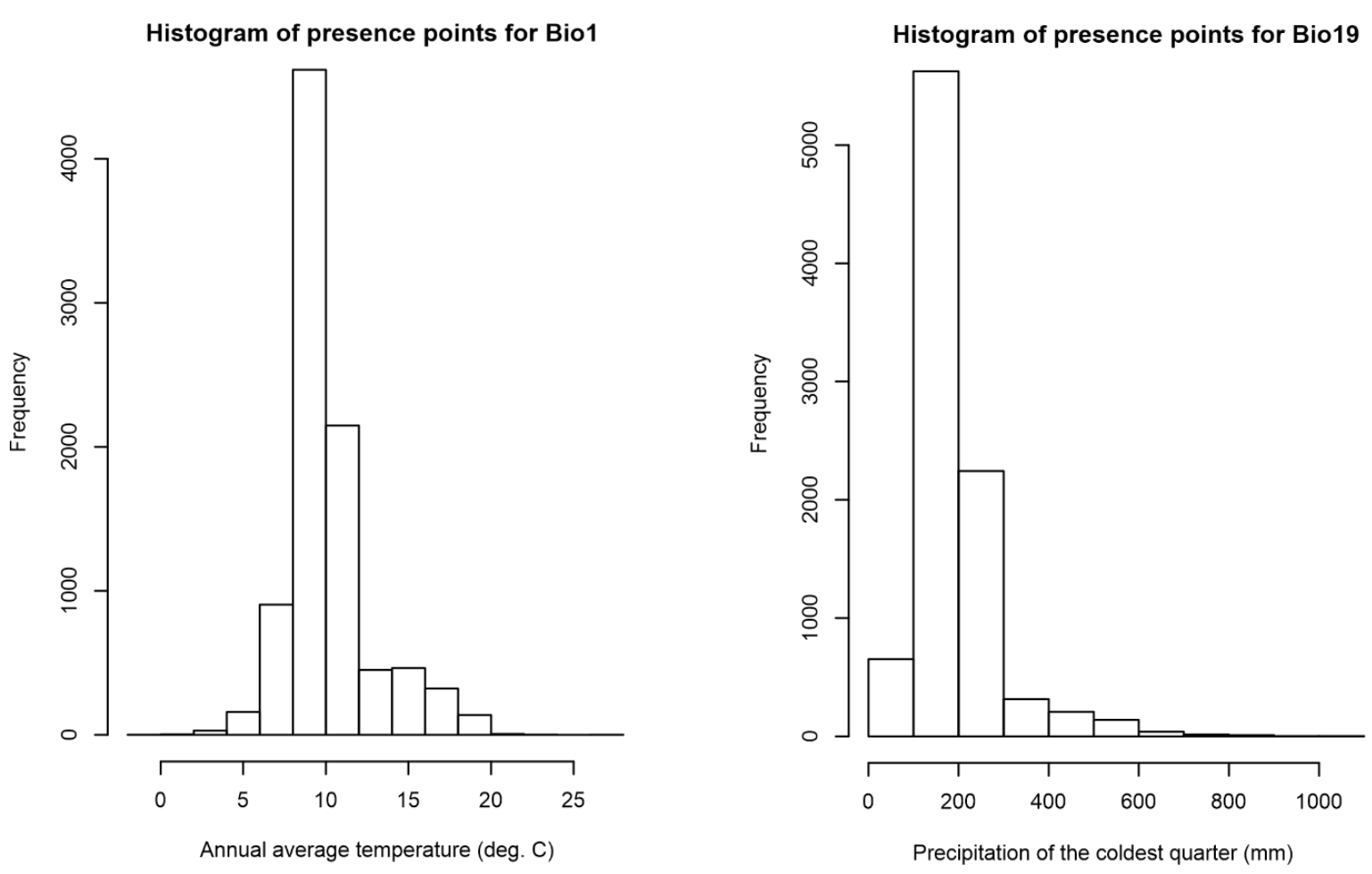

Figure 2.5: Histograms showing the distribution of bioclimatic values at known occurrences of $P$. dominula. Left is the distribution of annual average temperature (Bio1) and on the right the distribution of precipitation of the coldest quarter (Bio19). These two variables were chosen from the full list of 15 , based on their high permutation importance in the MAXENT modelling approach. 


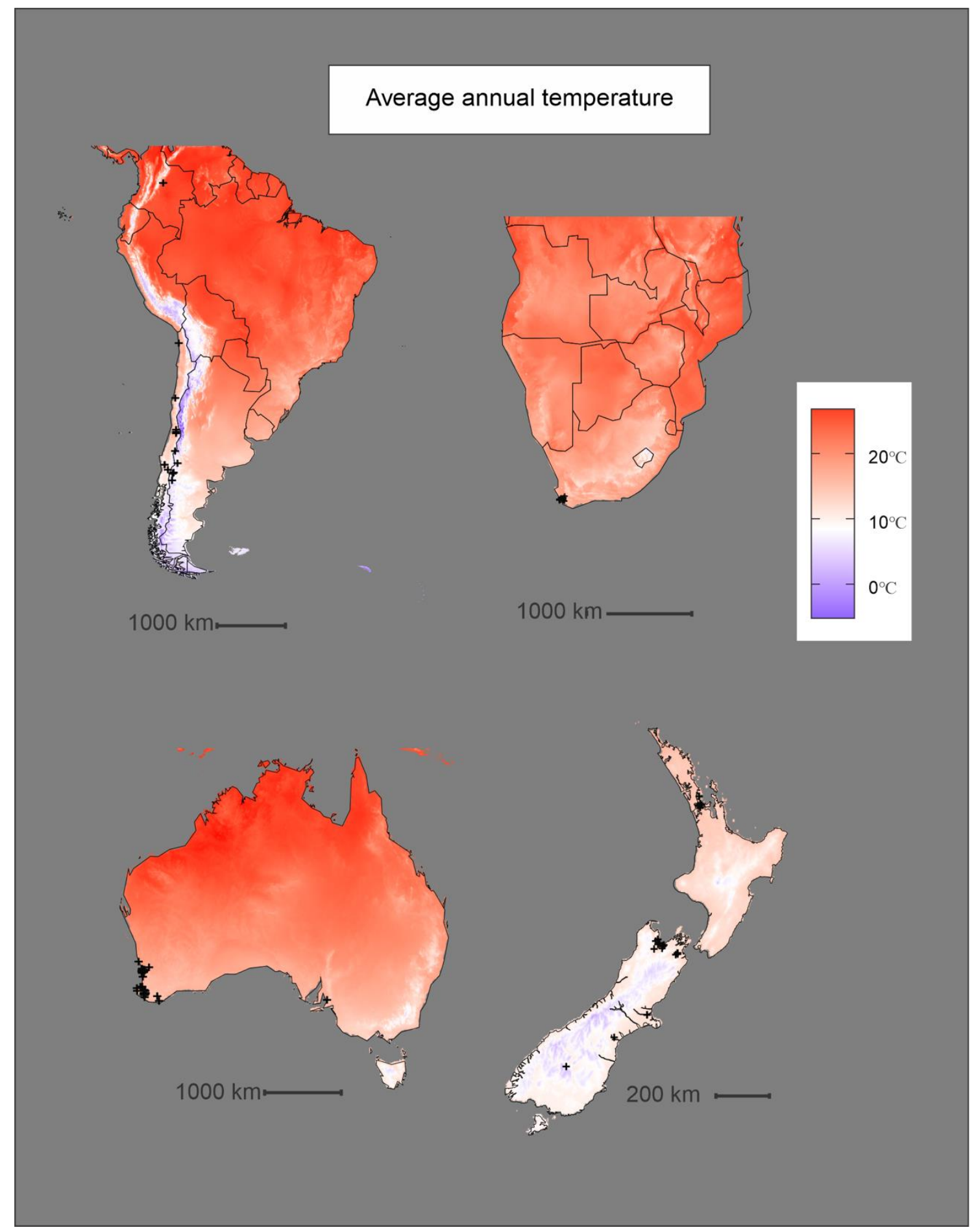

Figure 2.6: Plot of the average annual temperature (Bio1) bioclimatic layer at each region highlighted in this study. This variable had the highest permutation importance of $37.9 \%$. Black crosses indicate known occurrences of $P$. dominula. 


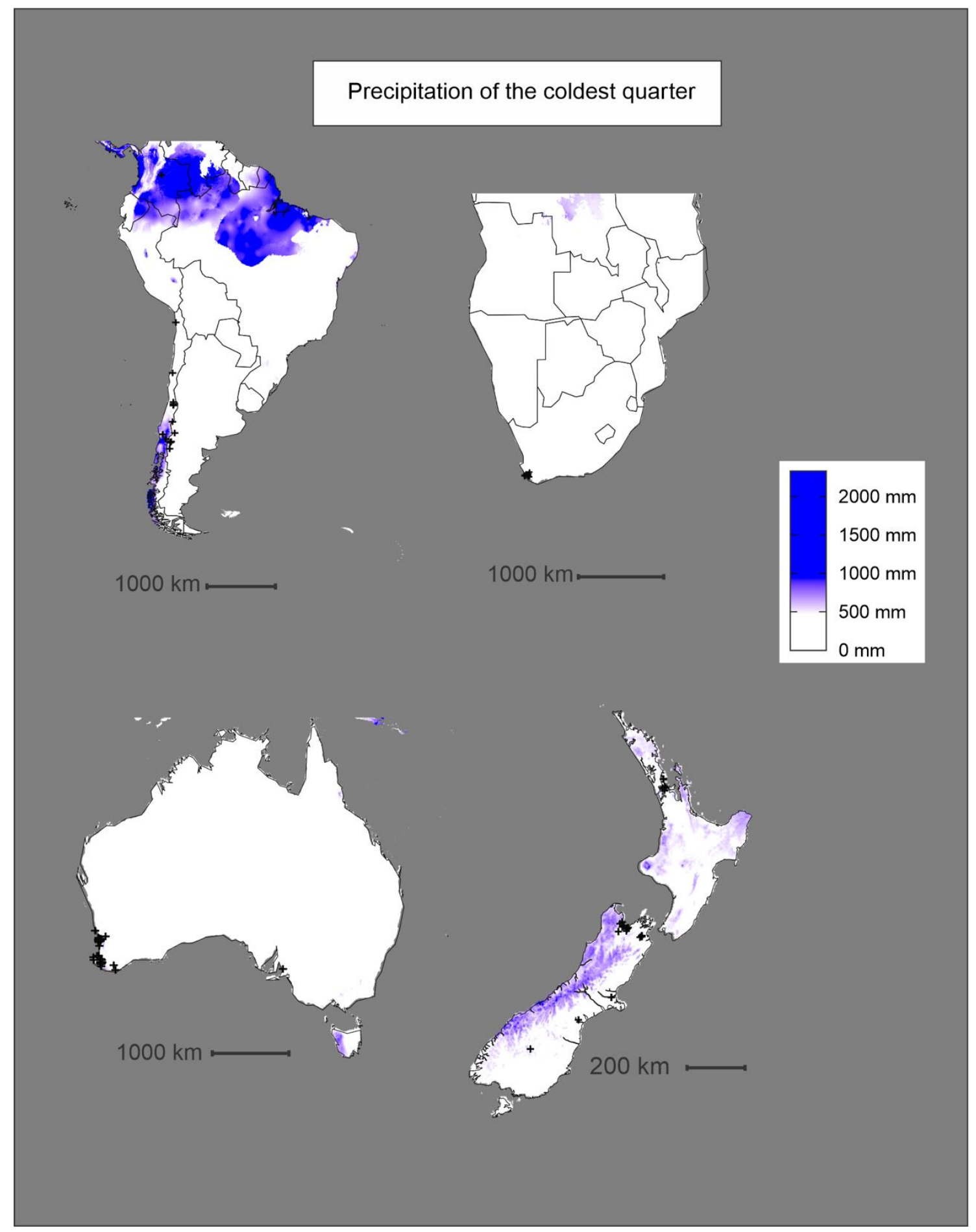

Figure 2.7: Plot of the precipitation of the coldest quarter (Bio19) bioclimatic layer at each region highlighted in this study. This variable had the second highest permutation importance of $15.9 \%$. Black crosses indicate known occurrences of $P$. dominula. 


\subsection{Discussion}

Polistes dominula is a widespread invader with introduced populations extending throughout North America, parts of South America, South Africa, Australia, and, more recently, New Zealand (Carpenter 1996, Buck et al. 2008, Ministry for Primary Industries 2016). This species has the potential to reach higher densities than other paper wasps (Gamboa et al. 2002), and their preference to live in close proximity to human habitation (Benadé et al. 2014) makes that an issue for human health. Invasive wasps have been linked to declines of native invertebrate species across the regions studied here (Toft and Rees 1998, Beggs and Rees 1999, Potter-Craven et al. 2018). Populations of $P$. dominula have already established across the four regions in this study but the estimated models predict a range expansion that could result in this species becoming present throughout more of the southern hemisphere.

The prediction models based on the BIOCLIM and MAXENT methods share some similarities in their predicted range of $P$. dominula across the four regions. In Australia, predicted distributions of $P$. dominula produced by both models closely follow patterns of average annual temperature. The majority of $P$. dominula occurrences fell in regions where the annual average temperature (Bio1) is between $8{ }^{\circ} \mathrm{C}$ and $12{ }^{\circ} \mathrm{C}$ with most of the country north of the predicted range averaging over $15^{\circ} \mathrm{C}$ (Figure 2.6). This same pattern can be seen in South America where the potential range of $P$. dominula appears to be constrained by cooler temperatures further south (Figures 2.3 and 2.6). The models incorporate the contribution of other variables too; however, it is apparent that some variables influence $P$. dominula distribution more than others. For example, the east coast of the North and South Islands of New Zealand were identified as climatically suitable for the establishment of $P$. dominula while areas such as the West Coast region of the South Island appear to be much less suitable (Figure 2.3). The limitation on their distribution there is likely due to the high precipitation. Mean precipitation of the coldest quarter (Bio19) was shown to be the second most important variable contributing to the MAXENT model's accuracy (Table 2.2). The mean value of Bio19 from all known occurrence data was $195 \mathrm{~mm}$ of precipitation. The West Coast receives over $500 \mathrm{~mm}$ of rain in the coldest quarter (Macarra 2016) and so is considerably wetter than most places known to contain $P$. dominula. Similar patterns are observed across 
the other regions with the west coast of Tasmania, Australia also receiving high precipitation, well above the levels preferred by $P$. dominula (Figures 3 and 7).

The two distribution models did produce slightly different predictions. Both models had high AUC values (Figure 4) indicating robust models. The BIOCLIM method may be prone to overfitting when using many variables, leading to a narrower potential distribution (Beaumont et al. 2005) and that method can be prone to underpredicting potential distributions, possibly explaining the difference in raw model outputs (Figure 2) (Ward 2007). MAXENT, by contrast, has been repeatedly identified as a more reliable method, classed as a high performing, stable modelling approach compared to the BIOCLIM method (Elith et al. 2006, Duan et al. 2014). Unlike the BIOCLIM modelling method, MAXENT weights variables differently depending on how their inclusion affects the models' AUC. This fundamental difference in modelling strategy leads to differences in the model outputs and hence explains some of the differences between predictions.

Threshold selection is another area that may explain differences between the BIOCLIM and MAXENT predictions. Thresholds were chosen using the maxSSS method, necessarily producing a different threshold for each method. The BIOCLIM method fitted models with a comparatively low threshold of 0.005 and so ranked nearly all the cells highlighted in the raw output plot as a presence value. The threshold for the MAXENT method was set at a comparatively higher 0.38 , meaning that only the most climatically suitable of the areas highlighted in the raw MAXENT output were denoted a presence value. This difference in threshold explains the pattern we see where MAXENT presence/absence predictions appear to be more conservative for Australia, South Africa, and South America (Figure 3). By contrast, in New Zealand the MAXENT method's raw values of habitat suitability were so high that even with a more restrictive threshold, the areas denoted a presence status were larger than those resulting from the BIOCLIM method. Despite these differences in the final outputs both models predict areas that experience more mild average annual temperatures and are drier in the cooler months to be more suitable for the establishment of $P$. dominula. Both models predict a range expansion of $P$. dominula throughout the southern hemisphere.

Polistes dominula has been shown to be an important predator of invertebrates. They have been linked to the decline of invertebrates in invaded ranges around the world (Stamp and Bowers 1988, Pilowsky and Starks 2018, Baker and Potter 2020). This is a pattern seen in invasive social wasp species due to their predatory behaviour and ability to reach high 
population densities (Beggs et al. 2011, Parent et al. 2020). With this species' continued range expansion, it is likely that $P$. dominula will compound existing pressures to native invertebrate fauna across the southern hemisphere. Molecular diet analysis performed on related Polistes species, also invasive to New Zealand, showed that both native and introduced Lepidopteran species made up the largest portion of their diets (Ward and Ramón-Laca 2013, Lefort et al. 2020). Over half of all of New Zealand's threatened native Lepidopterans are found on the east coast of the South Island (Stringer et al. 2012), a region that was identified as climatically suitable for $P$. dominula by both models. The seasonal nature of the $P$. dominula lifecycle (Gamboa et al. 2002, Höcherl and Tautz 2015) means only those prey species that are abundant or breed during the summer months are likely to be targeted (Beggs and Rees 1999). This seasonality will still likely impact assemblages of invertebrates in the predominantly temperate regions that are predicted to be most suitable for establishment of this species.

Both models predict rather significant areas of climatically suitable habitat across the southern hemisphere; however, these models have only considered the effects of temperature and precipitation on $P$. dominula establishment. Observations from the field in both native and invaded ranges show that $P$. dominula appear to preferentially nest near human habitation (Höcherl and Tautz 2015, Roets et al. 2019). This pattern of synanthropy is seen in related species (Parent et al. 2020) and has been shown to allow other taxa to invade regions where environmental conditions are unsuitable (Schapheer et al. 2018). Additional modelling including human habitation and land-use as variables may be able to produce a more realistic prediction of $P$. dominula potential range. Physical barriers, potential corridors, long-distance dispersal events (natural or human-related), and climatic change may influence colonization patterns. Polistes dominula was the most commonly reported nuisance wasp species in Colorado only four years after it was first identified in the state (Cranshaw et al. 2011). This species' ability to attain high densities close to human habitation could lead to the potential for an increased rate of human-wasp conflict in these predicted ranges.

Climate-based models such as the ones presented in this paper have been criticized for not considering biotic interactions when predicting habitat suitability (Godsoe and Harmon 2012, Giannini et al. 2013, Wisz et al. 2013). Other studies consider the presence or absence of competitors (Pellissier et al. 2010, Bulgarella et al. 2014, Mpakairi et al. 2017). This could be an important factor to consider in the spread of $P$. dominula, as other Polistes species are 
found in many of these regions. In southern South America there are 21 other species of Polistes, South Africa is home to six native species, Australia contains 15 other species while New Zealand contains two other invasive species of paper wasp (Carpenter 1996). These other, closely related species represent potential competitors that may impact the likelihood of establishment by $P$. dominula regardless of habitat suitability. While $P$. dominula has been shown to initially outcompete congener Polistes species, total displacement and replacement has not been shown to occur. It had been suggested that $P$. dominula was in the process of replacing the native Polistes fuscatus in the north-eastern United Sates (Gamboa et al. 2002, Gamboa et al. 2004, Liebert et al. 2006). A ten-year study of the two species in Michigan, USA, showed that despite initial displacement of $P$. fuscatus by $P$. dominula, populations eventually stabilized, likely due to the presence of a common parasitoid (Miller et al. 2013). In South Africa, however, $P$. dominula continued to outnumber its native counterpart, Polistes marginalis, and maintain more productive nests despite the higher infection rates by a parasitoid (Roets et al. 2019). Of the regions discussed in this paper, South America and Australia already contain a diverse range of Polistes species and so too presumably Polistes parasites and pathogens, which could have implications on invasion success.

\subsection{Conclusion}

Despite their relative simplicity, the use of climate based SDMs to predict potential ranges of species has been shown to provide strong predictive power (Kearney et al. 2010). Simple models such as these are still useful for making predictions over the broader scale and where more of the finer details of a species' ecology are not well understood. This paper presents the first attempt to use species distribution models to identify potentially suitable habitat for the establishment of the invasive $P$. dominula. Information gathered from these SDMs can help inform governments and conservation groups about the likelihood of $P$. dominula establishing in their respective regions. Regions with no known populations of $P$. dominula that were highlighted as suitable may invest in early detection and control to prevent the species from becoming established. Methods used here could be used and built on in future work to predict the range of other invasive species. 


\section{Chapter 3: DNA Barcoding Reveals the Diverse Prey Community of Two Invasive Paper Wasps (Hymenoptera: Vespidae)}

\subsection{Abstract}

The European paper wasp (Polistes dominula) is a globally important invasive species that has recently been discovered in New Zealand. As a generalist predator that can reach high population densities this species poses a potential risk to New Zealand's local entomofauna. In this study we used DNA barcoding to analyse the diet of both $P$. dominula and the closely related congener $P$. chinensis, in order to identify the species these wasps are feeding on in Nelson, a region of New Zealand where they co-occur. Both wasp species were shown to prey largely on Lepidoptera species but other orders such as Hemiptera, Diptera, Coleoptera were also represented. Both native and introduced fauna were represented in the diets of both wasps, including a number of important agricultural pests. While considerable prey overlap was identified between both wasps, $P$. dominula was shown to predate upon a wider range of prey taxa. The wider prey range of $P$. dominula, combined with known differences in nesting behaviour, and typically higher abundance, suggests that $P$. dominula may represent a more significant threat to invertebrate diversity than $P$. chinensis. These wasps are abundant in some coastal and urban habitats in New Zealand, where they likely consume pest species as well as species of conservation importance. This is the first diet analysis performed on $P$. dominula. Our results will inform conservation and biosecurity managers regarding the impacts that this invasive paper wasp is having on New Zealand's local invertebrate communities.

\subsection{Introduction}

Predation by invasive species has long been known to negatively impact native communities (Gorman 1975, Norman 1975, Savidge 1987). This trend is most apparent in island ecosystems where existing fauna are relatively depauperate and often specialised (Pyšek et al. 2017). While invasive mammalian predators often capture the public's attention, predatory invertebrates can also have significant impacts on native fauna (Crowder and Snyder 2010). These impacts are arguably most apparent in Vespidae, whose adaptive behaviours and ability to reach great population densities make these species particularly 
effective invasive predators (Beggs et al. 2011, Lester and Beggs 2019). Invasive wasps have repeatedly been shown to exert substantial predation pressure on recipient communities (Toft and Rees 1998, Beggs and Rees 1999, Wilson et al. 2009, Parent et al. 2020). When assessing the impacts of an invasive predator it is important to identify what species are likely to be incorporating into their diet.

Polistes dominula is a species of invasive paper wasp that was recently found in New Zealand in 2016 (Ministry for Primary Industries 2016). The predatory nature of $P$. dominula has been shown to threaten native species in its invaded range (Baker and Potter 2020, McGruddy et al. 2020). Due to the recent discovery of this species in New Zealand, it is not yet known how the establishment of $P$. dominula will affect local entomofauna. Identifying what this invasive wasp is feeding on in New Zealand may provide insights into how it will impact biodiversity. New Zealand does not contain any native paper wasps though two other species have been introduced, Polistes humilis and Polistes chinensis (Clapperton et al. 1989), the latter being the most widely distributed and found on both the North and South Islands (Clapperton and Dymock 1997). Polistes chinensis, like other Polistes species, is considered a significant predator of lepidopteran (butterflies and moths) larvae. These insects comprise a substantial portion of their diet (Clapperton 1999, Ward and Ramón-Laca 2013) though other groups are represented (Kudo 1998, 1999). Polistes dominula has similarly been shown to feed on Lepidoptera (Stamp and Bowers 1988, Rayor et al. 2007, McGruddy et al. 2020), however, it has been suggested that this species has a more generalist diet that that of other paper wasp species (Cervo et al. 2000, Schenk and Bacher 2002). In New Zealand, Polistes spp. have been shown to prey on both native and introduced species (Ward and Ramón-Laca 2013, Lefort et al. 2020). The presence of $P$. dominula could add to the threats that New Zealand's native invertebrates face, although it could also act as a natural biocontrol for current and new invasive pests. Polistes spp. have been considered for biocontrol of agricultural pests due to their heavy predation of butterfly and moth larvae which feed on various crops (Oliveira et al. 2017, Southon et al. 2019). Analysing the diet of this species will improve our understanding of the potential impacts this new invasive species will have on New Zealand's invertebrates.

Investigating species diet contents historically involved searching through diet samples, visually inspecting and identifying prey (Kasper et al. 2004, Parent et al. 2020). These methods are time consuming and not always accurate. With the advent of Next Generation DNA 
sequencing technology, it is now possible to inspect diets more thoroughly using DNA barcoding. This involves sequencing a conserved gene that contains species-specific signature sequences. The process consists of collecting a diet sample from a target species such as gut contents of faecal matter. Selected universal primers are then used in the polymerase chain reaction (PCR) to target specific gene homologues (Valentini et al. 2009). Genes that are conserved across a wide range of species, such as cytochrome c oxidase subunit 1 (CO1), are often used in DNA barcoding studies (Hebert et al. 2004, Steinke and Hanner 2011, Wirta et al. 2015, Cheng and Lin 2016, Turanov et al. 2016, Ayesha et al. 2019). The CO1 mitochondrial gene is an ideal candidate gene for DNA barcoding as it has been conserved across many taxonomic groups yet has enough variation to allow for the identification of organisms to the species level (Hebert et al. 2003). Next Generation DNA sequencing enables the identification of many different species in a single sample. This technique has been used widely in both vertebrate (Zeale et al. 2011, Lyke et al. 2019, Takahashi et al. 2020) and invertebrate groups (Paula et al. 2016, Nakano et al. 2017, Lafage et al. 2019) to analyse and compare the diets of different species.

In this investigation we describe and compare the diets of both $P$. dominula and $P$. chinensis in Nelson, New Zealand. This work will help provide insights into the predicted impacts that a new invader will have on New Zealand's entomofauna compared to that of an already established species. This information will inform biodiversity managers about what kind of impact this wasp will have on New Zealand's entomofauna by identifying what species are most at risk of predation.

\subsection{Methods}

Study site

Larvae of $P$. dominula and $P$. chinensis were collected across nine locations near the city of Nelson, New Zealand (Figure 3.1) over the 2019/2020 summer. These locations were confined to coastal areas within $200 \mathrm{~m}$ of the ocean. Vegetation consisted largely of shrubs with some small trees, representing recovering native coastal vegetation. The composition of plant species was mainly Myoporum spp., Coprosma spp., and Muehlenbeckia spp., however, the stage of restoration of these sites varied. At some sites, vegetation was well established while others had recently been planted, likely influencing wasp and prey species compositions. Sites were located a minimum of $700 \mathrm{~m}$ from each other which is regarded to be 
further than the typical foraging distance of other Polistes spp. (Suzuki 1978, Parent et al. 2020).

In November 2019, areas of approximately $1000 \mathrm{~m}^{2}$ were surveyed for the presence of paper wasp nests at each of the nine locations (Figure 3.1). A site was considered to be dominated by one species if over $80 \%$ of nests found belonged to one species. Where this was not possible the nests of other wasp species were physically removed from within the $1000 \mathrm{~m}^{2}$ area. Monitoring of species prevalence continued every month over four months until February 2020. In all, there were three sites of roughly even $P$. dominula and $P$. chinensis occupation, three sites of predominantly $P$. dominula occupation, and three sites of predominantly $P$. chinensis occupation. These sites were created to represent sympatric and allopatric populations of each wasp species and so were non-randomly selected. Both species were sampled at sites with approximately equal abundances of wasp species. At the singlespecies dominant sites only the wasp species most abundant was sampled. This resulted in approximately 135 samples of each species in total across all sites.

\section{Sampling}

Using forceps, fourth and fifth instar larvae were removed from the nest and placed in a solution of $90 \%$ ethanol for storage at $-18^{\circ} \mathrm{C}$ until dissection and DNA extraction. Wasp larvae were chosen as they are fed material by the adult foragers. Prey material is consumed by the larvae and retained in the gut until pupation. The largest and oldest larvae were sampled as these contain the most material in their gut. Forceps were rinsed and sterilised in an ethanol solution between each sampling event. One larva was removed from three of each species nests, at respective sites. This process was repeated over three months from December 2019 until February 2020. Samples were thawed slightly before dissection. The guts were removed under a dissecting microscope and placed in a vial with $100 \%$ ethanol and stored at $-80^{\circ} \mathrm{C}$ until DNA extraction. Ultimately, 102 Polistes gut samples were prepared for DNA extraction and further analysis. 


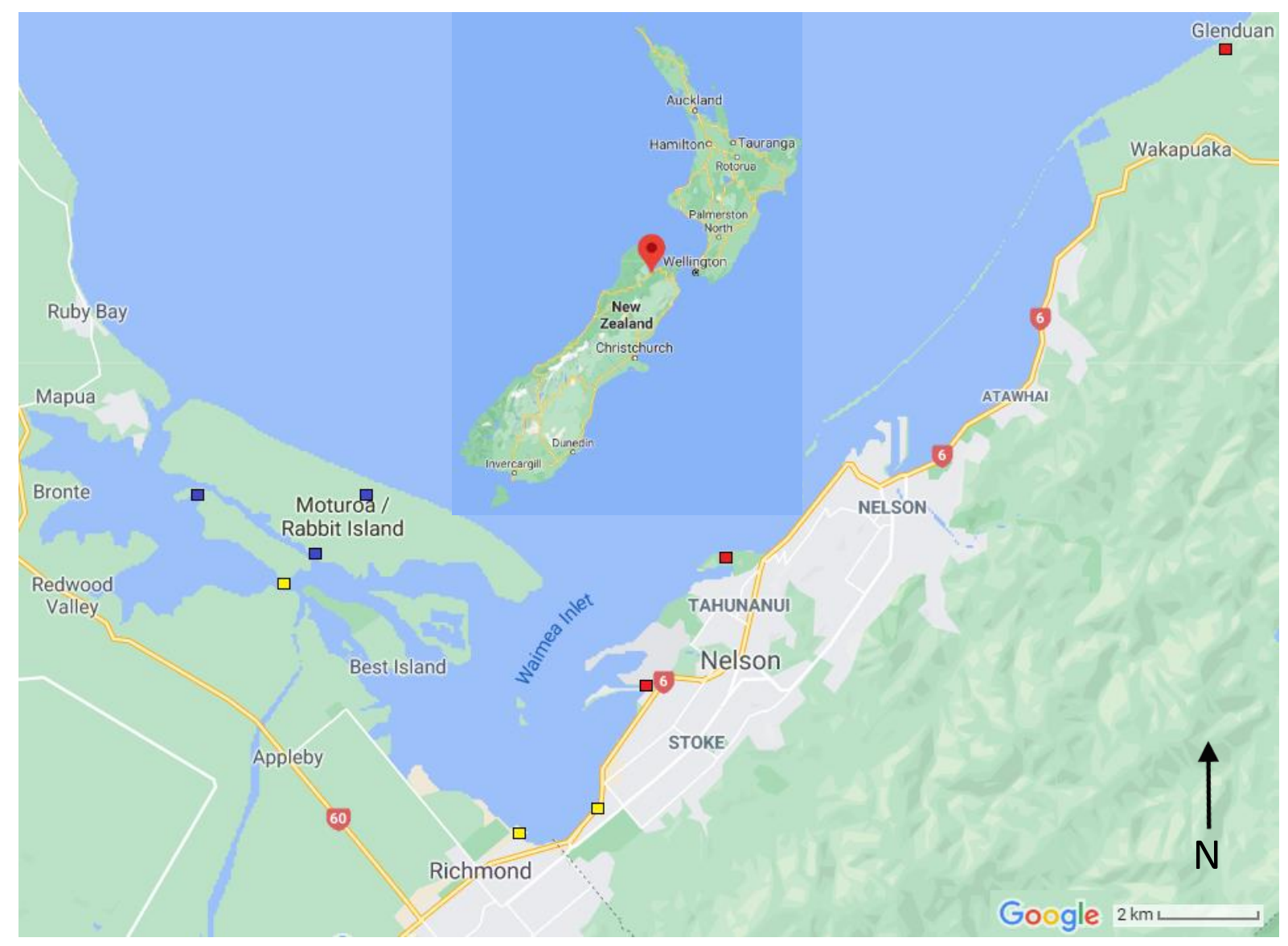

Figure 3.1: Map of sites where Polistes spp. larvae were sampled in Nelson, New Zealand. Blue squares indicate sites where $P$. dominula were sampled exclusively, while red squares indicate where $P$. chinensis were sampled exclusively. Yellow squares indicate sites where both $P$. dominula and $P$. chinensis were sampled. Base map was retrieved from Google Maps (https://www.google.co.nz/maps/).

DNA extraction, amplification, sequencing and taxonomic assignment

Following methods outlined in Loope et al. (2019), each gut sample was mechanically homogenised in a Precellys Evolution homogeniser (Bertin Technologies, France) with two stainless steel beads, $1 \mathrm{~mL}$ GENEzol DNA Plant Reagent (Geneaid, Taiwan) and $5 \mu \mathrm{L} \beta$ mercaptoethanol per tube. Chloroform and isopropanol were used to purify the DNA, which was then precipitated with $70 \%$ ethanol and then resuspended in $100 \mu \mathrm{L}$ nuclease-free $\mathrm{H}_{2} \mathrm{O}$. DNA concentrations were measured on a NanoPhotometer NP80 (Implen, Germany). Sample PCR amplification and Next Generation Sequencing were carried out by Custom Science (Auckland, New Zealand). PCR primers targeting mitochondrial gene, CO1, developed by Zeale et al. (2011), were used (ZBJ-ArtF1c: GATATTGGAACWTTATATTTTATTTTTTGG and ZBJ-ArtR2c: WACTAATCAATTWCCAAATCCTCC). These taxon-specific primers amplify a 157 base-pair (bp) region, and have been successfully used to identify arthropod prey in bat faecal samples 
(Zeale et al. 2011, Alberdi et al. 2020). Of the 102 Polistes gut samples sent, 58 amplified successfully (30 P. dominula and 28 P. chinensis) and were sequenced on a HiSeq platform (Illumina, USA) generating 150 nucleotide paired end reads.

Taxonomic assignment was performed using BLAST searches in the NCBI database to generate Molecular Operational Taxonomic Units (MOTU). MOTU sequences were identified to genus level. As we cannot rule out that a single MOTU represents multiple species they are presented as the genus named followed by the "spp." qualifier (for example "Lycaena spp."). Most alignments were clustered around $157 \mathrm{bp}$, the expected length of the amplicon generated by the CO1 primers (Zeale et al. 2011). To increase the confidence in the accuracy of the MOTU identification and reduce false positives, only those for which alignments exceeded $100 \mathrm{bp}$ long were retained for analysis. MOTUs with BLAST matches less than $98 \%$ percent identity were removed (Vesterinen et al. 2018). Reads identified as belonging to Polistes spp. were filtered out prior to analysis as these reads are likely from remaining tissue from the wasp larvae rather than from their diet. The presence-absence table was constructed using these remaining reads to be used as an overall diet community. Presenceabsence data were used to reduce the impact caused by recovery bias during DNA amplification and sequencing (Pompanon et al. 2012). For statistical analyses, however, this prey taxa community was further filtered on the basis of relative read abundance, keeping MOTUs that represented at least $1 \%$ of the reads in a gut sample (Mclnnes et al. 2017). This approach has previously been shown to reduce the likelihood of over estimating the importance of rarer taxa to the diets of each species (Deagle et al. 2019). By presenting both diet communities, an estimate of the full breadth of each species' diets can be shown while not impacting the validity of statistical analyses.

\section{Data Analysis}

A Permutational Multivariate Analysis of Variance (PERMANOVA) test using Bray Curtis indices was performed (Oksanen et al. 2019) using the subset diet communities of taxa that made up over $1 \%$ of reads in a sample. The relative read abundance of each of the MOTUs in this subset was set as the dependent variable with wasp species, site and month of sample collection set as independent variables. The number of permutations was set to 9999.

To assess the completeness and diversity of each wasp diet, a species accumulation curve was constructed using the 'speccaccum' function in the 'vegan' package (Oksanen et al. 2019) 
in $R$ version 4.0.2 ( $R$ Core Team 2020). These curves show the diversity of taxa found with increasing sample size. These curves are steep to begin with as common taxa are observed quickly, eventually plateauing as fewer, rarer taxa are added with increasing sample sizes. The flatter the curve the closer our samples are to representing a complete paper wasp diet at our study site. Overlapping curves indicate both species prey on a similar diversity of taxa while non-overlapping curves may indicate that one species is more generalist than the other. In addition, MOTUs identified from samples of both species were plotted as Venn diagrams to visually assess the dietary overlap of both species with the results analysed using a twosample proportion test. For all statistical tests, significance was considered at any $p$-value less than 0.05 .

\subsection{Results}

DNA sequencing identified a total of $26,596,280$ reads across 58 samples (30 from $P$. dominula and 28 from $P$. chinesis). After filtering out reads identified as belonging to Polistes spp., $27 \%(7,260,112)$ of the reads remained. Filtering reads shorter than $100 \mathrm{bp}$ left a total of $7,193,653$. Reads were also removed if they had a match percent identity of less than $98 \%$, resulting in 3,214,149 reads. These corresponded to 315 distinct MOTUs representing 10 taxonomic Orders, 50 Families and 299 genera (Appendix A).

Across all samples from both species, 289 of the 315 MOTUs were taxa within the Order Lepidoptera. Unsurprisingly, this Order was the most represented across all wasp samples with taxa from this Order being found in all gut samples of both Polistes species (Figure 3.2). Studies analysing the diet of Polistes spp. have repeatedly shown that these wasps are lepidopteran specialists (Kasper et al. 2004, Ward and Ramón-Laca 2013, Oliveira et al. 2017, Jeon et al. 2019, Southon et al. 2019, Parent et al. 2020). The next most represened Order across all samples was Diptera (flies), with 10 of the 315 MOTUs falling within this group. Taxa from this order were found in 20 (67\%) samples from $P$. dominula, and $16(57 \%)$ samples from P. chinensis. Despite only four of the 315 MOTUs belonging to the Order Hemiptera (true bugs), these taxa were found in 24 (80\%) samples from $P$. dominula and 16 (57\%) from $P$. chinensis. Other Orders represented in both species' diets included Coleoptera (beetles), Araneae (spiders), Mantodea (mantids), Orthoptera (crickets, wētā and grasshoppers) and Hymenoptera (ants, bees and wasps). The order Neuroptera (net-wing insects) was represented from just one $P$. chinensis sample while another sample from $P$. dominula 
contained a MOTU belonging to the order Apusomonadida (protozoan zooflagellate). This protozoan taxon is not likely a true prey item for these wasps but was likley present within other prey or in the surrounding environment and so was identified in the wasp larvae's gut contents.

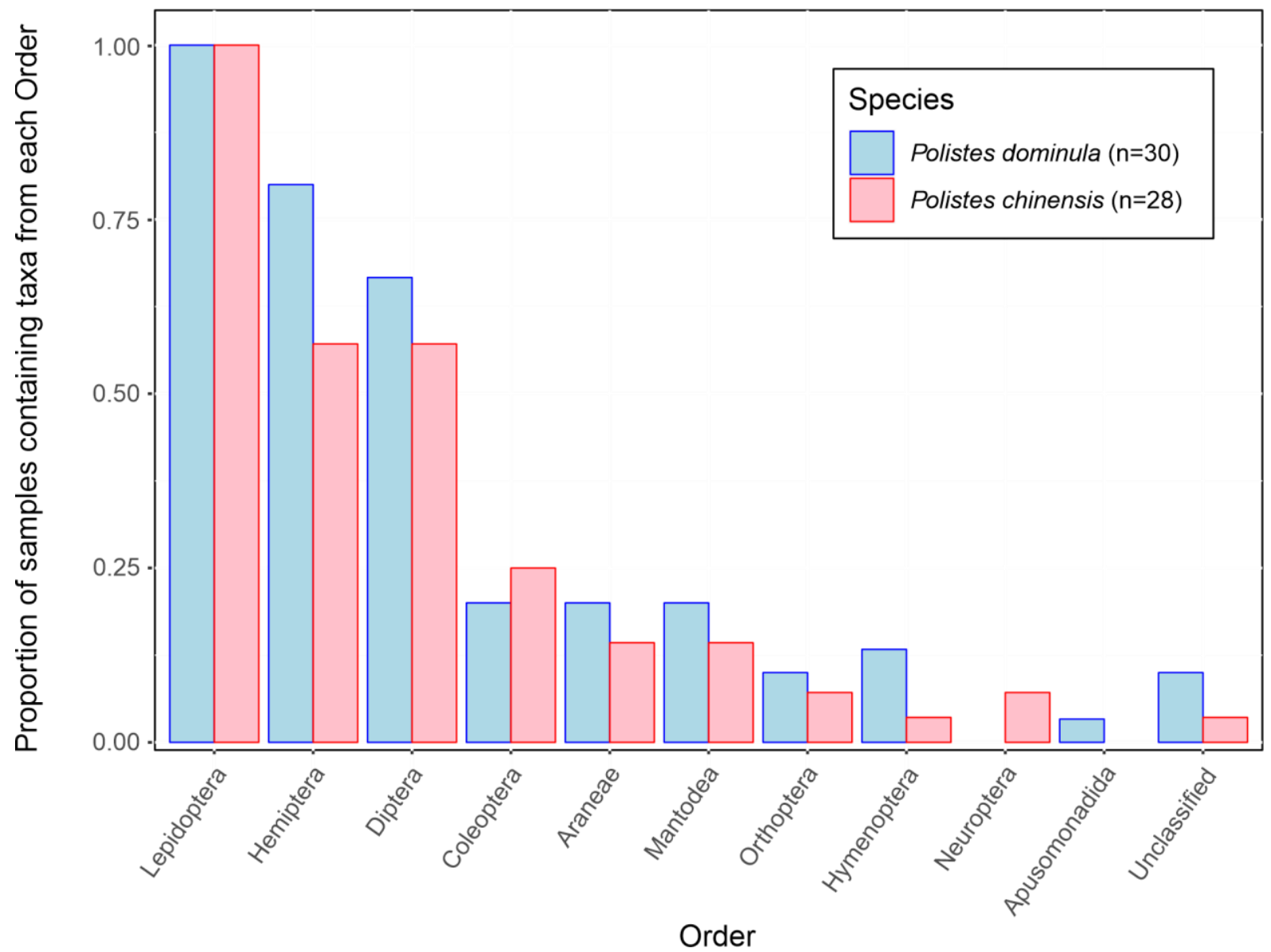

Figure 3.2: Proportion of samples that contain prey taxa from each Order, across all sites. The $x$ axis shows the Orders that were represented in the diets of the wasps while the $y$ axis is the proportion of samples that contain at least one taxon that belongs to the order. Blue bars represent Polistes dominula samples $(\mathrm{n}=30)$ while the red bars represent $P$. chinensis samples $(\mathrm{n}=28)$. Polistes spp. reads were excluded prior to this analysis and so Hymenoptera refers to non-Polistes taxa. 
Of the 315 MOTUs identified overall, 45 were found to make up over $1 \%$ of reads in any given sample (Table 3.1). A number of native and introduced taxa were identified in the diets of both wasps. The most highly represented native taxa in the diets of Polistes spp. were species of blue butterflies (Zizina spp.), New Zealand cicadas (Kikihia spp.), owlet moths (Ectopatria spp.), magpie moths (Nyctemera spp.) and leaf roller moths (Holocola spp.). Other native taxa that were less common but still represented were New Zealand mantids (Orthodera spp.), biting midges (Forcipomyia spp.) and Braconid wasps (Diolcogaster spp.), the latter two taxa containing parasitic species that may have entered the diets of wasps through parasitised prey. Non-native taxa included owlet moths (Leucania spp. and Thysanoplusia spp.), apple looper moths (Phrissogonus spp.) and gum moths (Opodipthera spp.). Some of these introduced taxa include genera that contain agricultural pests such as the light brown apple moth (Epiphyas postvittana) and the cosmopolitan army worm (Mythimna separata). MOTUs such as these are able to be identified to species level as they are the only species of their genus in New Zealand, however, this is not possible for all taxa. Interestingly, a genus of fly (Trigonospila spp.) was identified in the diet of both wasp species with a member of this genus, T. brevifacies, imported to New Zealand as biocontrol for invasive pests such as the light brown apple moth (Shaw et al. 2001). Some taxa that were identified in this study were not listed as present in New Zealand within the New Zealand Organism Registry. New Zealand entomofauna has many understudied groups (New and Samways 2014) so it is likely that these taxa do not have sequences in the NCBI database. In this case, the closest DNA match on the database may then be used and the MOTU identified as an organism not known to occur in New Zealand. If the MOTU meets all other requirements outlined in our methods, we find no reason to remove it from the results. 
Table 3.1: List of MOTUs identified from DNA that made up at least $1 \%$ of the non-wasp reads extracted from a given sample. If available the Order, Family and genus name are provided for each MOTU with the lowest taxonomic unit identified used to describe the MOTU. Counts of how many wasp larvae samples these MOTUs were found in are presented as well as a break down for each wasp species. The status column reports the origins of the MOTUs that were identified to genus level (native or introduced to New Zealand). If a MOTU is considered a pest, then that qualifier is also shown where known using the New Zealand Organism Registry (http://www.nzor.org.nz/). Some genera contain both native and introduced species and this is indicated.

\begin{tabular}{|c|c|c|c|c|c|c|c|}
\hline Order & Family & Genus & MOTU & Count & P. dominula & P. chinensis & Status \\
\hline Lepidoptera & Lycaenidae & Zizina & Zizina spp. & 35 & 18 & 17 & Native \\
\hline Lepidoptera & Noctuidae & Leucania & Leucania spp. & 27 & 10 & 17 & Introduced \\
\hline Hemiptera & Cicadidae & Kikihia & Kikihia spp. & 24 & 14 & 10 & Native \\
\hline Lepidoptera & Geometridae & Phrissogonus & Phrissogonus spp. & 24 & 9 & 15 & Introduced \\
\hline Lepidoptera & Noctuidae & Ectopatria & Ectopatria spp. & 23 & 10 & 13 & Native \\
\hline Lepidoptera & Tortricidae & Epiphyas & Epiphyas spp. & 16 & 7 & 9 & Introduced (Pest) ${ }^{1}$ \\
\hline Lepidoptera & Noctuidae & Thysanoplusia & Thysanoplusia spp. & 16 & 7 & 9 & Introduced (Pest) ${ }^{2}$ \\
\hline Lepidoptera & Erebidae & Nyctemera & Nyctemera spp. & 15 & 10 & 5 & Native \\
\hline Lepidoptera & Tortricidae & Holocola & Holocola spp. & 11 & 4 & 7 & Native \\
\hline Lepidoptera & Unclassified & Unclassified & Lepidoptera & 10 & 5 & 5 & - \\
\hline Lepidoptera & Noctuidae & Agrotis & Agrotis spp. & 9 & 5 & 4 & Native/Introduced \\
\hline Lepidoptera & Noctuidae & Mythimna & Mythimna spp. & 9 & 3 & 6 & Introduced (Pest) ${ }^{3}$ \\
\hline Lepidoptera & Geometridae & Chloroclystis & Chloroclystis spp. & 7 & 1 & 6 & Native/Introduced \\
\hline Mantodea & Mantidae & Orthodera & Orthodera spp. & 7 & 5 & 2 & Native \\
\hline Lepidoptera & Saturniidae & Opodiphthera & Opodiphthera spp. & 6 & 4 & 2 & Introduced \\
\hline Lepidoptera & Geometridae & Unclassified & Geometridae & 5 & 2 & 3 & - \\
\hline Diptera & Agromyzidae & Cerodontha & Cerodontha spp. & 4 & 2 & 2 & Native/Introduced \\
\hline Lepidoptera & Noctuidae & Unclassified & Noctuidae & 4 & 4 & 0 & - \\
\hline Hemiptera & Aphrophoridae & Philaenus & Philaenus spp. & 4 & 0 & 4 & Introduced \\
\hline Diptera & Tabanidae & Unclassified & Tabanidae & 4 & 2 & 2 & - \\
\hline Lepidoptera & Lycaenidae & Lycaena & Lycaena spp. & 3 & 2 & 1 & Native \\
\hline
\end{tabular}




\begin{tabular}{|c|c|c|c|c|c|c|c|}
\hline Lepidoptera & Choeutidae & Tebenna & Tebenna spp. & 3 & 0 & 3 & Native \\
\hline Lepidoptera & Tortricidae & Unclassified & Tortricidae & 3 & 3 & 0 & - \\
\hline Lepidoptera & Nolidae & Uraba & Uraba spp. & 3 & 1 & 2 & Introduced (Pest) \\
\hline Lepidoptera & Crambidae & Achyra & Achyra spp. & 2 & 2 & 0 & Introduced \\
\hline Lepidoptera & Geometridae & Atmosceras & Atmosceras spp. & 2 & 0 & 2 & Not listed \\
\hline Coleoptera & Coccinellidae & Coccinella & Coccinella spp. & 2 & 1 & 1 & Native/Introducec \\
\hline Araneae & Theridiidae & Cryptachaea & Cryptachaea spp. & 2 & 2 & 0 & Introduced \\
\hline Lepidoptera & Geometridae & Declana & Declana spp. & 2 & 2 & 0 & Native \\
\hline Diptera & Ceratopogonidae & Forcipomyia & Forcipomyia spp. & 2 & 2 & 0 & Native \\
\hline Diptera & Syrphidae & Melanostoma & Melanostoma spp. & 2 & 0 & 2 & Native \\
\hline Diptera & Tachinidae & Trigonospila & Trigonospila spp. & 2 & 2 & 0 & Introduced \\
\hline Lepidoptera & Geometridae & Arcobara & Arcobara spp. & 1 & 0 & 1 & Not listed \\
\hline Lepidoptera & Coleophoridae & Coleophora & Coleophora spp. & 1 & 0 & 1 & Introduced (Pest) \\
\hline Lepidoptera & Noctuidae & Ctenoplusia & Ctenoplusia spp. & 1 & 1 & 0 & Introduced \\
\hline Hymenoptera & Braconidae & Diolcogaster & Diolcogaster spp. & 1 & 1 & 0 & Native \\
\hline Lepidoptera & Erebidae & Egone & Egone spp. & 1 & 1 & 0 & Not listed \\
\hline Lepidoptera & Saturniidae & Gamelia & Gamelia spp. & 1 & 1 & 0 & Not listed \\
\hline Lepidoptera & Tortricidae & Merophyas & Merophyas spp. & 1 & 1 & 0 & Native/Introduced \\
\hline Lepidoptera & Geometridae & Peribatodes & Peribatodes spp. & 1 & 1 & 0 & Not listed \\
\hline Diptera & Syrphidae & Platycheirus & Platycheirus spp. & 1 & 0 & 1 & Native \\
\hline Lepidoptera & Geometridae & Scopula & Scopula spp. & 1 & 1 & 0 & Native \\
\hline Lepidoptera & Noctuidae & Thoracolopha & Thoracolopha spp. & 1 & 0 & 1 & Not listed \\
\hline Unclassified & Unclassified & Unclassified & Unclassified & 1 & 1 & 0 & - \\
\hline Lepidoptera & Pyralidae & Vincia & Vincia spp. & 1 & 1 & 0 & Native \\
\hline
\end{tabular}

(Suckling and Brockerhoff 2010) ${ }^{1}\left(\right.$ Cameron et al. 2008) ${ }^{2}\left(\right.$ Sharma and Davies 1983) ${ }^{3}$ (Berndt and Allen 2010) ${ }^{4}$ Chynoweth et al. 2018) ${ }^{5}$ 

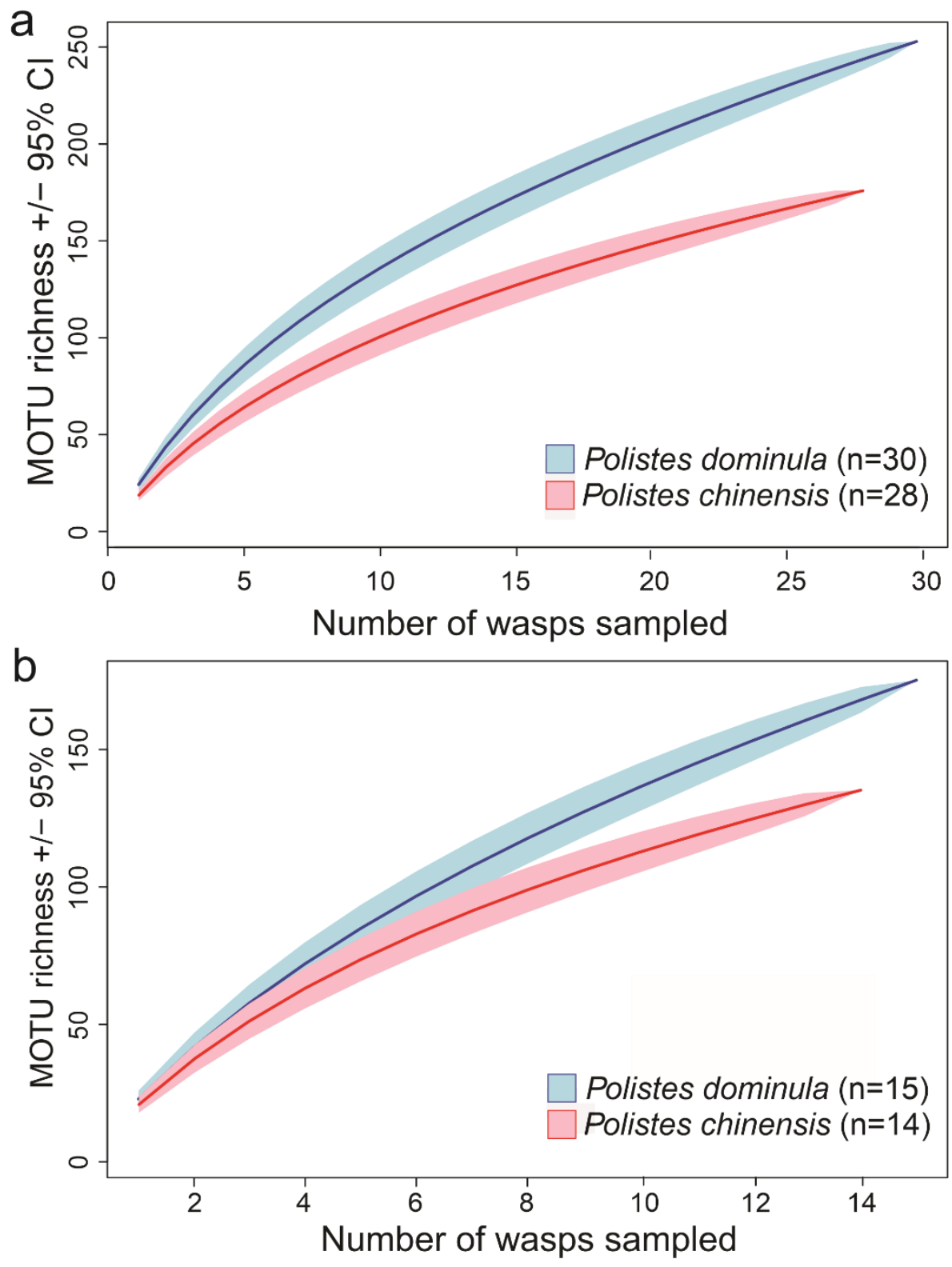

Figure 3.3: Accumulation curves fitted using the rarefaction method showing the number of unique MOTUs $( \pm 95 \% \mathrm{Cl}$ ) expected to be found in increasing numbers of wasps sampled at all sites (a), and at sympatric sites only (b). Blue shows the accumulation curve for $P$. dominula while red shows the curve for $P$. chinensis. Although there are more $P$. dominula samples, the two curves diverge from one another. This pattern indicates that $P$. dominula samples typically contain more identified taxa on average than those from $P$. chinensis.

When accumulation curves were plotted using the full range of MOTUs identified in wasp larvae, $P$. dominula samples consistently contained a higher diversity of MOTUs than $P$. chinensis samples (Figure 3.3). This pattern was repeated again when only samples from sympatric sites were considered. The two curves differed significantly with minimal overlap 
in confidence intervals. The species accumulation curve did not reach a plateau for either wasp, suggesting that additional taxa are likely to be present in the diets of both wasp species. Across all sites, of the 315 unique MOTUs that were identified, $252(80 \%)$ were found in $P$. dominula samples with 175 (55\%) identified from $P$. chinensis samples. These results indicate that the diet of $P$. dominula is significantly more diverse than that of $P$. chinensis (two-sample proportion test of no difference: $z=6.564, p$-value $<0.001)$. In terms of diet overlap, $112(36 \%)$ MOTUs were present in both $P$. dominula and $P$. chinensis diets. This overlap indicates that $P$. dominula shares $44 \%$ of its diet with $P$. chinensis, while $P$. chinensis shares $64 \%$ of its diet with P. dominula (two-sample proportion test of no difference: $z=-3.980, p$-value $<0.001$ ) (Figure 3.4).

\section{MOTUs in Polistes spp. diets}

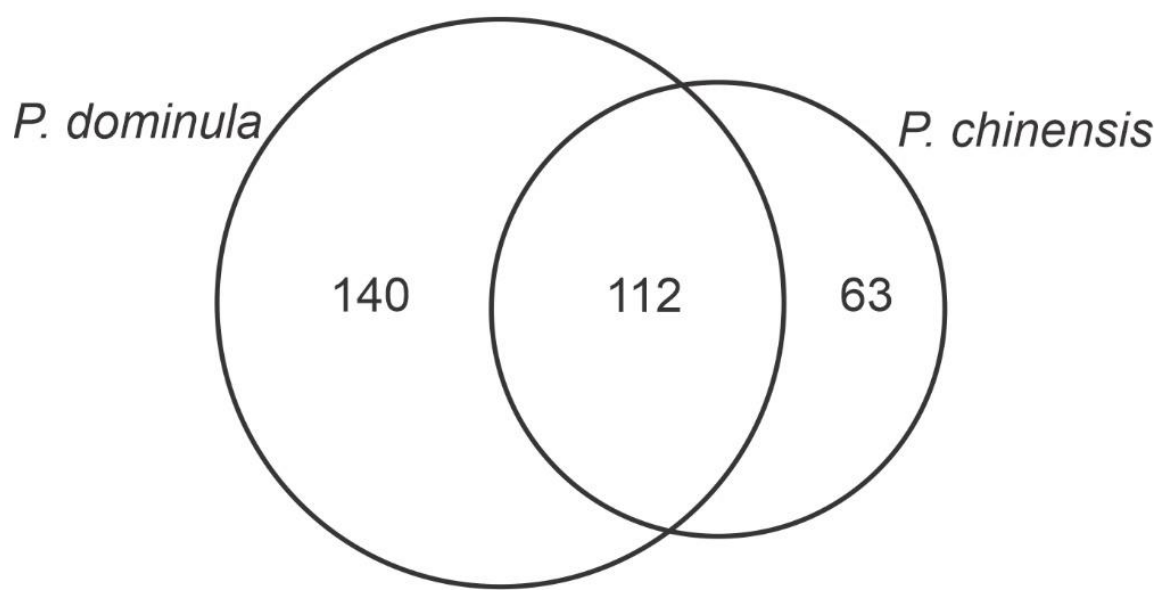

Figure 3.4: Venn diagram of the distribution of MOTUs between the diets of $P$. dominula $(n=30)$ and $P$. chinensis $(n=28)$ across all sites sampled. Three hundred and fifteen MOTUs were found to be present in wasp larvae gut samples. Two hundred and fifty two $(80 \%)$ of these MOTUs were found in the diet of $P$. dominula while $175(56 \%)$ were found in that of $P$. chinensis. The diet of $P$. dominula was found to be significantly more diverse than $P$. chinensis (two-sample proportion test: $z=6.564, p$-value $<0.001$ ).

To ensure these differences were not a result of differences in prey availability between sites, analyses were repeated with data from sites where both species were found in roughly the same abundances, therefore, we assume they had access to the same prey. At these sites, 227 unique MOTUs were identified with 175 (77\%) found in P. dominula samples and 135 (59\%) found in sample from $P$. chinensis (Figure 3.5). These results similarly indicated that the diet of $P$. dominula is more diverse than that of $P$. chinensis (two-sample proportion test: $z=4.03, p$-value<0.001). Of the 227 MOTUs, 83 (37\%) were found in both $P$. dominula and $P$. 
chinensis diets (Figure 3.5). A similar pattern was once again observed in terms of diet overlap, with $P$. dominula sharing $47 \%$ of its diet with $P$. chinensis, while $P$. chinensis sharied more with $61 \%$ of its diet also consumed by $P$. dominula (two-sample proportion test of no difference: $z=-2.460, p$-value $=0.014)$.

\section{MOTUs in Polistes spp. diets at sympatric sites}

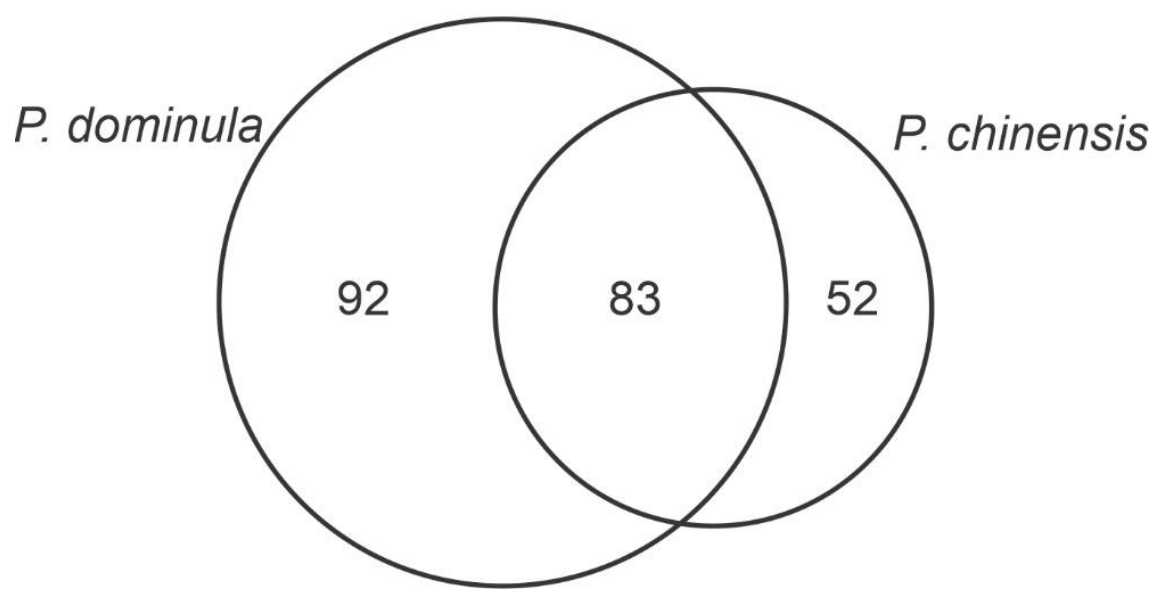

Figure 3.5: Venn diagram of the distribution of MOTUs between the diets of $P$. dominula $(n=15)$ and $P$. chinensis $(n=14)$ in sympatric sites only. Two-hundred and twenty seven of the 315 MOTUs identified were present in samples from these sites with $175(77 \%)$ of these being found in the diet of $P$. dominula and 135 (60\%) being found in that of $P$. chinensis. The diet of $P$. dominula was found to be significantly more diverse than $P$. chinensis in sympatric sites (two-sample proportion test: $z=4.03 p$-value $<0.001$ ).

The interaction term between species and site was significant (PERMANOVA: $F=1.600$, $d f=2, p$-value $=0.044)$. This result suggests that, given prey availability differed from site to site, the prey utilised by each wasp species was different. We attempted to look for any effect of when larvae were sampled by including a term that represented the month of sample collection, however, month of collection was not found to be significant (PERMANOVA: $F=1.0008, d f=2, p$-value $=0.445)$. We did not detect an effect of month sampled on the wasps' diet. This result is likely due to the low number of comparable samples across species, sites and months rather than a true reflection of foraging patterns.

\subsection{Discussion}

Our study shows that $P$. dominula and $P$. chinensis consume many of the same prey taxa in Nelson, New Zealand. Polistes dominula does appear, however, to consume a wider range of prey than $P$. chinensis. As generalist predators, both wasps likely preyed on species that were most commonly available in a given habitat. These results suggest that the 
establishment of $P$. dominula will likely negatively impact many of the same species already predated upon by $P$. chinensis but additionally other potentially rarer species in the environment.

Lepidoptera (butterflies and moths) made up the majority of prey for both species, an expected pattern based on the findings of similar analyses performed on $P$. chinensis (Ward and Ramón-Laca 2013, Lefort et al. 2020), from the observations of $P$. dominula foraging behaviour (Stamp and Bowers 1988, Rayor et al. 2007, Baker and Potter 2020) and from diet analyses of other Polistes species (Kasper et al. 2004, Jeon et al. 2019). Two-hundred and eighty-nine (92\%) of the taxa identified belong to the Order Lepidoptera. Of these taxa, both native and introduced genera were represented. Zizina is a genus containing species such as the native blue butterfly (Z. labradus) and was found in 23 out of $30(77 \%) P$. dominula samples and in 21 of 28 (75\%) P. chinensis samples. This species is one of the most common butterflies in New Zealand due in part to its similarly widespread host plants such as clover and other legumes (Fabaceae) (Gillespie and Wratten 2012). Polistes dominula has already been linked to the decline of this species and two other common butterflies in Nelson, New Zealand (McGruddy et al. 2020). It is likely that these wasps' preference for disturbed, humandominated habitats (Clapperton et al. 1996, Roets et al. 2019) heavily influence their diet. Native and introduced prey that also thrive in similar human-altered habitats are therefore heavily represented in their diets, as opposed to rarer species typical of more intact habitats such as forests. The spread of human influence into these more intact habitats may, however, increase the incidences of predation of native species by introduced wasps.

Another highly represented genus was Epiphyas, which is solely represented in New Zealand by the light brown apple moth (Epiphyas postvittana), a globally important pest species (Suckling and Brockerhoff 2010). This genus was found to be represented in $70 \%$ and $64 \%$ of $P$. dominula and $P$. chinensis samples, respectively. Four other pest species were also found to make up a significant portion of Polistes spp. diets (Table 3.1). Polistes spp. have been shown to exert significant predation pressure on agricultural pests suggesting that these wasps may be ideal candidates for biocontrol (Gould and Jeanne 1984, Oliveira et al. 2017, Prezoto et al. 2019, Southon et al. 2019). These wasps have even been linked to the recent eradication of the invasive great white butterfly (Pieris brassicae), in New Zealand (Phillips et al. 2020). While Polistes spp. prey on pest species, they also feed on a wide range of other native and endemic species, reducing their effectiveness as a method of targeted pest control 
(Gould and Jeanne 1984, Southon et al. 2019). In New Zealand, the threat these wasps pose to native biodiversity likely outweighs the benefits they could provide by controlling other invasive species (Maclntyre and Hellstrom 2015, Lester 2018).

Many important herbivores were found to be present in the diet of both species. Lepidoptera, as discussed above, are important herbivores and pollinators. Hemiptera, especially cicadas (Kikihia spp.), were also shown to be significant components of Polistes' diets. Despite only four out of 315 MOTUs identified as taxa belonging to Hemiptera, this Order was represented in 24 (80\%) samples from $P$. dominula and 16 (57\%) from $P$. chinensis. Hemiptera are also often important herbivores (Koch et al. 2016). The prevalence of important herbivores and pollinators in these wasps' diets may mean that sufficient numbers of either wasp species could impact not only invertebrate assemblages, but also have flowon effects to the plant communities and the wider ecosystem. Disruption of herbivory and pollination can impact plant fitness, potentially altering the plant communities through trophic cascades. It has been shown that in the Nelson region, predation pressure exerted by P. dominula on monarch butterfly (Danaus plexippus) caterpillars was high enough to reduce herbivory on the host plant (Gomphocarpus sp.) to the extent that the plants reproductive fitness was increased (McGruddy et al. 2020). The flow-on effects produced by these invasive predators may affect more ecological communities across New Zealand as these wasps expand their range.

New Zealand's invertebrates are already facing predation pressure from invasive wasps (Harris 1991, Beggs and Rees 1999, Clapperton 1999). Polistes chinensis has been estimated to remove up to $957 \mathrm{~g}$ of prey per ha over a season from New Zealand ecosystems (Clapperton 1999). It is likely that $P$. dominula populations could exhibit higher harvest rates than those reported for $P$. chinensis due to differences in their life history. Polistes dominula readily exhibits pleometrosis, a behaviour where multiple foundresses found a single colony (Höcherl and Tautz 2015, Field and Leadbeater 2016). Pleometrosis is correlated with increased colony productivity and survival (Tibbetts and Reeve 2003, Höcherl and Tautz 2015). P. chinensis is much less likely to exhibit this behaviour, with as low as $1.5 \%$ of nests containing multiple foundresses (Hoshikawa 1979). McGruddy (2021) found that nests of $P$. dominula were more productive than $P$. chinensis nests and experienced lower failure rates suggesting they could reach higher population densities. Polistes dominula are therefore likely to exert a higher 
predation pressure on New Zealand's invertebrates, presenting a greater threat to local invertebrate diversity than $P$. chinensis.

Wasp populations can be heavily impacted and structured by interspecific competition (Beggs et al. 2011). It has been suggested that competition between invasive $P$. dominula and resident Polistes species could explain the pattern of declines in native Polistes species where they co-occur (Gamboa et al. 2002, Gamboa et al. 2004, Downing 2012, Benadé et al. 2014, Pilowsky and Starks 2018, Roets et al. 2019). Quantifying the degree of diet overlap has been used to measure the degree of competition in a wide range of systems (Spitz et al. 2006, Sampson et al. 2009, Museth et al. 2010, Ustups et al. 2016). An overlap in diet coupled with the higher colony productivity of $P$. dominula means that these wasps likely exert a high degree of competitive pressure on other Polistes species as well. It is therefore possible that the establishment of $P$. dominula in New Zealand could lead to declines in other Polistes spp. populations due to competitive exclusion. Long-term research looking at the population dynamics of the two species and direct observations of changes to reproductive fitness would be required to confirm competition is occurring here (Wojcik et al. 2018). So far, both wasp species have coexisted in the Nelson region for several years with no evidence of any largescale exclusion. Although there are allopatric and sympatric populations of each species, dispersal over time and space will likely bring these species increasingly into sympatry.

The samples collected for this study were all from coastal locations and so the diets of both species may not represent the paper wasp diet across all of New Zealand. Polistes dominula has been shown to nest preferentially in human-altered habitats (Benadé et al. 2014, Roets et al. 2019). Similar work carried out in Nelson, found that $P$. dominula nests translocated to sites close to human habitation and coastal sites were more productive and had higher survival rates than those in forested habitats (McGruddy 2021). The same research found no naturally occurring Polistes spp. nests in surveys of forested habitat. It is therefore likely that forest species may escape most of the predation pressure by these invasive wasps. Forest species make up only 34 of the 114 butterflies and moths deemed 'at-risk' in New Zealand, with over $60 \%$ of these 'at-risk' species found in non-alpine shrubland/grasslands and coastal vegetation (Patrick and Dugdale 2000). The species that inhabit open and more human-altered habitats may experience higher predation with the establishment of one or both Polistes wasps. 


\subsection{Conclusion}

In this study, DNA barcoding was used to analyse the diet of two species of invasive wasps in Nelson, New Zealand. Both wasp species were shown to prey largely on Lepidoptera species, but other orders were represented including Hemiptera, Diptera, Coleoptera and others. Prey identified in this study consisted of both native and introduced taxa, some containing important agricultural pests. Prey taxa tended to vary depending on where wasps were sampled, indicating that both species likely preyed on invertebrates that were most common in an environment, which is typical of generalist predators (Schenk and Bacher 2002). While the two species were shown to overlap in diet, $P$. dominula was shown to have wider prey range. The wider prey range combined with differences in nesting behaviour indicates that $P$. dominula likely represents a more significant threat to New Zealand's local invertebrate fauna than the already well-established $P$. chinensis. These results also raise questions surrounding potential competition between the two wasp species. More research is required to identify how the presence of the recent invader, $P$. dominula impacts the reproductive fitness of $P$. chinensis. This is the first molecular diet analysis preformed on $P$. dominula and results found here may inform conservation and biosecurity managers on the impact that invasive paper wasps are having on New Zealand's local invertebrate communities. 


\section{Chapter 4: General Discussion}

In this thesis, I first predicted the extent of climatically suitable habitat for the establishment of Polistes dominula. In the following chapter, I described the diet composition of $P$. dominula and its related congener $P$. chinensis in Nelson, New Zealand.

In chapter 2, bioclimatic modelling identified suitable ranges throughout the southern hemisphere for the establishment of $P$. dominula. In many cases the range identified was outside of areas where the species is currently found, indicating the potential for this species to expand its range. This information is most relevant to New Zealand as $P$. dominula has only recently established in the country over the last decade. New populations are still being discovered across New Zealand, with the results from this chapter hinting we are likely to find more.

In chapter 3 , diet analysis showed that $P$. dominula preys on a wide range of invertebrates in Nelson, New Zealand. Taxa belonging to the insect order Lepidoptera (butterflies and moths) made up the majority of their prey. Other orders such as Hemiptera (true bugs) and Diptera (flies) also made up a considerable portion of their diet. The prey range of $P$. dominula overlapped considerably with that of $P$. chinensis, however, $P$. dominula was found to contain a higher diversity of taxa in their diet than $P$. chinensis. This result suggests that the newly invasive $P$. dominula potentially poses a higher threat to local invertebrate species than that of the already well-established $P$. chinensis.

In this section of my thesis, I will discuss how these findings can inform us about the potential impacts of this new invasive species, make recommendations about the future management of this wasp and suggest key avenues of future research.

\subsection{Polistes dominula spread and their impact on local species}

Polistes dominula is a very successful invader, spreading from their native range to every continent except Antarctica (Carpenter 1996, Buck et al. 2008). A high reproductive output, generalist feeding behaviours and phenological plasticity appear to allow $P$. dominula to readily establish in new environments (Cervo et al. 2000, Beggs et al. 2011, Lester and Beggs 2019). Bioclimatic modelling, performed in chapter 2, identified large areas of New Zealand, and other regions in the southern hemisphere, that were climatically suitable for the establishment of $P$. dominula but have not yet been colonised. This wasp is a synanthropic 
species, preferring to nest in human-altered habitats (Gamboa et al. 2005, Roets et al. 2019). McGruddy (2021) found that Polistes spp. were absent from forested habitats with no nests discovered in any areas searched. In a follow up experiment, nests were translocated to forested habitats. Translocated nests experienced high levels of mortality and much reduced productivity compared to nests in more human-dominated sites. A similar pattern has also been observed in P. dominula populations of North America (Gamboa et al. 2005). Furthermore, Polistes wasp abundance in New Zealand has been shown to be negatively correlated with forest canopy cover (Schmack et al. 2020). With the increasing spread of human influence across New Zealand and the world, invasive species are able to spread and establish across more of the globe (Cordonnier et al. 2020, Bertelsmeier 2021). These findings suggest that $P$. dominula is likely to spread across New Zealand and impact insect communities across a greater geographic range than they currently exist, especially in humandominated habitats.

Not all impacts of increased $P$. dominula establishment in New Zealand are likely to be negative. Polistes spp. have been shown to prey on agriculturally important pests (Gould and Jeanne 1984, Oliveira et al. 2017, Prezoto et al. 2019, Southon et al. 2019) and it is possible that some horticultural industries may benefit from the spread of this wasp. Phytophagous insects make up nearly $50 \%$ of all non-native insects in New Zealand (Edney-Browne et al. 2018) and cost the country as much as $\$ 880$ million per year in pest control and damages to crops (Barlow et al. 2002b). Diet analysis conducted in chapter 3, and in other studies (Kasper et al. 2004, Ward and Ramón-Laca 2013, Jeon et al. 2019, Lefort et al. 2020) have shown that Polistes spp. prey on a range of phytophagous taxa including non-native taxa and agricultural pests. The light brown apple moth (Epiphyas postvittana) is one such globally important pest species (Suckling and Brockerhoff 2010) that was identified in the diets of these wasps. The establishment of $P$. dominula across more of New Zealand may lead to a reduced likelihood of other non-native species or agricultural pests establishing. Polistes dominula has already been linked to the reduction in exotic butterfly numbers including an agricultural pest species, the cabbage white butterfly (Pieris rapae), in New Zealand (McGruddy 2021). Invasive wasps such as Vespula spp. and Polistes chinensis were linked to the suppression of and eventual eradication of the large white butterfly (Pieris brassicae) in Nelson, New Zealand (Phillips et al. 2020). Bioclimatic modelling identified horticulturally important regions such as Waikato, Bay of Plenty, Hawke's Bay and Otago as suitable for the establishment of these wasps. As 
these wasps establish across more of the country, new predation pressures may act to control some agricultural pests, potentially benefitting some industries in these regions.

Diet analysis showed that $P$. dominula preyed on a number of native species. Genera containing native species such as blue butterflies (Zizina spp.), copper butterflies (Lycaena spp.), lichen moths (Declana spp.), and others were identified in the diets of both Polistes species. Species found in open habitats such as coastal and human-altered environments are likely most at risk of predation. Studies in Nelson, New Zealand, showed these habitats were most suitable for the establishment of $P$. dominula (McGruddy 2021), while prey experienced highest predation pressure by $P$. dominula in these habitats (McGruddy et al. 2020). Over 60\% of New Zealand's 'at-risk' butterfly and moth species are found in open shrubland/grasslands and coastal habitats (Patrick and Dugdale 2000) that appear vulnerable to $P$. dominula establishment. In chapter 2, it was predicted that much of the eastern South Island of New Zealand was climatically suitable for $P$. dominula to survive. This region contains over half of New Zealand's threatened native butterflies and moths (Stringer et al. 2012). Species especially vulnerable include those that inhabit small ranges especially in coastal habitats. For example, Notoreas peromata is a species of moth endemic to small coastal habitats around New Zealand. The species is made up of a several vulnerable and endangered subspecies such as Notoreas peromata subsp. "Castlepoint" and subsp. "Cape Turnagain" found only in two small areas of coastal habitat in the North Island (Hoare et al. 2017). Similarly, a species of copper butterfly, Lycaena sp. "Chrystall's Beach" is found only at one location on the east coast of the South Island (Hoare et al. 2017). This species could be especially vulnerable to predation by $P$. dominula, with Lycaena spp. being well represented in the diet of these wasps according to the results found in chapter 3. Additionally, bioclimatic modelling in chapter 2 has predicted the ranges of these threatened lepidopterans to be suitable for the establishment of $P$. dominula. The spread and establishment of $P$. dominula could lead to the population decline of other species also found in small and vulnerable habitats.

Native species that inhabit coastal and human-altered habitats may not be the only ones at risk. Forest dwelling species may also face increased predation in certain areas. Nests of Polistes spp. have been observed on manmade structures built close to forested habitat (Figure 4.1) suggesting that workers could forage around forest edges. In this way, $P$. dominula could potentially prey on forest species that would otherwise be considered safe from predation by these wasps. Through the exploitation of habitat edges, other invasive 
species have been shown to impact ecosystems, even where conditions are unfavourable. For example, Argentine ants (Linepithelma humile) were shown to permeate up to two-hundred metres into habitat at forest edges that was otherwise unsuitable for nesting or year round habitation (Holway 2005). With accelerating spread of human influence and habitat fragmentation, invasive species such as Polistes dominula are more able to expand their range and utilise more diverse prey in a variety of habitats. The forest ringlet (Dodonidia helmsii) is a species of forest dwelling butterfly that is threatened in New Zealand (Stringer et al. 2012). Invasive wasps (Vespula spp.) have been noted as predators of this species (Griffiths et al. 2017, Hare et al. 2019). In smaller forest fragments and at forest edges, Polistes spp. could also impact forest ringlet butterfly populations, especially at forest edges, as these wasps establish populations across more of New Zealand.
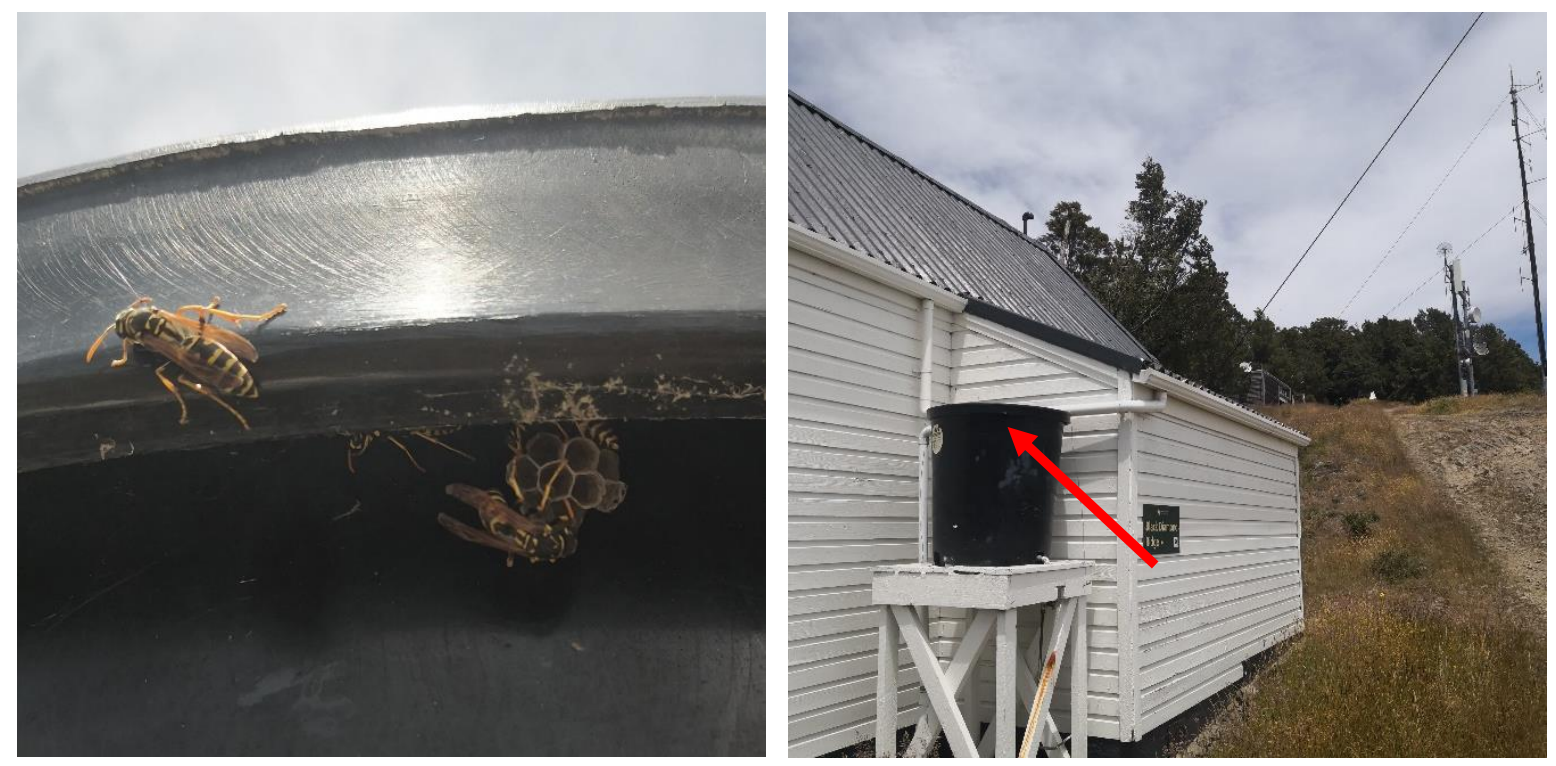

Figure 4.1: This Polistes dominula nest (left) was one of three observed around this building at Fringed Hill $(-41.310098,173.317058)$ in Nelson, New Zealand. The nest's position is indicated by the red arrow in the right image. The structure sits in a clearing at an elevation of $793 \mathrm{~m}$ between a pine plantation and beech-forest that adjoins the Richmond Hill Forest park. Polistes dominula typically nest in humandominated habitats especially in urban areas, however wasps on nests such as this one may prey on forest dwelling species at habitat edges. Photos by Matthew Howse (2020).

\subsection{Implications for management}

The research carried out in this thesis represents two firsts in the study of Polistes dominula with implications to how the species is managed in the future. My results could inform the early detection and mitigation of the impacts of $P$. dominula establishment across New Zealand. Chapter 2 represents the first time that bioclimatic modelling has been used to 
identify potentially suitable habitat for this species. Models of this kind have been used to predict ranges of invasive species (Lozier and Mills 2011, Ørsted and Ørsted 2019, Curry et al. 2020) and are increasingly being used to inform conservation and biosecurity decisions (Guisan et al. 2013). The results of my modelling could inform biosecurity managers to prioritise resources in certain regions deemed more suitable for the establishment of this wasp. The molecular diet analysis carried out in chapter 3 is the first such work attempted on P. dominula in New Zealand and globally. This work, in conjunction with the habitat modelling, could be used to identify species most at risk of predation by $P$. dominula. Research has already shown that these wasps can reduce populations of butterflies in New Zealand (McGruddy et al. 2020), while similar diet studies have informed management decisions in the past (Egeter et al. 2019). Based on these findings we recommend that increased protection be afforded to high priority species in vulnerable habitats such as Notoreas peromata subsp. "Castlepoint", N. peromata subsp. "Cape Turnagain", and Lycaena sp. "Chrystall's Beach".

Additional education provided to the public may allow biosecurity and conservation managers to monitor the spread of this species across New Zealand. As this is a synanthropic species (Höcherl and Tautz 2015, Roets et al. 2019), more of the general public will likely come into contact with this species as it expands its range. If the public are aware of, and able to identify this species, they may be more likely to report it and help quantify its range expansion. Programs already in place such as the "Wasp Wipeout" have had success in increasing public awareness and support of wasp control throughout New Zealand (Mercier et al. 2019). This program in particular was instrumental in the data collection phase of this thesis and other research conducted (McGruddy et al. 2020, McGruddy 2021). News articles published under the Wasp Wipeout program led to public engagement that provided data for the monitoring of Polistes spp. populations in Nelson over two summers (Bohny 2019, 2020). Citizen science initiatives have been used to monitor invasive wasps overseas, providing high quality data, quicker than traditional methods (Sumner et al. 2019). The implementation of such programs will help to inform future management and control of these wasps as well as understanding its effects on species of conservation importance. 


\subsection{Limitations and suggestions for future study}

The results described in this thesis also represent a starting point for future avenues of research. Modelling techniques and methods of diet analysis used in this study could be improved upon to provide more accurate predictions of habitat suitability and diet composition. Current climate-based models fail to recognise the importance of biotic interactions in the establishment of species in new environments (Godsoe and Harmon 2012, Giannini et al. 2013, Wisz et al. 2013). Future models should aim to consider these interactions to improve the accuracy of predictions made. Land-use type and potential invasion pathways may also be considered to allow for more accurate predictions of range expansion and invasion risk (Barbet-Massin et al. 2012b, Tingley et al. 2018). Similarly, additional diet analysis of wasps from a broader range of locations across New Zealand would also provide a more representative picture of what species are being consumed here. More long-term studies on prey populations may provide insight into how different species are impacted by the establishment of $P$. dominula.

Polistes dominula has been linked to the declines of other Polistes species where they have become established overseas (Gamboa et al. 2004, Downing 2012, Benadé et al. 2014, Pilowsky and Starks 2018, Roets et al. 2019). In chapter 3, molecular analysis showed a significant overlap in the diets of $P$. dominula and $P$. chinensis in New Zealand and other research has shown $P$. dominula nests to be more productive and experience higher survival rates than those of $P$. chinensis (McGruddy 2021). Large diet overlaps have been used as a proxy for competition before (Spitz et al. 2006, Sampson et al. 2009, Museth et al. 2010, Ustups et al. 2016) and observations from the field in New Zealand, as well as trends observed overseas (Gamboa et al. 2004, Downing 2012, Benadé et al. 2014, Pilowsky and Starks 2018, Roets et al. 2019) hint at the possibility of competitive exclusion occurring in this newly invasive range. More focussed and long-term studies of both species' population dynamics are required to identify if such a pattern is occurring in New Zealand.

The results of this thesis suggest that Polistes dominula is likely to become invasive across much of New Zealand. The potential threat this species poses to local invertebrates is concerning as there are currently no effective methods to control Polistes wasps. Current wasp control methods such as the fipronil based Vespex ${ }^{\circledR}$ rely on wasps' scavenging behaviours to take the toxic bait away and distribute it throughout the nest (Edwards et al. 
2017). Polistes spp. do not scavenge carrion as other invasive wasps do (Kasper et al. 2004), rendering traditional protein-based baits ineffective for these wasps (Toft and Harris 2004). Work on developing more effective baits has often relied on the use of carbohydrate-based lures (Sorvari 2013, Brown et al. 2014, Landolt and Zhang 2016, Elmquist and Landolt 2018). The use of these lures to develop a toxic bait is not recommended as carbohydrate-based baits would also attract beneficial, non-target species such as honey bees (Spurr 1995, 1996, Wegner and Jordan 2005). Other pheromone-based chemical attractants have been identified and used to attract wasps, limiting the impact on nontarget species (Buteler et al. 2018, Elmquist et al. 2020) representing more promising methods of control for these wasps. Foraging Polistes wasps have been shown to be more attracted to wounded prey items, suggesting that these wasps may be attracted to chemicals in their prey's body tissues (Hirose and Takagi 1980). Similarly, other paper wasps have been shown to use chemicals released by plants experiencing herbivory to find prey (Cornelius 1993, Saraiva et al. 2017). Developing a toxic bait is likely the best method to control invasive Polistes wasps. Similar baits developed for invasive Vespula wasps experience high levels of success (Hanna et al. 2012, Edwards et al. 2017) while methods like trapping foraging wasps have been found to be ineffective (Toft and Harris 2004). More work is required to isolate specific compounds that can be used to develop an effective bait for Polistes wasps. Continued research into their diet and behaviour may uncover associations and chemicals that could be used in the development of an effective control method.

Similar to the development of effective baits and lures, biocontrol options are currently being investigated. Entomopathogenic fungi such as Beauvaria bassinia has been shown to infect P. dominula under laboratory conditions (Manfredini et al. 2013, Van Zyl 2016, Mhlongwe 2018). Insect parasites and parasitoids have also been shown to infect $P$. dominula (Hughes et al. 2010, Miller et al. 2013, Benadé et al. 2014). As many as $25 \%$ of overwintering $P$. dominula queens were found to be parasitised by the strepsipteran parasite, Xenos vesparum, which can prevent reproduction the following season (Hughes et al. 2010). The parasitic wasp, Dibrachys cavus was found to parasitise as many as $51 \%$ of $P$. dominula nests (Miller et al. 2013). While these parasites can exhibit relatively high infection rates they often do not lead to significant mortality or reduction in wasp populations. More research is required to develop an effective control method for this species. 


\section{References}

Abbas, N., M. ljaz, S. A. Shad, and M. Binyameen. 2016. Assessment of resistance risk to fipronil and cross resistance to other insecticides in the Musca domestica L. (Diptera: Muscidae). Veterinary Parasitology 223:71-76.

Alberdi, A., O. Razgour, O. Aizpurua, R. Novella-Fernandez, J. Aihartza, I. Budinski, I. Garin, C. Ibáñez, E. Izagirre, and H. Rebelo. 2020. DNA metabarcoding and spatial modelling link diet diversification with distribution homogeneity in European bats. Nature Communications 11:1-8.

Ayesha, U. R., N. Shafi, T. Akhtar, A. Zareen, and H. Ayub. 2019. DNA barcoding of cyprinids (Labeo rohita, Catla catla and Cirrhinus mrigala), mitochondrial CO1-based study. Mitochondrial DNA Part B 4:405-407.

Baker, A. M., and D. A. Potter. 2020. Invasive paper wasp turns urban pollinator gardens into ecological traps for monarch butterfly larvae. Scientific Reports 10:9553.

Barbet-Massin, M., F. Jiguet, C. H. Albert, and W. Thuiller. 2012a. Selecting pseudo-absences for species distribution models: how, where and how many? Methods in ecology and evolution 3:327-338.

Barbet-Massin, M., W. Thuiller, and F. Jiguet. 2012b. The fate of European breeding birds under climate, land-use and dispersal scenarios. Global Change Biology 18:881-890.

Barlow, N., J. Beggs, and M. Barron. 2002a. Dynamics of common wasps in New Zealand beech forests: a model with density dependence and weather. Journal of Animal Ecology 71:663671.

Barlow, N. D., S. L. Goldson, and D. Pimentel. 2002b. Alien invertebrates in New Zealand. Pages 195216 in D. Pimentel, editor. Biological Invasions Economic and Environmental Costs of Alien Plant, Animal, and Microbe Species. CRC Press, Boca Raton, USA.

Beaumont, L. J., L. Hughes, and M. Poulsen. 2005. Predicting species distributions: use of climatic parameters in BIOCLIM and its impact on predictions of species' current and future distributions. Ecological Modelling 186:251-270.

Beckham, J. L., and S. Atkinson. 2017. An updated understanding of Texas bumble bee (Hymenoptera: Apidae) species presence and potential distributions in Texas, USA. PeerJ 5:e3612.

Beggs, J., J. Rees, R. Toft, T. Dennis, and N. Barlow. 2008. Evaluating the impact of a biological control parasitoid on invasive Vespula wasps in a natural forest ecosystem. Biological Control 44:399-407.

Beggs, J. R. 2001. The ecological consequences of social wasps (Vespula spp.) invading an ecosystem that has abundant carbohydrate resource. Biological Conservation 99:17-28.

Beggs, J. R., E. G. Brockerhoff, J. C. Corley, M. Kenis, M. Masciocchi, F. Muller, Q. Rome, and C. Villemant. 2011. Ecological effects and management of invasive alien Vespidae. BioControl 56:505-526.

Beggs, J. R., and J. S. Rees. 1999. Restructuring of Lepidoptera communities by introduced Vespula wasps in a New Zealand beech forest. Oecologia 119:565-571.

Beggs, J. R., J. S. Rees, and R. J. Harris. 2002. No evidence for establishment of the wasp parasitoid, Sphecophaga vesparum burra (Cresson)(Hymenoptera: Ichneumonidae) at two sites in New Zealand. New Zealand Journal of Zoology 29:205-211.

Beggs, J. R., and P. R. Wilson. 1991. The kaka Nestor meridionalis, a New Zealand parrot endangered by introduced wasps and mammals. Biological Conservation 56:23-38.

Bellard, C., P. Cassey, and T. M. Blackburn. 2016a. Alien species as a driver of recent extinctions. Biology Letters 12:20150623. 
Bellard, C., P. Genovesi, and J. Jeschke. 2016b. Global patterns in threats to vertebrates by biological invasions. Proceedings of the Royal Society B: Biological Sciences 283:20152454.

Benadé, P. C., R. Veldtman, M. J. Samways, and F. Roets. 2014. Rapid range expansion of the invasive wasp Polistes dominula (Hymenoptera: Vespidae: Polistinae) and first record of parasitoids on this species and the native Polistes marginalis in the Western Cape province of South Africa. African Entomology 22:220-225.

Berndt, L. A., and G. R. Allen. 2010. Biology and pest status of Uraba lugens Walker (Lepidoptera: Nolidae) in Australia and New Zealand. Australian Journal of Entomology 49:268-277.

Bertelsmeier, C. 2021. Globalization and the anthropogenic spread of invasive social insects. Current Opinion in Insect Science 46:16-23.

Bohny, S. 2019. Wasp wipeout: Why we're targeting the gardeners' friend. Stuff, https://www.stuff.co.nz/environment/wasp-wipeout/117810326/wasp-wipeout-why-weretargeting-the-gardeners-friend.

Bohny, S. 2020. Wasp wipeout: forensic analysis to name victims of latest wasp invader. Stuff, https://www.stuff.co.nz/environment/wasp-wipeout/119701364/wasp-wipeout-forensicanalysis-to-name-victims-of-latest-wasp-invader.

Booth, T. H., H. A. Nix, J. R. Busby, and M. F. Hutchinson. 2014. bioclim: the first species distribution modelling package, its early applications and relevance to most current MaxEnt studies. Diversity and Distributions 20:1-9.

Brown, R., A. Payne, K. K. Graham, and P. T. Starks. 2012. Prey capture and caste-specific payload capacities in the European paper wasp Polistes dominulus. Insectes Sociaux 59:519-525.

Brown, R. L., A. M. El-Sayed, C. R. Unelius, and D. M. Suckling. 2014. Attraction of the invasive social wasp, Vespula vulgaris, by volatiles from fermented brown sugar. Entomologia Experimentalis et Applicata 151:182-190.

Buck, M., S. A. Marshall, and D. K. Cheung. 2008. Identification atlas of the Vespidae (Hymenoptera, Aculeata) of the northeastern Nearctic region. Canadian Journal of Arthropod Identification 5:1-492.

Bulgarella, M., S. A. Trewick, N. A. Minards, M. J. Jacobson, and M. Morgan-Richards. 2014. Shifting ranges of two tree weta species (Hemideina spp.): competitive exclusion and changing climate. Journal of Biogeography 41:524-535.

Buteler, M., P. Fernandez, T. Stadler, D. K. Weaver, B. Yossen, and M. Lozada. 2018. Heptyl butyrate, a putative pheromone involved in social communication of Vespula germanica wasps. Insectes Sociaux 65:95-101.

Cameron, P., G. Walker, S. Winkler, and M. Hill. 2008. Interaction of a newly established immigrant, soybean looper Thysanoplusia orichalcea and the indigenous green looper Chrysodeixis eriosoma (Plusiinae: Noctuidae) in New Zealand. New Zealand Journal of Crop and Horticultural Science 36:31-39.

Carpenter, J. M. 1996. Distributional checklist of species of the genus Polistes (Hymenoptera: Vespidae; Polistinae, Polistini). American Museum Novitates 3188:1-39.

Cervo, R., F. Zacchi, and S. Turillazzi. 2000. Polistes dominulus (Hymenoptera, Vespidae) invading North America: Some hypotheses for its rapid spread. Insectes Sociaux 47:155-157.

Cheng, Y.-C., and C.-P. Lin. 2016. Dietary Niche Partitioning of Euphaea formosa and Matrona cyanoptera (Odonata: Zygoptera) on the Basis of DNA Barcoding of Larval Feces. Journal of Insect Science 16:1-5.

Chynoweth, R., P. Rolston, M. McNeill, S. Hardwick, and O. Bell. 2018. Red clover casebearer moth (Coleophora deauratella) is widespread throughout New Zealand. New Zealand Plant Protection 71:232-239.

Clapperton, B., H. Möller, and G. Sandlant. 1989. Distribution of social wasps (Hymenoptera: Vespidae) in New Zealand in 1987. New Zealand Journal of Zoology 16:315-323. 
Clapperton, B., J. Tilley, and R. Pierce. 1996. Distribution and abundance of the Asian paper wasp Polistes chinensis antennalis Perez and the Australian paper wasp $P$. humilis (Fab.)(Hymenoptera: Vespidae) in New Zealand. New Zealand Journal of Zoology 23:19-25.

Clapperton, B. K. 1999. Abundance of wasps and prey consumption of paper wasps (Hymenoptera, Vespidae: Polistinae) in Northland, New Zealand. New Zealand Journal of Ecology 23:11-19.

Clapperton, B. K., and J. J. Dymock. 1997. Growth and survival of colonies of the Asian paper wasp, Polistes chinensis antennalis (Hymenoptera: Vespidae). New Zealand Journal of Zoology 24:9-15.

Cordonnier, M., A. Bellec, G. Escarguel, and B. Kaufmann. 2020. Effects of urbanization-climate interactions on range expansion in the invasive European pavement ant. Basic and Applied Ecology 44:46-54.

Cornelius, M. L. 1993. Influence of caterpillar-feeding damage on the foraging behavior of the paper wasp Mischocyttarus flavitarsis (Hymenoptera: Vespidae). Journal of Insect Behavior 6:771781.

Cranshaw, W. S., H. J. Larsen, and R. J. Zimmerman. 2011. Notes on fruit damage by the European paper wasp, Polistes dominula (Christ) (Hymenoptera: Vespidae). Southwestern Entomologist 36:103-105.

Crowder, D. W., and W. E. Snyder. 2010. Eating their way to the top? Mechanisms underlying the success of invasive insect generalist predators. Biological Invasions 12:2857-2876.

Curry, P. A., N. W. Yeung, K. A. Hayes, and R. H. Cowie. 2020. The potential tropical island distribution of a temperate invasive snail, Oxychilus alliarius, modeled on its distribution in Hawaii. Biological Invasions 22:307-327.

Deagle, B. E., A. C. Thomas, J. C. McInnes, L. J. Clarke, E. J. Vesterinen, E. L. Clare, T. R. Kartzinel, and J. P. Eveson. 2019. Counting with DNA in metabarcoding studies: How should we convert sequence reads to dietary data? Molecular Ecology 28:391-406.

Doherty, T. S., A. S. Glen, D. G. Nimmo, E. G. Ritchie, and C. R. Dickman. 2016. Invasive predators and global biodiversity loss. Proceedings of the National Academy of Sciences 113:11261-11265.

Donovan, B. J. 1984. Occurrence of the common wasp, Vespula vulgaris (L.) (Hymenoptera: Vespidae) in New Zealand. New Zealand Journal of Zoology 11:417-427.

Downing, H. 2012. Nest parameters of Polistes and Mischocyttarus species (Hymenoptera: Vespidae) before and after detection of the invasive wasp, Polistes dominula in western South Dakota and Wyoming. Journal of the Kansas Entomological Society 85:23-31.

Duan, R.-Y., X.-Q. Kong, M.-Y. Huang, W.-Y. Fan, and Z.-G. Wang. 2014. The predictive performance and stability of six species distribution models. PloS One 9:e112764.

Dudaniec, R. Y., C. J. Yong, L. T. Lancaster, E. I. Svensson, and B. Hansson. 2018. Signatures of local adaptation along environmental gradients in a range-expanding damselfly (Ischnura elegans). Molecular Ecology 27:2576-2593.

Eardley, C., F. Koch, and A. Wood. 2009. Polistes dominulus (Christ, 1791)(Hymenoptera: Polistinae: Vespidae) newly recorded from South Africa. African Entomology 17:226-227.

Edney-Browne, E., E. G. Brockerhoff, and D. Ward. 2018. Establishment patterns of non-native insects in New Zealand. Biological Invasions 20:1657-1669.

Edwards, E., R. Toft, N. Joice, and I. Westbrooke. 2017. The efficacy of Vespex ${ }^{\circledR}$ wasp bait to control Vespula species (Hymenoptera: Vespidae) in New Zealand. International Journal of Pest Management 63:266-272.

Egeter, B., C. Roe, S. Peixoto, P. Puppo, L. J. Easton, J. Pinto, P. J. Bishop, and B. C. Robertson. 2019. Using molecular diet analysis to inform invasive species management: A case study of introduced rats consuming endemic New Zealand frogs. Ecology and Evolution 9:5032-5048.

Elgueta, M. 1989. Antecedentes sobre especies de reciente introducción a Chile (Diptera: Stratiomyidae; Hymenoptera: Vespidae). Revista Chilena de Entomología 17:97-98. 
Elith, J., C. H. Graham, R. P. Anderson, M. Dudík, S. Ferrier, A. Guisan, R. J. Hijmans, F. Huettmann, J. R. Leathwick, and A. Lehmann. 2006. Novel methods improve prediction of species' distributions from occurrence data. Ecography 29:129-151.

Elith, J., S. J. Phillips, T. Hastie, M. Dudík, Y. E. Chee, and C. J. Yates. 2011. A statistical explanation of MaxEnt for ecologists. Diversity and Distributions 17:43-57.

Elmquist, D. C., and P. J. Landolt. 2018. Associative learning of food odors by the European paper wasp, Polistes dominula Christ (Hymenoptera: Vespidae). Environmental Entomology 47:960-968.

Elmquist, D. C., P. J. Landolt, W. R. Cooper, H. Reed, J. Foutz, T. Clepper, B. Kacprzyk, D. Teig, and R. S. Zack. 2020. The Venom Compound N-(3-methylbutyl)acetamide Attracts Several Polistes (Fuscopolistes) Species (Hymenoptera: Vespidae). Journal of Economic Entomology 113:1073-1079.

Fick, S. E., and R. J. Hijmans. 2017. WorldClim 2: new 1-km spatial resolution climate surfaces for global land areas. International Journal of Climatology 37:4302-4315.

Field, J., and E. Leadbeater. 2016. Cooperation between non-relatives in a primitively eusocial paper wasp, Polistes dominula. Philosophical Transactions of the Royal Society B: Biological Sciences 371:20150093.

Gamboa, G., E. Greig, and M. Thom. 2002. The comparative biology of two sympatric paper wasps, the native Polistes fuscatus and the invasive Polistes dominulus (Hymenoptera, Vespidae). Insectes Sociaux 49:45-49.

Gamboa, G., M. Noble, M. Thom, J. Togal, R. Srinivasan, and B. Murphy. 2004. The comparative biology of two sympatric paper wasps in Michigan, the native Polistes fuscatus and the invasive Polistes dominulus (Hymenoptera, Vespidae). Insectes Sociaux 51:153-157.

Gamboa, G. J., J. A. Austin, and K. M. Monnet. 2005. Effects of different habitats on the productivity of the native paper wasp Polistes fuscatus and the invasive, exotic paper wasp P. dominulus (Hymenoptera: Vespidae). The Great Lakes Entomologist 38:7.

GBIF.org. 2020. GBIF occurence download. https://doi.org/10.15468/dl.jzezgu.

Giannini, T. C., D. S. Chapman, A. M. Saraiva, I. Alves-dos-Santos, and J. C. Biesmeijer. 2013. Improving species distribution models using biotic interactions: a case study of parasites, pollinators and plants. Ecography 36:649-656.

Gibbs, G. W. 2009. The end of an 80-million year experiment: a review of evidence describing the impact of introduced rodents on New Zealand's 'mammal-free' invertebrate fauna. Biological Invasions 11:1587-1593.

Gillespie, M., and S. D. Wratten. 2012. The importance of viticultural landscape features and ecosystem service enhancement for native butterflies in New Zealand vineyards. Journal of Insect Conservation 16:13-23.

Godsoe, W., and L. J. Harmon. 2012. How do species interactions affect species distribution models? Ecography 35:811-820.

González, R. H. 1989. Insectos y ácaros de importancia agrícola y cuarentenaria en Chile. Universidad de Chile Santiago, Santiago.

Gorman, M. L. 1975. The diet of feral Herpestes auropunctatus (Carnivora: Viverridae) in the Fijian Islands. Journal of Zoology 175:273-278.

Gould, W. P., and R. L. Jeanne. 1984. Polistes wasps (Hymenoptera: Vespidae) as control agents for Lepidopterous cabbage pests. Environmental Entomology 13:150-156.

Griffiths, R., E. Bell, J. Campbell, P. Cassey, J. G. Ewen, C. Green, L. Joyce, M. Rayner, R. Toy, D. Towns, L. Wade, R. Walle, and C. R. Veitch. 2017. Costs and benefits for biodiversity following rat and cat eradication on Te Hauturu-o-Toi/Little Barrier Island. Pages 558-567 in Island invasives: scaling up to meet the challenge. IUCN, Dundee, Scotland.

Guisan, A., R. Tingley, J. B. Baumgartner, I. Naujokaitis-Lewis, P. R. Sutcliffe, A. I. Tulloch, T. J. Regan, L. Brotons, E. McDonald-Madden, and C. Mantyka-Pringle. 2013. Predicting species distributions for conservation decisions. Ecology Letters 16:1424-1435. 
Hanna, C., D. Foote, and C. Kremen. 2012. Short- and long-term control of Vespula pensylvanica in Hawaii by fipronil baiting. Pest Management Science 68:1026-1033.

Hare, K. M., S. B. Borrelle, H. L. Buckley, K. J. Collier, R. Constantine, J. K. Perrott, C. H. Watts, and D. R. Towns. 2019. Intractable: species in New Zealand that continue to decline despite conservation efforts. Journal of the Royal Society of New Zealand 49:301-319.

Harris, R. J. 1991. Diet of the wasps Vespula vulgaris and V. germanica in honeydew beech forest of the South Island, New Zealand. New Zealand Journal of Zoology 18:159-169.

Harris, R. J., and J. Rees. 2000. Aerial poisoning of wasps. Science for Conservation 162:26.

Hebert, P. D., E. H. Penton, J. M. Burns, D. H. Janzen, and W. Hallwachs. 2004. Ten species in one: DNA barcoding reveals cryptic species in the neotropical skipper butterfly Astraptes fulgerator. Proceedings of the National Academy of Sciences 101:14812-14817.

Hebert, P. D., S. Ratnasingham, and J. R. De Waard. 2003. Barcoding animal life: cytochrome c oxidase subunit 1 divergences among closely related species. Proceedings of the Royal Society of London. Series B: Biological Sciences 270:S96-S99.

Hijmans, R. J. 2020. raster: Geographic Data Analysis and Modeling. R package version 3.3-13.

Hijmans, R. J., and J. Elith. 2017. Species distribution modeling with R. Available from: http://cran.rproject.org/web/packages/dismo/vignettes/ [Accessed on 3 March 2020].

Hijmans, R. J., S. Phillips, J. Leathwick, and J. Elith. 2017. dismo: Species distribution modeling. R package version 1.1-4.

Hirose, Y., and M. Takagi. 1980. Attraction of two species of Polistes wasps to prey wounded by them. Applied Entomology and Zoology 15:108-110.

Hoare, R. J., J. S. Dugdale, E. D. Edwards, G. W. Gibbs, B. Patrick, R. Hitchmough, and J. R. Rolfe. 2017. Conservation status of New Zealand butterflies and moths (Lepidoptera), 2015. Publishing Team, Department of Conservation, Wellington, New Zealand.

Höcherl, N., and J. Tautz. 2015. Nesting behavior of the paper wasp Polistes dominula in Central Europe-a flexible system for expanding into new areas. Ecosphere 6:262-262.

Holway, D. A. 2005. Edge effects of an invasive species across a natural ecological boundary. Biological Conservation 121:561-567.

Hoshikawa, T. 1979. Observations on the polygynous nests of Polistes chinensis antennalis Pérez (Hymenoptera: Vespidae) in Japan. Kontyu 47:239-243.

Hosmer, D. W., S. Lemeshow, and R. X. Sturdivant. 2013. Assessing the fit of the model. Pages 153226 Applied Logistic Regression. John Wiley \& Sons, Inc., Hoboken, USA.

Hughes, D. P., J. Kathirithamby, and L. Beani. 2010. Prevalence of the parasite Strepsiptera in adult Polistes wasps: field collections and literature overview. Ethology Ecology \& Evolution 16:363-375.

Jeon, M. G., T. G. Kim, J. C. Jung, and M. B. Choi. 2019. Prey diversity of Polistes rothneyi koreanus in different landscapes using DNA barcoding. Journal of Applied Entomology 143:1052-1063.

Kasper, M. L., A. F. Reeson, S. J. Cooper, K. D. Perry, and A. D. Austin. 2004. Assessment of prey overlap between a native (Polistes humilis) and an introduced (Vespula germanica) social wasp using morphology and phylogenetic analyses of 16S rDNA. Molecular Ecology 13:20372048.

Kearney, M. R., B. A. Wintle, and W. P. Porter. 2010. Correlative and mechanistic models of species distribution provide congruent forecasts under climate change. Conservation Letters 3:203213.

Koch, K. G., K. Chapman, J. Louis, T. Heng-Moss, and G. Sarath. 2016. Plant tolerance: a unique approach to control Hemipteran pests. Frontiers in Plant Science 7:1-12.

Kudo, K. 1998. High efficiency of prey foraging achieved by frequent foraging for sawfly larvae by the foundresses of Polistes chinensis (Hymenoptera: Vespidae). Entomological Science 1:341345 . 
Kudo, K. 1999. Immature spiders of Araneus abscissus, as a prey for the pre-founding foundresses of the paper wasp, Polistes chinensis (Hymenoptera: Vespidae). Entomological Science 2:195196.

Lafage, D., V. Elbrecht, J. P. Cuff, D. Steinke, P. A. Hambäck, and A. Erlandsson. 2019. A new primer for metabarcoding of spider gut contents. Environmental DNA 00:1-10.

Landolt, P., and Q.-H. Zhang. 2016. Discovery and development of chemical attractants used to trap pestiferous social wasps (Hymenoptera: Vespidae). Journal of Chemical Ecology 42:655-665.

Leathwick, D., and P. Godfrey. 1996. Overwintering colonies of the common wasp (Vespula vulgaris) in Palmerston North, New Zealand. New Zealand Journal of Zoology 23:355-358.

Leathwick, J., D. Rowe, J. Richardson, J. Elith, and T. Hastie. 2005. Using multivariate adaptive regression splines to predict the distributions of New Zealand's freshwater diadromous fish. Freshwater Biology 50:2034-2052.

Lefort, M.-C., J. R. Beggs, T. R. Glare, T. E. Saunders, E. J. Doyle, and S. Boyer. 2020. A molecular approach to study Hymenoptera diets using wasp nests. NeoBiota 63.

Lester, P. 2018. The Vulgar Wasp: The Story of a Ruthless Invader and Ingenious Predator. Victoria University Press, Wellington, New Zealand.

Lester, P., J. Beggs, R. Brown, E. Edwards, R. Groenteman, R. Toft, A. Twidle, and D. Ward. 2013. The outlook for control of New Zealand's most abundant, widespread and damaging invertebrate pests: social wasps. New Zealand Science Review 70:54-60.

Lester, P., S. Brown, E. Edwards, G. Holwell, S. Pawson, D. Ward, and C. Watts. 2014. Critical issues facing New Zealand entomology. New Zealand Entomologist 37:1-13.

Lester, P. J., and J. R. Beggs. 2019. Invasion success and management strategies for social Vespula wasps. Annual Review of Entomology 64:51-71.

Liebert, A. E., G. J. Gamboa, N. E. Stamp, T. R. Curtis, K. M. Monnet, S. Turillazzi, and P. T. Starks. 2006. Genetics, behavior and ecology of a paper wasp invasion: Polistes dominulus in North America. Annales Zoologici Fennici 43:595-624.

Liu, C., G. Newell, and M. White. 2016. On the selection of thresholds for predicting species occurrence with presence-only data. Ecology and Evolution 6:337-348.

Liu, C., M. White, and G. Newell. 2013. Selecting thresholds for the prediction of species occurrence with presence-only data. Journal of Biogeography 40:778-789.

Lockwood, J. L., P. Cassey, and T. Blackburn. 2005. The role of propagule pressure in explaining species invasions. Trends in Ecology \& Evolution 20:223-228.

Loope, K. J., J. W. Baty, P. J. Lester, and E. E. Wilson Rankin. 2019. Pathogen shifts in a honeybee predator following the arrival of the Varroa mite. Proceedings of the Royal Society B 286:20182499.

Lowe, S., M. Browne, S. Boudjelas, and M. De Poorter. 2000. 100 of the world's worst invasive alien species: a selection from the global invasive species database. Invasive Species Specialist Group Auckland, Auckland, New Zealand.

Lozier, J. D., and N. J. Mills. 2011. Predicting the potential invasive range of light brown apple moth (Epiphyas postvittana) using biologically informed and correlative species distribution models. Biological Invasions 13:2409-2421.

Lyke, M. M., A. Di Fiore, N. Fierer, A. A. Madden, and J. E. Lambert. 2019. Metagenomic analyses reveal previously unrecognized variation in the diets of sympatric Old World monkey species. PloS One 14:e0218245.

Macarra, G. R. 2016. The climate and weather of West Coast. 1173-0382, National Institute of Water and Atmospheric Research, Christchurch, New Zealand.

Maclntyre, P., and J. Hellstrom. 2015. An evaluation of the costs of pest wasps (Vespula species) in New Zealand. International Pest Control 57:162-163.

Manfredini, F., C. M. Grozinger, and L. Beani. 2013. Examining the "evolution of increased competitive ability" hypothesis in response to parasites and pathogens in the invasive paper wasp Polistes dominula. Naturwissenschaften 100:219-228. 
McGruddy, R. 2021. The nesting ecology, habitat preference, abundance and impacts of Polistes dominula in New Zealand [Unpublished master's thesis]. Victoria University of Wellington, Wellington, New Zealand.

McGruddy, R. A., M. W. F. Howse, J. Haywood, C. J. I. Ward, T. B. Staufer, M. Hayek-Williams, R. J. Toft, and P. J. Lester. 2020. Invasive paper wasps have strong cascading effects on the host plant of monarch butterflies. Ecological Entomology:1-11.

McInnes, J. C., S. N. Jarman, M.-A. Lea, B. Raymond, B. E. Deagle, R. A. Phillips, P. Catry, A. Stanworth, H. Weimerskirch, A. Kusch, M. Gras, Y. Cherel, D. Maschette, and R. Alderman. 2017. DNA metabarcoding as a marine conservation and management tool: A circumpolar examination of fishery discards in the diet of threatened albatrosses. Frontiers in Marine Science 4:1-22.

Mercier, O. R., A. King Hunt, and P. Lester. 2019. Novel biotechnologies for eradicating wasps: seeking Māori studies students' perspectives with Q method. Kōtuitui: New Zealand Journal of Social Sciences Online 14:136-156.

Merow, C., M. J. Smith, and J. A. Silander Jr. 2013. A practical guide to MaxEnt for modeling species' distributions: what it does, and why inputs and settings matter. Ecography 36:1058-1069.

Mhlongwe, T. R. 2018. The search for a biological control agent to control invasive Polistes dominula wasps in the Western Cape region, South Africa. MSc. Stellenbosch University, Stellenbosch, South Africa.

Miller, G. L., C. R. Donnelly, and G. J. Gamboa. 2013. A ten-year comparative study of the population dynamics and parasitoidism in the native paper wasp Polistes fuscatus and the invasive $P$. dominulus. Insectes Sociaux 60:49-56.

Ministry for Primary Industries. 2016. Pest Watch. Page 26 Surveillance. New Zealand Government, Wellington, New Zealand.

Moller, H. 1996. Lessons for invasion theory from social insects. Biological Conservation 78:125-142.

Moller, H., J. Tilley, B. Thomas, and P. Gaze. 1991. Effect of introduced social wasps on the standing crop of honeydew in New Zealand beech forests. New Zealand Journal of Zoology 18:171179.

Moor, H., K. Hylander, and J. Norberg. 2015. Predicting climate change effects on wetland ecosystem services using species distribution modeling and plant functional traits. Ambio 44:113-126.

Mpakairi, K. S., H. Ndaimani, P. Tagwireyi, T. W. Gara, M. Zvidzai, and D. Madhlamoto. 2017. Missing in action: Species competition is a neglected predictor variable in species distribution modelling. PloS One 12:e0181088.

Muscarella, R., P. J. Galante, M. Soley-Guardia, R. A. Boria, J. Kass, M. Uriarte, and R. P. Anderson. 2014. ENMeval: An R package for conducting spatially independent evaluations and estimating optimal model complexity for ecological niche models. Methods in ecology and evolution 5:1198-1205.

Museth, J., R. Borgstrøm, and J. E. Brittain. 2010. Diet overlap between introduced European minnow (Phoxinus phoxinus) and young brown trout (Salmo trutta) in the lake, Øvre Heimdalsvatn: a result of abundant resources or forced niche overlap? Hydrobiologia 642:93-100.

Nakano, D., M. Kamiya, and O. Tominaga. 2017. Molecular identification of macroalgal fragments in gut contents of the sea urchin Hemicentrotus pulcherrimus. Fisheries Science 83:425-432.

New, T. R., and M. J. Samways. 2014. Insect conservation in the southern temperate zones: an overview. Austral Entomology 53:26-31.

$\mathrm{Nix}, \mathrm{H}$. A. 1986. A biogeographic analysis of Australian elapid snakes. Pages 16-77 in R. Longmore, editor. Atlas of Elapid Snakes of Australia. Australian Government Publishing Service, Canberra.

Norman, F. I. 1975. The murine rodents Rattus rattus, exulans and norvegicus as avian predators. Atoll Research Bulletin 182:1-15. 
Oksanen, J., F. G. Blanchet, M. Friendly, R. Kindt, P. Legendre, D. McGlinn, P. R. Minchin, R. B. O'Hara, G. L. Simpson, P. Solymos, M. H. H. Stevens, E. Szoecs, and H. Wagner. 2019. vegan: Community Ecology Package.

Oliveira, M. M., F. B. Gomes, A. Somavilla, and C. Krug. 2017. Polistes canadensis (Linnaeus, 1758)(Vespidae: Polistinae) in the Western Amazon: a potential biological control agent. Sociobiology 64:477-483.

$\emptyset$ rsted, I. V., and M. Ørsted. 2019. Species distribution models of the Spotted Wing Drosophila (Drosophila suzukii, Diptera: Drosophilidae) in its native and invasive range reveal an ecological niche shift. Journal of Applied Ecology 56:423-435.

Parent, C. E., S. B. Peck, C. E. Causton, L. Roque-Albelo, P. J. Lester, and M. Bulgarella. 2020. Polistes versicolor (Hymenoptera: Vespidae), an introduced wasp in the Galapagos Islands: Its life cycle and ecological impact. Environmental Entomology 49:1480-1491.

Patrick, B., and J. S. Dugdale. 2000. Conservation status of the New Zealand Lepidoptera. Department of Conservation, Wellington, New Zealand.

Paula, D. P., B. Linard, A. Crampton-Platt, A. Srivathsan, M. J. T. N. Timmermans, E. R. Sujii, C. S. S. Pires, L. M. Souza, D. A. Andow, and A. P. Vogler. 2016. Uncovering trophic interactions in arthropod predators through DNA shotgun-sequencing of gut contents. PloS One 11:e0161841.

Pearson, R. G. 2007. Species' distribution modeling for conservation educators and practitioners. Lessons in Conservation 3:54-89.

Pellissier, L., K. Anne Bråthen, J. Pottier, C. F. Randin, P. Vittoz, A. Dubuis, N. G. Yoccoz, T. Alm, N. E. Zimmermann, and A. Guisan. 2010. Species distribution models reveal apparent competitive and facilitative effects of a dominant species on the distribution of tundra plants. Ecography 33:1004-1014.

Phillips, C. B., K. Brown, C. Green, R. Toft, G. Walker, and K. Broome. 2020. Eradicating the large white butterfly from New Zealand eliminates a threat to endemic Brassicaceae. PloS One 15:e0236791.

Phillips, S. J., R. P. Anderson, and R. E. Schapire. 2006. Maximum entropy modeling of species geographic distributions. Ecological Modelling 190:231-259.

Pickett, K., and J. Wenzel. 2000. High productivity in haplometrotic colonies of the introduced paper wasp Polistes dominulus (Hymenoptera: Vespidae; Polistinae). Journal of the New York Entomological Society 108:314-325.

Pilowsky, J., and P. Starks. 2018. Displacement and replacement in real time: Polistes dominula's impact on P. fuscatus in the northeastern U.S. Biological Invasions 20:1161-1169.

Pisa, L. W., V. Amaral-Rogers, L. P. Belzunces, J. M. Bonmatin, C. A. Downs, D. Goulson, D. P. Kreutzweiser, C. Krupke, M. Liess, M. McField, C. A. Morrissey, D. A. Noome, J. Settele, N. Simon-Delso, J. D. Stark, J. P. Van der Sluijs, H. Van Dyck, and M. Wiemers. 2015. Effects of neonicotinoids and fipronil on non-target invertebrates. Environmental Science and Pollution Research 22:68-102.

Plunkett, G., H. Moller, C. Hamilton, B. Clapperton, and C. Thomas. 1989. Overwintering colonies of German (Vespula germanica) and common wasps (Vespula vulgaris)(Hymenoptera: Vespidae) in New Zealand. New Zealand Journal of Zoology 16:345-353.

Pompanon, F., B. E. Deagle, W. O. C. Symondson, D. S. Brown, S. N. Jarman, and P. Taberlet. 2012. Who is eating what: diet assessment using next generation sequencing. Molecular Ecology 21:1931-1950.

Potter-Craven, J., J. B. Kirkpatrick, P. B. McQuillan, and P. Bell. 2018. The effects of introduced vespid wasps (Vespula germanica and $V$. vulgaris) on threatened native butterfly (Oreixenica ptunarra) populations in Tasmania. Journal of Insect Conservation 22:521-532.

Prezoto, F., T. T. Maciel, M. Detoni, A. Z. Mayorquin, and B. C. Barbosa. 2019. Pest control potential of social wasps in small farms and urban gardens. Insects 10:192. 
Pyšek, P., T. M. Blackburn, E. García-Berthou, I. Perglová, and W. Rabitsch. 2017. Displacement and Local Extinction of Native and Endemic Species. Pages 157-175 in M. Vilà and P. E. Hulme, editors. Impact of Biological Invasions on Ecosystem Services. Springer International Publishing, Cham, Switzerland.

R Core Team. 2020. R: A language and environment for statistical computing. R Foundation for Statistical Computing, Vienna, Austria.

Raghavan, R. K., A. T. Peterson, M. E. Cobos, R. Ganta, and D. Foley. 2019. Current and future distribution of the lone star tick, Amblyomma americanum (L.)(Acari: Ixodidae) in North America. PloS One 14:e0209082.

Rayor, L. S., L. J. Mooney, and J. A. Renwick. 2007. Predatory behavior of Polistes dominulus wasps in response to cardenolides and glucosinolates in Pieris napi caterpillars. Journal of Chemical Ecology 33:1177-1185.

Ricciardi, A. 2007. Are modern biological invasions an unprecedented form of global change? Conservation Biology 21:329-336.

Rodder, D., S. Schmidtlein, M. Veith, and S. Lotters. 2009. Alien invasive slider turtle in unpredicted habitat: a matter of niche shift or of predictors studied? PloS One 4:e7843.

Roets, F., P. Benadé, M. Samways, and R. Veldtman. 2019. Better colony performance, not natural enemy release, explains numerical dominance of the exotic Polistes dominula wasp over a native congener in South Africa. Biological Invasions 21:925-933.

Romanuk, T. N., Y. Zhou, F. S. Valdovinos, and N. D. Martinez. 2017. Robustness trade-offs in model food webs: Invasion probability decreases while invasion consequences increase with connectance. Advances in Ecological Research 56:263-291.

Rust, M. K., D.-H. Choe, E. Wilson-Rankin, K. Campbell, J. Kabashima, and M. Dimson. 2017. Controlling yellow jackets with fipronil-based protein baits in urban recreational areas. International Journal of Pest Management 63:234-241.

Sackmann, P., J. M. Villacide, and J. Corley. 2003. Presencia de una nueva avispa social exótica, Polistes dominulus (Hymenoptera: Vespidae) en la Patagonia Argentina. Revista de la Sociedad Entomológica Argentina 62:68-70.

Sampson, S. J., J. H. Chick, and M. A. Pegg. 2009. Diet overlap among two Asian carp and three native fishes in backwater lakes on the Illinois and Mississippi rivers. Biological Invasions 11:483496.

Sandlant, G., and H. Moller. 1989. Abundance of common and German wasps (Hymenoptera: Vespidae) in the honeydew beech forests of New Zealand in 1987. New Zealand Journal of Zoology 16:333-343.

Sands, D. P. A. 2018. Important issues facing insect conservation in Australia: now and into the future. Austral Entomology 57:150-172.

Saraiva, N. B., F. Prezoto, M. d. G. Fonseca, M. C. Blassioli-Moraes, M. Borges, R. A. Laumann, and A. M. Auad. 2017. The social wasp Polybia fastidiosuscula Saussure (Hymenoptera: Vespidae) uses herbivore-induced maize plant volatiles to locate its prey. Journal of Applied Entomology 141:620-629.

Savidge, J. A. 1987. Extinction of an island forest avifauna by an introduced snake. Ecology 68:660668.

Schapheer, C., G. Sandoval, and C. A. Villagra. 2018. Pest cockroaches may overcome environmental restriction due to anthropization. Journal of Medical Entomology 55:1357-1364.

Schenk, D., and S. Bacher. 2002. Functional response of a generalist insect predator to one of its prey species in the field. Journal of Animal Ecology 71:524-531.

Schmack, J. M., M. Schleuning, D. F. Ward, and J. R. Beggs. 2020. Biogeography and anthropogenic impact shape the success of invasive wasps on New Zealand's offshore islands. Diversity and Distributions 26:441-452.

Seebens, H., T. M. Blackburn, E. E. Dyer, P. Genovesi, P. E. Hulme, J. M. Jeschke, S. Pagad, P. Pyšek, M. Winter, M. Arianoutsou, S. Bacher, B. Blasius, G. Brundu, C. Capinha, L. Celesti-Grapow, 
W. Dawson, S. Dullinger, N. Fuentes, H. Jäger, J. Kartesz, M. Kenis, H. Kreft, I. Kühn, B. Lenzner, A. Liebhold, A. Mosena, D. Moser, M. Nishino, D. Pearman, J. Pergl, W. Rabitsch, J. Rojas-Sandoval, A. Roques, S. Rorke, S. Rossinelli, H. E. Roy, R. Scalera, S. Schindler, K. Štajerová, B. Tokarska-Guzik, M. van Kleunen, K. Walker, P. Weigelt, T. Yamanaka, and F. Essl. 2017. No saturation in the accumulation of alien species worldwide. Nature Communications 8:14435.

Sharma, H., and J. Davies. 1983. The oriental armyworm, Mythimna separata (Wlk.) distribution, biology and control: a literature review. 0851351328, Overseas Development Administration, London, England.

Shaw, P., P. Lo, and D. Wallis. 2001. Recent introduction and establishment of the leafroller parasitoid Trigonospila brevifacies (Hardy) (Diptera Tachinidae) in Nelson. New Zealand Plant Protection 54:33-36.

Sorvari, J. 2013. Social wasp (Hymenoptera: Vespidae) beer trapping in Finland 2008-2012: a German surprise. Entomologica Fennica 24:156-164.

Southon, R. J., O. A. Fernandes, F. S. Nascimento, and S. Sumner. 2019. Social wasps are effective biocontrol agents of key lepidopteran crop pests. Proceedings of the Royal Society B: Biological Sciences 286:20191676.

Spitz, J., Y. Rousseau, and V. Ridoux. 2006. Diet overlap between harbour porpoise and bottlenose dolphin: An argument in favour of interference competition for food? Estuarine, Coastal and Shelf Science 70:259-270.

Spurr, E. 1995. Protein bait preferences of wasps (Vespula vulgaris and V. germanica) at Mt Thomas, Canterbury, New Zealand. New Zealand Journal of Zoology 22:281-289.

Spurr, E. 1996. Carbohydrate bait preferences of wasps (Vespula vulgaris and V. germanica)(Hymenoptera: Vespidae) in New Zealand. New Zealand Journal of Zoology 23:315-324.

Srivastava, V., V. Lafond, and V. C. Griess. 2019. Species distribution models (SDM): applications, benefits and challenges in invasive species management. CAB Reviews: Perspectives in Agriculture, Veterinary Science, Nutrition and Natural Resources 14:1-13.

Stamp, N., and M. Bowers. 1988. Direct and indirect effects of predatory wasps (Polistes sp.: Vespidae) on gregarious caterpillars (Hemileuca lucina: Saturniidae). Oecologia 75:619-624.

Steinke, D., and R. Hanner. 2011. The FISH-BOL collaborators' protocol. Mitochondrial DNA 22:10-14.

Stringer, I., and R. Hitchmough. 2012. Assessing the conservation status of New Zealand's native terrestrial invertebrates. New Zealand Entomologist 35:77-84.

Stringer, I., R. Hitchmough, J. Dugdale, E. Edwards, R. Hoare, and B. Patrick. 2012. The conservation status of New Zealand Lepidoptera. New Zealand Entomologist 35:120-127.

Suckling, D. M., and E. G. Brockerhoff. 2010. Invasion biology, ecology, and management of the light brown apple moth (Tortricidae). Annual Review of Entomology 55:285-306.

Sumner, S., P. Bevan, A. G. Hart, and N. J. B. Isaac. 2019. Mapping species distributions in 2 weeks using citizen science. Insect Conservation and Diversity 12:382-388.

Suzuki, T. 1978. Area, efficiency and time of foraging in Polistes chinensis antennalis Pérez (Hymenoptera, Vespidae). Japanese Journal of Ecology 28:179-189.

Takahashi, M., J. D. DiBattista, S. Jarman, S. J. Newman, C. B. Wakefield, E. S. Harvey, and M. Bunce. 2020. Partitioning of diet between species and life history stages of sympatric and cryptic snappers (Lutjanidae) based on DNA metabarcoding. Scientific Reports 10:1-13.

Taylor, R. W., D. R. Brown, and J. C. Cardale. 1985. Hymenoptera: Formicoidea, Vespoidea and Sphecoidea. Australian Government Publishing Service, Canberra, Australia.

Thomson, G. M. 1922. The naturalisation of animals and plants in New Zealand. Cambridge University Press, Cambridge, England.

Tibbetts, E. A., and H. K. Reeve. 2003. Benefits of foundress associations in the paper wasp Polistes dominulus: increased productivity and survival, but no assurance of fitness returns. Behavioural Ecology 14:510-514. 
Tingley, R., P. García-Díaz, C. R. R. Arantes, and P. Cassey. 2018. Integrating transport pressure data and species distribution models to estimate invasion risk for alien stowaways. Ecography 41:635-646.

Toft, R. J., and R. J. Harris. 2004. Can trapping control Asian paper wasp (Polistes chinensis antennalis) populations? New Zealand Journal of Ecology 28:279-282.

Toft, R. J., and J. S. Rees. 1998. Reducing predation of orb-web spiders by controlling common wasps (Vespula vulgaris) in a New Zealand beech forest. Ecological Entomology 23:90-95.

Troczka, B., C. T. Zimmer, J. Elias, C. Schorn, C. Bass, T. G. E. Davies, L. M. Field, M. S. Williamson, R. Slater, and R. Nauen. 2012. Resistance to diamide insecticides in diamondback moth, Plutella xylostella (Lepidoptera: Plutellidae) is associated with a mutation in the membrane-spanning domain of the ryanodine receptor. Insect Biochemistry and Molecular Biology 42:873-880.

Turanov, S., Y. P. Kartavtsev, V. Lipinsky, V. Zemnukhov, A. Balanov, Y.-H. Lee, and D. Jeong. 2016. DNA-barcoding of perch-like fishes (Actinopterygii: Perciformes) from far-eastern seas of Russia with taxonomic remarks for some groups. Mitochondrial DNA Part A 27:1188-1209.

Ustups, D., U. Bergström, A. Florin, E. Kruze, D. Zilniece, D. Elferts, E. Knospina, and D. Uzars. 2016. Diet overlap between juvenile flatfish and the invasive round goby in the central Baltic Sea. Journal of Sea Research 107:121-129.

Valentini, A., F. Pompanon, and P. Taberlet. 2009. DNA barcoding for ecologists. Trends in Ecology \& Evolution 24:110-117.

Valéry, L., H. Fritz, J.-C. Lefeuvre, and D. Simberloff. 2008. In search of a real definition of the biological invasion phenomenon itself. Biological Invasions 10:1345-1351.

Van Zyl, C. 2016. Status of the invasive wasp species, Vespula germanica and Polistes dominula in South Africa, and the feasibility of various management strategies. Stellenbosch University, Stellenbosch, South Africa.

Vesterinen, E. J., A. I. Puisto, A. S. Blomberg, and T. M. Lilley. 2018. Table for five, please: Dietary partitioning in boreal bats. Ecology and Evolution 8:10914-10937.

Villemant, C., M. Barbet-Massin, A. Perrard, F. Muller, O. Gargominy, F. Jiguet, and Q. Rome. 2011. Predicting the invasion risk by the alien bee-hawking Yellow-legged hornet Vespa velutina nigrithorax across Europe and other continents with niche models. Biological Conservation 144:2142-2150.

Ward, D. F. 2007. Modelling the potential geographic distribution of invasive ant species in New Zealand. Biological Invasions 9:723-735.

Ward, D. F., and A. Ramón-Laca. 2013. Molecular identification of the prey range of the invasive Asian paper wasp. Ecology and Evolution 3:4408-4414.

Wegner, G. S., and K. K. Jordan. 2005. Comparison of three liquid lures for trapping social wasps (Hymenoptera: Vespidae). Journal of Economic Entomology 98:664-666.

Wilson, E. E., and D. A. Holway. 2010. Multiple mechanisms underlie displacement of solitary Hawaiian Hymenoptera by an invasive social wasp. Ecology 91:3294-3302.

Wilson, E. E., L. M. Mullen, and D. A. Holway. 2009. Life history plasticity magnifies the ecological effects of a social wasp invasion. Proceedings of the National Academy of Sciences 106:12809-12813.

Wilson, J. R., P. García-Díaz, P. Cassey, D. M. Richardson, P. Pyšek, and T. M. Blackburn. 2016. Biological invasions and natural colonisations are different-the need for invasion science. NeoBiota 31:87.

Wirta, H. K., E. Weingartner, P. A. Hambäck, and T. Roslin. 2015. Extensive niche overlap among the dominant arthropod predators of the High Arctic. Basic and Applied Ecology 16:86-92.

Wisz, M. S., J. Pottier, W. D. Kissling, L. Pellissier, J. Lenoir, C. F. Damgaard, C. F. Dormann, M. C. Forchhammer, J. A. Grytnes, and A. Guisan. 2013. The role of biotic interactions in shaping distributions and realised assemblages of species: implications for species distribution modelling. Biological Reviews 88:15-30. 
Wojcik, V. A., L. A. Morandin, L. Davies Adams, and K. E. Rourke. 2018. Floral resource competition between honey bees and wild bees: Is there clear evidence and can we guide management and conservation? Environmental Entomology 47:822-833.

Zeale, M. R. K., R. K. Butlin, G. L. A. Barker, D. C. Lees, and G. Jones. 2011. Taxon-specific PCR for DNA barcoding arthropod prey in bat faeces. Molecular Ecology Resources 11:236-244. 


\section{Appendices}

Appendix A: Table of the 315 MOTUs identified within the guts of Polistes dominula $(n=30)$ and $P$. chinensis $(n=28)$ larvae across all nine sites in Nelson, New Zealand. Prey taxa were identified down to genus level where possible.

\begin{tabular}{|c|c|c|c|c|c|}
\hline Order & Family & Genus & MOTU & P. dominula & P. chinensis \\
\hline Apusomonadida & Thecamonas & Unclassified & Thecamonas & $\checkmark$ & \\
\hline Araneae & Theridiidae & Cryptachaea & Cryptachaea spp. & $\checkmark$ & $\checkmark$ \\
\hline \multirow[t]{3}{*}{ Coleoptera } & \multirow[t]{2}{*}{ Coccinellidae } & Coccinella & Coccinella spp. & $\checkmark$ & $\checkmark$ \\
\hline & & Scymnus & Scymnus spp. & & $\checkmark$ \\
\hline & Curculionidae & Sitona & Sitona spp. & $\checkmark$ & $\checkmark$ \\
\hline \multirow[t]{10}{*}{ Diptera } & Agromyzidae & Cerodontha & Cerodontha spp. & $\checkmark$ & $\checkmark$ \\
\hline & \multirow[t]{2}{*}{ Ceratopogonidae } & Forcipomyia & Forcipomyia spp. & $\checkmark$ & $\checkmark$ \\
\hline & & Unclassified & Ceratopogonidae & $\checkmark$ & \\
\hline & Drosophilidae & Drosophila & Drosophila spp. & $\checkmark$ & \\
\hline & Sarcophagidae & Oxysarcodexia & Oxysarcodexia spp. & $\checkmark$ & \\
\hline & Stratiomyidae & Inopus & Inopus spp. & & $\checkmark$ \\
\hline & \multirow[t]{2}{*}{ Syrphidae } & Melanostoma & Melanostoma spp. & $\checkmark$ & $\checkmark$ \\
\hline & & Platycheirus & Platycheirus spp. & & $\checkmark$ \\
\hline & Tabanidae & Unclassified & Tabanidae & $\checkmark$ & $\checkmark$ \\
\hline & Tachinidae & Trigonospila & Trigonospila spp. & $\checkmark$ & $\checkmark$ \\
\hline \multirow[t]{4}{*}{ Hemiptera } & Aphrophoridae & Philaenus & Philaenus spp. & $\checkmark$ & $\checkmark$ \\
\hline & \multirow[t]{3}{*}{ Cicadidae } & Amphipsalta & Amphipsalta spp. & $\checkmark$ & \\
\hline & & Cicadetta & Cicadetta spp. & $\checkmark$ & \\
\hline & & Kikihia & Kikihia spp. & $\checkmark$ & $\checkmark$ \\
\hline \multirow[t]{3}{*}{ Hymenoptera } & \multirow[t]{3}{*}{ Braconidae } & Cotesia & Cotesia spp. & $\checkmark$ & \\
\hline & & Diolcogaster & Diolcogaster spp. & $\checkmark$ & $\checkmark$ \\
\hline & & Meteorus & Meteorus spp. & $\checkmark$ & \\
\hline \multirow[t]{14}{*}{ Lepidoptera } & Anthelidae & Anthela & Anthela spp. & & $\checkmark$ \\
\hline & Batrachedridae & Unclassified & Batrachedridae & $\checkmark$ & \\
\hline & Brahmaeidae & Brahmaea & Brahmaea spp. & & $\checkmark$ \\
\hline & Castniidae & Synemon & Synemon spp. & $\checkmark$ & $\checkmark$ \\
\hline & Choreutidae & Tebenna & Tebenna spp. & $\checkmark$ & $\checkmark$ \\
\hline & Coleophoridae & Coleophora & Coleophora spp. & $\checkmark$ & $\checkmark$ \\
\hline & Cossidae & Cryptoholcocerus & Cryptoholcocerus spp. & $\checkmark$ & \\
\hline & \multirow[t]{7}{*}{ Crambidae } & Achyra & Achyra spp. & $\checkmark$ & $\checkmark$ \\
\hline & & Canuza & Canuza spp. & $\checkmark$ & $\checkmark$ \\
\hline & & Crambus & Crambus spp. & $\checkmark$ & \\
\hline & & Elophila & Elophila spp. & $\checkmark$ & \\
\hline & & Eudonia & Eudonia spp. & $\checkmark$ & $\checkmark$ \\
\hline & & Maruca & Maruca spp. & $\checkmark$ & \\
\hline & & Metallarcha & Metallarcha spp. & $\checkmark$ & \\
\hline
\end{tabular}




\begin{tabular}{|c|c|c|c|c|}
\hline & Metasia & Metasia spp. & $\checkmark$ & \\
\hline & Omiodes & Omiodes spp. & $\checkmark$ & \\
\hline & Palpita & Palpita spp. & $\checkmark$ & \\
\hline & Sedenia & Sedenia spp. & $\checkmark$ & \\
\hline & Uresiphita & Uresiphita spp. & $\checkmark$ & \\
\hline \multirow[t]{3}{*}{ Depressariidae } & Eutorna & Eutorna spp. & & $\checkmark$ \\
\hline & Nites & Nites spp. & $\checkmark$ & \\
\hline & Tonica & Tonica spp. & $\checkmark$ & \\
\hline \multirow[t]{3}{*}{ Elachistidae } & Elachista & Elachista spp. & $\checkmark$ & $\checkmark$ \\
\hline & Stenoma & Stenoma spp. & $\checkmark$ & \\
\hline & Unclassified & Elachistidae & $\checkmark$ & \\
\hline \multirow[t]{34}{*}{ Erebidae } & Acanthodica & Acanthodica spp. & & $\checkmark$ \\
\hline & Apantesis & Apantesis spp. & $\checkmark$ & \\
\hline & Arrade & Arrade spp. & & $\checkmark$ \\
\hline & Asota & Asota spp. & & $\checkmark$ \\
\hline & Balacra & Balacra spp. & $\checkmark$ & $\checkmark$ \\
\hline & Bertholdia & Bertholdia spp. & $\checkmark$ & \\
\hline & Callindra & Callindra spp. & $\checkmark$ & \\
\hline & Dysschema & Dysschema spp. & & $\checkmark$ \\
\hline & Egone & Egone spp. & $\checkmark$ & $\checkmark$ \\
\hline & Elysius & Elysius spp. & $\checkmark$ & \\
\hline & Episcepsis & Episcepsis spp. & $\checkmark$ & \\
\hline & Erebus & Erebus spp. & $\checkmark$ & \\
\hline & Eucereon & Eucereon spp. & & $\checkmark$ \\
\hline & Euchaetes & Euchaetes spp. & $\checkmark$ & \\
\hline & Eudesmia & Eudesmia spp. & $\checkmark$ & \\
\hline & Eulepidotis & Eulepidotis spp. & $\checkmark$ & \\
\hline & Herminia & Herminia spp. & $\checkmark$ & \\
\hline & Hypocrita & Hypocrita spp. & & $\checkmark$ \\
\hline & Kodiosoma & Kodiosoma spp. & $\checkmark$ & \\
\hline & Lophocampa & Lophocampa spp. & & $\checkmark$ \\
\hline & Loxophlebia & Loxophlebia spp. & $\checkmark$ & \\
\hline & Melese & Melese spp. & $\checkmark$ & \\
\hline & Nyctemera & Nyctemera spp. & $\checkmark$ & $\checkmark$ \\
\hline & Panilla & Panilla spp. & $\checkmark$ & \\
\hline & Pantydia & Pantydia spp. & $\checkmark$ & \\
\hline & Phalaenostola & Phalaenostola spp. & $\checkmark$ & $\checkmark$ \\
\hline & Renia & Renia spp. & & $\checkmark$ \\
\hline & Simplicia & Simplicia spp. & $\checkmark$ & \\
\hline & Sosxetra & Sosxetra spp. & $\checkmark$ & \\
\hline & Spilosoma & Spilosoma spp. & $\checkmark$ & \\
\hline & Tatargina & Tatargina spp. & $\checkmark$ & \\
\hline & Trichromia & Trichromia spp. & $\checkmark$ & \\
\hline & Virbia & Virbia spp. & $\checkmark$ & $\checkmark$ \\
\hline & Zanclognatha & Zanclognatha spp. & $\checkmark$ & $\checkmark$ \\
\hline
\end{tabular}




\begin{tabular}{|c|c|c|c|c|}
\hline & Zelicodes & Zelicodes spp. & $\checkmark$ & $\checkmark$ \\
\hline & Unclassified & Erebidae & & $\checkmark$ \\
\hline \multirow[t]{2}{*}{ Euteliidae } & Paectes & Paectes spp. & $\checkmark$ & \\
\hline & Penicillaria & Penicillaria spp. & $\checkmark$ & \\
\hline \multirow[t]{10}{*}{ Gelechiidae } & Anarsia & Anarsia spp. & $\checkmark$ & \\
\hline & Apatetris & Apatetris spp. & $\checkmark$ & \\
\hline & Ardozyga & Ardozyga spp. & $\checkmark$ & \\
\hline & Chionodes & Chionodes spp. & $\checkmark$ & \\
\hline & Exoteleia & Exoteleia spp. & $\checkmark$ & \\
\hline & Gnorimoschema & Gnorimoschema spp. & & $\checkmark$ \\
\hline & Hypatima & Hypatima spp. & $\checkmark$ & \\
\hline & Macrenches & Macrenches spp. & & $\checkmark$ \\
\hline & Symmetrischema & Symmetrischema spp. & $\checkmark$ & \\
\hline & Unclassified & Gelechiidae & $\checkmark$ & \\
\hline \multirow[t]{31}{*}{ Geometridae } & Alcis & Alcis spp. & $\checkmark$ & $\checkmark$ \\
\hline & Amelora & Amelora spp. & $\checkmark$ & \\
\hline & Anisodes & Anisodes spp. & $\checkmark$ & $\checkmark$ \\
\hline & Arcobara & Arcobara spp. & & $\checkmark$ \\
\hline & Arichanna & Arichanna spp. & $\checkmark$ & \\
\hline & Atmoceras & Atmoceras spp. & & $\checkmark$ \\
\hline & Calluga & Calluga spp. & & $\checkmark$ \\
\hline & Capusa & Capusa spp. & $\checkmark$ & \\
\hline & Celerena & Celerena spp. & $\checkmark$ & $\checkmark$ \\
\hline & Chiasmia & Chiasmia spp. & $\checkmark$ & \\
\hline & Chloroclystis & Chloroclystis spp. & $\checkmark$ & $\checkmark$ \\
\hline & Chrysolarentia & Chrysolarentia spp. & $\checkmark$ & \\
\hline & Cnephora & Cnephora spp. & & $\checkmark$ \\
\hline & Cundinamarca & Cundinamarca spp. & $\checkmark$ & \\
\hline & Cyclophora & Cyclophora spp. & $\checkmark$ & $\checkmark$ \\
\hline & Dalima & Dalima spp. & & $\checkmark$ \\
\hline & Declana & Declana spp. & $\checkmark$ & $\checkmark$ \\
\hline & Deileptenia & Deileptenia spp. & $\checkmark$ & \\
\hline & Dinophalus & Dinophalus spp. & $\checkmark$ & \\
\hline & Dysstroma & Dysstroma spp. & $\checkmark$ & \\
\hline & Eois & Eois spp. & $\checkmark$ & $\checkmark$ \\
\hline & Epyaxa & Epyaxa spp. & $\checkmark$ & $\checkmark$ \\
\hline & Eucyclodes & Eucyclodes spp. & $\checkmark$ & \\
\hline & Eulithis & Eulithis spp. & $\checkmark$ & \\
\hline & Eupithecia & Eupithecia spp. & $\checkmark$ & $\checkmark$ \\
\hline & Glaucoclystis & Glaucoclystis spp. & $\checkmark$ & \\
\hline & Gymnoscelis & Gymnoscelis spp. & $\checkmark$ & $\checkmark$ \\
\hline & Hemipterodes & Hemipterodes spp. & $\checkmark$ & \\
\hline & Hypochroma & Hypochroma spp. & $\checkmark$ & \\
\hline & Idaea & Idaea spp. & & $\checkmark$ \\
\hline & Iridopsis & Iridopsis spp. & $\checkmark$ & \\
\hline
\end{tabular}




\begin{tabular}{|c|c|c|c|c|}
\hline & Melanolophia & Melanolophia spp. & & $\checkmark$ \\
\hline & Microdes & Microdes spp. & $\checkmark$ & $\checkmark$ \\
\hline & Myrteta & Myrteta spp. & & $\checkmark$ \\
\hline & Neazata & Neazata spp. & $\checkmark$ & \\
\hline & Nebula & Nebula spp. & $\checkmark$ & $\checkmark$ \\
\hline & Nephodia & Nephodia spp. & $\checkmark$ & \\
\hline & Oenoptila & Oenoptila spp. & & $\checkmark$ \\
\hline & Oxydia & Oxydia spp. & $\checkmark$ & \\
\hline & Ozola & Ozola spp. & & $\checkmark$ \\
\hline & Paradromulia & Paradromulia spp. & $\checkmark$ & \\
\hline & Patalene & Patalene spp. & $\checkmark$ & \\
\hline & Peribatodes & Peribatodes spp. & $\checkmark$ & $\checkmark$ \\
\hline & Phrissogonus & Phrissogonus spp. & $\checkmark$ & $\checkmark$ \\
\hline & Phyllodonta & Phyllodonta spp. & & $\checkmark$ \\
\hline & Physocleora & Physocleora spp. & $\checkmark$ & $\checkmark$ \\
\hline & Plesiolaea & Plesiolaea spp. & $\checkmark$ & \\
\hline & Poecilasthena & Poecilasthena spp. & $\checkmark$ & $\checkmark$ \\
\hline & Protorhoe & Protorhoe spp. & & $\checkmark$ \\
\hline & Psaliodes & Psaliodes spp. & $\checkmark$ & $\checkmark$ \\
\hline & Pycnostega & Pycnostega spp. & & $\checkmark$ \\
\hline & Pyrinia & Pyrinia spp. & & $\checkmark$ \\
\hline & Scopula & Scopula spp. & $\checkmark$ & $\checkmark$ \\
\hline & Scotocyma & Scotocyma spp. & $\checkmark$ & \\
\hline & Selidosema & Selidosema spp. & $\checkmark$ & \\
\hline & Simopteryx & Simopteryx spp. & $\checkmark$ & \\
\hline & Tacparia & Tacparia spp. & $\checkmark$ & \\
\hline & Thalassodes & Thalassodes spp. & $\checkmark$ & \\
\hline & Tolmera & Tolmera spp. & $\checkmark$ & \\
\hline & Xanthorhoe & Xanthorhoe spp. & $\checkmark$ & $\checkmark$ \\
\hline & Zeugma & Zeugma spp. & & $\checkmark$ \\
\hline & Ziridava & Ziridava spp. & $\checkmark$ & \\
\hline & Unclassified & Geometridae & $\checkmark$ & $\checkmark$ \\
\hline Hesperiidae & Telemiades & Telemiades spp. & $\checkmark$ & $\checkmark$ \\
\hline Immidae & Unclassified & Immidae & $\checkmark$ & \\
\hline Lecithoceridae & Crocanthes & Crocanthes spp. & $\checkmark$ & \\
\hline & Synesarga & Synesarga spp. & & $\checkmark$ \\
\hline Limacodidae & Pantoctenia & Pantoctenia spp. & $\checkmark$ & \\
\hline Lycaenidae & Arhopala & Arhopala spp. & $\checkmark$ & \\
\hline & Callophrys & Callophrys spp. & $\checkmark$ & $\checkmark$ \\
\hline & Calycopis & Calycopis spp. & $\checkmark$ & $\checkmark$ \\
\hline & Cupido & Cupido spp. & $\checkmark$ & \\
\hline & Hypochrysops & Hypochrysops spp. & $\checkmark$ & \\
\hline & laspis & laspis spp. & $\checkmark$ & \\
\hline & Lycaena & Lycaena spp. & $\checkmark$ & $\checkmark$ \\
\hline & Neolycaena & Neolycaena spp. & $\checkmark$ & \\
\hline
\end{tabular}




\begin{tabular}{|c|c|c|c|c|}
\hline & Nicolaea & Nicolaea spp. & $\checkmark$ & $\checkmark$ \\
\hline & Panthiades & Panthiades spp. & $\checkmark$ & \\
\hline & Philiris & Philiris spp. & $\checkmark$ & $\checkmark$ \\
\hline & Satyrium & Satyrium spp. & $\checkmark$ & $\checkmark$ \\
\hline & Strephonota & Strephonota spp. & $\checkmark$ & \\
\hline & Theorema & Theorema spp. & $\checkmark$ & \\
\hline & Thereus & Thereus spp. & $\checkmark$ & $\checkmark$ \\
\hline & Zizina & Zizina spp. & $\checkmark$ & $\checkmark$ \\
\hline & Unclassified & Lycaenidae & $\checkmark$ & \\
\hline Nepticulidae & Stigmella & Stigmella spp. & $\checkmark$ & \\
\hline \multirow[t]{35}{*}{ Noctuidae } & Acontia & Acontia spp. & $\checkmark$ & \\
\hline & Acrapex & Acrapex spp. & $\checkmark$ & $\checkmark$ \\
\hline & Acronicta & Acronicta spp. & $\checkmark$ & $\checkmark$ \\
\hline & Agrotis & Agrotis spp. & $\checkmark$ & $\checkmark$ \\
\hline & Amephana & Amephana spp. & $\checkmark$ & \\
\hline & Anagrapha & Anagrapha spp. & $\checkmark$ & \\
\hline & Anarta & Anarta spp. & & $\checkmark$ \\
\hline & Apamea & Apamea spp. & & $\checkmark$ \\
\hline & Armactica & Armactica spp. & $\checkmark$ & $\checkmark$ \\
\hline & Bagisara & Bagisara spp. & & $\checkmark$ \\
\hline & Capis & Capis spp. & $\checkmark$ & \\
\hline & Caradrina & Caradrina spp. & $\checkmark$ & \\
\hline & Catocala & Catocala spp. & $\checkmark$ & \\
\hline & Chytonix & Chytonix spp. & $\checkmark$ & \\
\hline & Condica & Condica spp. & $\checkmark$ & $\checkmark$ \\
\hline & Craniophora & Craniophora spp. & $\checkmark$ & $\checkmark$ \\
\hline & Cryphia & Cryphia spp. & $\checkmark$ & $\checkmark$ \\
\hline & Ctenoplusia & Ctenoplusia spp. & $\checkmark$ & $\checkmark$ \\
\hline & Dichonia & Dichonia spp. & $\checkmark$ & \\
\hline & Drobeta & Drobeta spp. & $\checkmark$ & $\checkmark$ \\
\hline & Ectopatria & Ectopatria spp. & $\checkmark$ & $\checkmark$ \\
\hline & Elaphria & Elaphria spp. & $\checkmark$ & \\
\hline & Emarginea & Emarginea spp. & $\checkmark$ & \\
\hline & Enargia & Enargia spp. & & $\checkmark$ \\
\hline & Epitausa & Epitausa spp. & & $\checkmark$ \\
\hline & Eremohadena & Eremohadena spp. & & $\checkmark$ \\
\hline & Eucarta & Eucarta spp. & $\checkmark$ & $\checkmark$ \\
\hline & Eulocastra & Eulocastra spp. & $\checkmark$ & $\checkmark$ \\
\hline & Eurois & Eurois spp. & $\checkmark$ & \\
\hline & Euxoa & Euxoa spp. & & $\checkmark$ \\
\hline & Flavala & Flavala spp. & $\checkmark$ & $\checkmark$ \\
\hline & Hada & Hada spp. & & $\checkmark$ \\
\hline & Helicoverpa & Helicoverpa spp. & $\checkmark$ & \\
\hline & Heliocheilus & Heliocheilus spp. & $\checkmark$ & $\checkmark$ \\
\hline & Hoplodrina & Hoplodrina spp. & $\checkmark$ & \\
\hline
\end{tabular}




\begin{tabular}{|c|c|c|c|c|}
\hline & Leucania & Leucania spp. & $\checkmark$ & $\checkmark$ \\
\hline & Leuconycta & Leuconycta spp. & $\checkmark$ & $\checkmark$ \\
\hline & Lithacodia & Lithacodia spp. & $\checkmark$ & $\checkmark$ \\
\hline & Manga & Manga spp. & $\checkmark$ & \\
\hline & Melipotis & Melipotis spp. & $\checkmark$ & $\checkmark$ \\
\hline & Mythimna & Mythimna spp. & $\checkmark$ & $\checkmark$ \\
\hline & Oligia & Oligia spp. & $\checkmark$ & $\checkmark$ \\
\hline & Orthosia & Orthosia spp. & & $\checkmark$ \\
\hline & Pachetra & Pachetra spp. & $\checkmark$ & $\checkmark$ \\
\hline & Panchrysia & Panchrysia spp. & $\checkmark$ & \\
\hline & Perigea & Perigea spp. & $\checkmark$ & $\checkmark$ \\
\hline & Photedes & Photedes spp. & & $\checkmark$ \\
\hline & Poeonoma & Poeonoma spp. & $\checkmark$ & $\checkmark$ \\
\hline & Polia & Polia spp. & & $\checkmark$ \\
\hline & Praina & Praina spp. & & $\checkmark$ \\
\hline & Properigea & Properigea spp. & & $\checkmark$ \\
\hline & Proteuxoa & Proteuxoa spp. & & $\checkmark$ \\
\hline & Pseudeustrotia & Pseudeustrotia spp. & $\checkmark$ & \\
\hline & Pseudopanthea & Pseudopanthea spp. & $\checkmark$ & \\
\hline & Raphia & Raphia spp. & $\checkmark$ & \\
\hline & Schinia & Schinia spp. & $\checkmark$ & $\checkmark$ \\
\hline & Sesamia & Sesamia spp. & $\checkmark$ & $\checkmark$ \\
\hline & Sideridis & Sideridis spp. & $\checkmark$ & \\
\hline & Speiredonia & Speiredonia spp. & $\checkmark$ & \\
\hline & Spodoptera & Spodoptera spp. & $\checkmark$ & \\
\hline & Technemon & Technemon spp. & & $\checkmark$ \\
\hline & Thoracolopha & Thoracolopha spp. & $\checkmark$ & $\checkmark$ \\
\hline & Thysanoplusia & Thysanoplusia spp. & $\checkmark$ & $\checkmark$ \\
\hline & Trichocosmia & Trichocosmia spp. & $\checkmark$ & \\
\hline & Tripudia & Tripudia spp. & $\checkmark$ & \\
\hline & Ulolonche & Ulolonche spp. & $\checkmark$ & $\checkmark$ \\
\hline & Xanthodes & Xanthodes spp. & $\checkmark$ & $\checkmark$ \\
\hline & Zale & Zale spp. & $\checkmark$ & $\checkmark$ \\
\hline & Unclassified & Noctuidae & $\checkmark$ & $\checkmark$ \\
\hline Nolidae & Acatapaustus & Acatapaustus spp. & $\checkmark$ & \\
\hline & Earias & Earias spp. & $\checkmark$ & $\checkmark$ \\
\hline & Meganola & Meganola spp. & $\checkmark$ & $\checkmark$ \\
\hline & Nola & Nola spp. & $\checkmark$ & $\checkmark$ \\
\hline & Uraba & Uraba spp. & $\checkmark$ & $\checkmark$ \\
\hline Notodontidae & Leucodonta & Leucodonta spp. & & $\checkmark$ \\
\hline & Nystalea & Nystalea spp. & $\checkmark$ & \\
\hline & Phalera & Phalera spp. & & $\checkmark$ \\
\hline & Poresta & Poresta spp. & $\checkmark$ & $\checkmark$ \\
\hline & Rifargia & Rifargia spp. & $\checkmark$ & $\checkmark$ \\
\hline & Unclassified & Notodontidae & $\checkmark$ & \\
\hline
\end{tabular}




\begin{tabular}{|c|c|c|c|c|}
\hline \multirow[t]{2}{*}{ Nymphalidae } & Danaus & Danaus spp. & & $\checkmark$ \\
\hline & Unclassified & Nymphalidae & & $\checkmark$ \\
\hline \multirow[t]{13}{*}{ Oecophoridae } & Crassa & Crassa spp. & $\checkmark$ & $\checkmark$ \\
\hline & Denisia & Denisia spp. & $\checkmark$ & $\checkmark$ \\
\hline & Eochrois & Eochrois spp. & & $\checkmark$ \\
\hline & Eulechria & Eulechria spp. & $\checkmark$ & \\
\hline & Hesperoptila & Hesperoptila spp. & & $\checkmark$ \\
\hline & Hoplomorpha & Hoplomorpha spp. & $\checkmark$ & \\
\hline & Hybocrossa & Hybocrossa spp. & $\checkmark$ & \\
\hline & Philobota & Philobota spp. & $\checkmark$ & $\checkmark$ \\
\hline & Phloeograptis & Phloeograptis spp. & & $\checkmark$ \\
\hline & Polix & Polix spp. & $\checkmark$ & $\checkmark$ \\
\hline & Prionocris & Prionocris spp. & $\checkmark$ & \\
\hline & Sclerocris & Sclerocris spp. & $\checkmark$ & \\
\hline & Stathmopoda & Stathmopoda spp. & $\checkmark$ & $\checkmark$ \\
\hline Oenosandridae & Diceratucha & Diceratucha spp. & & $\checkmark$ \\
\hline \multirow[t]{3}{*}{ Pyralidae } & Aphomia & Aphomia spp. & & $\checkmark$ \\
\hline & Salma & Salma spp. & $\checkmark$ & \\
\hline & Vinicia & Vinicia spp. & $\checkmark$ & $\checkmark$ \\
\hline \multirow[t]{6}{*}{ Saturniidae } & Automeris & Automeris spp. & $\checkmark$ & $\checkmark$ \\
\hline & Catacantha & Catacantha spp. & $\checkmark$ & \\
\hline & Gamelia & Gamelia spp. & $\checkmark$ & $\checkmark$ \\
\hline & Opodiphthera & Opodiphthera spp. & $\checkmark$ & $\checkmark$ \\
\hline & Rhodinia & Rhodinia spp. & $\checkmark$ & \\
\hline & Schausiella & Schausiella spp. & & $\checkmark$ \\
\hline \multirow[t]{2}{*}{ Sphingidae } & Clarina & Clarina spp. & $\checkmark$ & \\
\hline & Manduca & Manduca spp. & $\checkmark$ & \\
\hline \multirow[t]{2}{*}{ Thyrididae } & Banisia & Banisia spp. & & $\checkmark$ \\
\hline & Unclassified & Thyrididae & $\checkmark$ & \\
\hline Tineidae & Opogona & Opogona spp. & $\checkmark$ & \\
\hline \multirow[t]{15}{*}{ Tortricidae } & Acroclita & Acroclita spp. & $\checkmark$ & \\
\hline & Aeolostoma & Aeolostoma spp. & & $\checkmark$ \\
\hline & Aethes & Aethes spp. & $\checkmark$ & \\
\hline & Ancylis & Ancylis spp. & $\checkmark$ & \\
\hline & Archips & Archips spp. & & $\checkmark$ \\
\hline & Clepsis & Clepsis spp. & $\checkmark$ & $\checkmark$ \\
\hline & Cryptophlebia & Cryptophlebia spp. & $\checkmark$ & \\
\hline & Epinotia & Epinotia spp. & $\checkmark$ & \\
\hline & Epiphyas & Epiphyas spp. & $\checkmark$ & $\checkmark$ \\
\hline & Eucosma & Eucosma spp. & $\checkmark$ & $\checkmark$ \\
\hline & Holocola & Holocola spp. & $\checkmark$ & $\checkmark$ \\
\hline & Merophyas & Merophyas spp. & $\checkmark$ & $\checkmark$ \\
\hline & Metendothenia & Metendothenia spp. & $\checkmark$ & \\
\hline & Olethreutes & Olethreutes spp. & $\checkmark$ & \\
\hline & Paralobesia & Paralobesia spp. & $\checkmark$ & $\checkmark$ \\
\hline
\end{tabular}




\begin{tabular}{|c|c|c|c|c|c|}
\hline & & Phricanthes & Phricanthes spp. & & $\checkmark$ \\
\hline & & Strepsicrates & Strepsicrates spp. & $\checkmark$ & $\checkmark$ \\
\hline & & Taeniarchis & Taeniarchis spp. & $\checkmark$ & \\
\hline & & Unclassified & Tortricidae & $\checkmark$ & $\checkmark$ \\
\hline & Unclassified & Unclassified & Lepidoptera & $\checkmark$ & $\checkmark$ \\
\hline Mantodea & Mantidae & Orthodera & Orthodera spp. & $\checkmark$ & $\checkmark$ \\
\hline Neuroptera & Hemerobiidae & Wesmaelius & Wesmaelius spp. & & $\checkmark$ \\
\hline Orthoptera & Gryllidae & Teleogryllus & Teleogryllus spp. & $\checkmark$ & $\checkmark$ \\
\hline Unclassified & Unclassified & Unclassified & Unclassified & $\checkmark$ & $\checkmark$ \\
\hline
\end{tabular}

